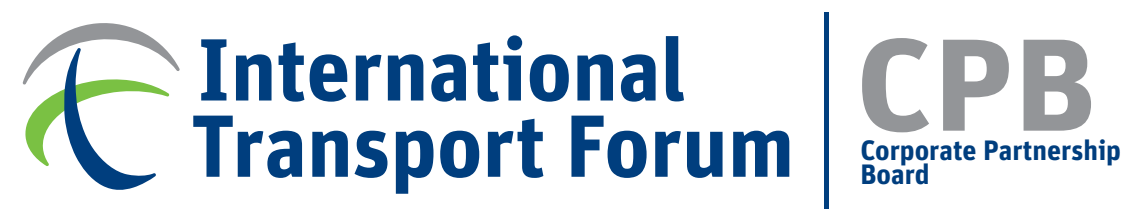

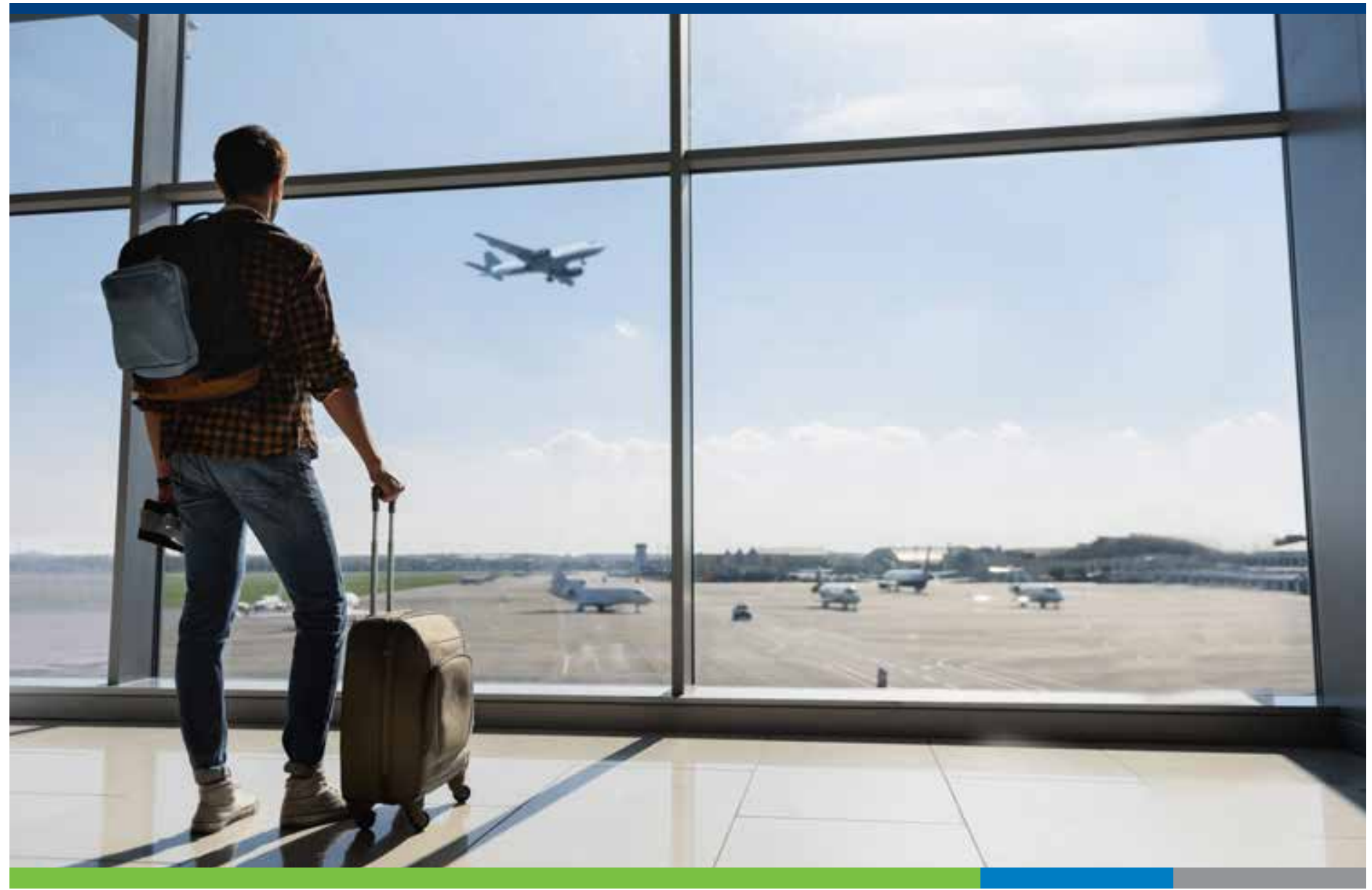

Defining, Measuring

and Improving

Air Connectivity

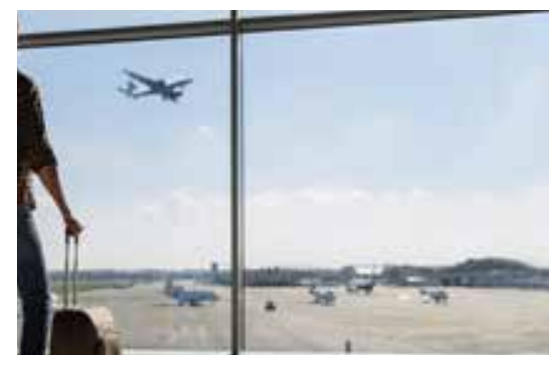

Corporate Partnership Board Report 


\section{Defining, Measuring and Improving Air Connectivity}

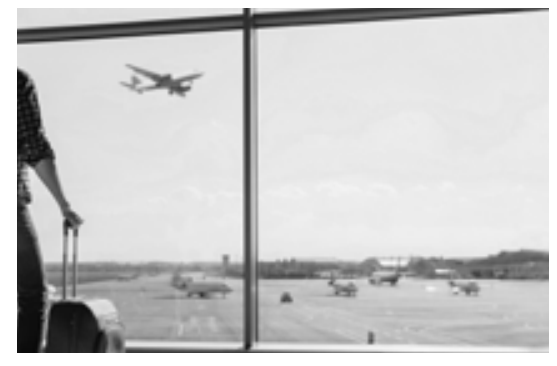

Corporate Partnership Board Report 


\section{About the International Transport Forum}

The International Transport Forum at the OECD is an intergovernmental organisation with 59 member countries. It acts as a think tank for transport policy and organises the Annual Summit of transport ministers. ITF is the only global body that covers all transport modes. It is administratively integrated with the OECD, yet politically autonomous.

ITF works for transport policies that improve peoples' lives. Our mission is to foster a deeper understanding of the role of transport in economic growth, environmental sustainability and social inclusion and to raise the public profile of transport policy.

ITF organises global dialogue for better transport. We act as a platform for discussion and pre-negotiation of policy issues across all transport modes. We analyse trends, share knowledge and promote exchange among transport decision makers and civil society. ITF's Annual Summit is the world's largest gathering of transport ministers and the leading global platform for dialogue on transport policy.

Our member countries are: Albania, Argentina, Armenia, Australia, Austria, Azerbaijan, Belarus, Belgium, Bosnia and Herzegovina, Bulgaria, Canada, Chile, China (People's Republic of), Croatia, Czech Republic, Denmark, Estonia, Finland, France, Former Yugoslav Republic of Macedonia, Georgia, Germany, Greece, Hungary, Iceland, India, Ireland, Israel, Italy, Japan, Kazakhstan, Korea, Latvia, Liechtenstein, Lithuania, Luxembourg, Malta, Mexico, Republic of Moldova, Montenegro, Morocco, Netherlands, New Zealand, Norway, Poland, Portugal, Romania, Russian Federation, Serbia, Slovak Republic, Slovenia, Spain, Sweden, Switzerland, Turkey, Ukraine, the United Arab Emirates, the United Kingdom and the United States.

\section{Disclaimer}

Funding for this work has been provided by the ITF Corporate Partnership Board. This report is published under the responsibility of the Secretary-General of the ITF. It has not been subject to the scrutiny of ITF or OECD member countries, and does not necessarily reflect their official views or those of the members of the Corporate Partnership Board. 


\section{Acknowledgements}

The work for this report was carried out in the context of a project initiated and funded by the International Transport Forum's Corporate Partnership Board (CPB). CPB projects are designed to enrich policy discussion with a business perspective. They are launched in areas where CPB member companies identify an emerging issue in transport policy or an innovation challenge to the transport system. Led by the ITF, work is carried out in a collaborative fashion in working groups consisting of CPB member companies, external experts and ITF staff.

Many thanks to the members of the Corporate Partnership Board companies involved in this work: Incheon Airport and PTV Group.

The report draws conclusions from a workshop held in Korea on 13-14 December 2017, kindly hosted by Incheon Airport at their headquarters.

Participants of the workshop included:

Guillaume Burghouwt, Royal Schiphol Group

Mina Choi, Incheon International Airport Corporation

Philippe Crist, International Transport Forum

Jagoda Egeland, International Transport Forum

Alastair Evanson, PTV Group

Fazlin Hassan Naziri, Malaysian Aviation Commission

Kyoo-Hyuk Jo, Incheon International Airport Corporation

Gilbert Kim, Incheon International Airport Corporation

Minjeong Kim, Incheon International Airport Corporation

Vin Kim, Incheon International Airport Corporation

Yoon-Sub Kim, Incheon International Airport Corporation

Hee-Jeong Lee, Incheon International Airport Corporation

Sang Yong Lee, Incheon International Airport Corporation

Rogier Lieshout, SEO Amsterdam Economics

Chen-Yue Lok, Malaysian Aviation Commission

Won Park, Director, Incheon International Airport Corporation

Daniel Dongsik Shin, Incheon International Airport Corporation

Anming Zhang, University of British Columbia

The principle author of this report was Jagoda Egeland of the International Transport Forum. The modelling work for this report was conducted by Rogier Lieshout and Thijs Boonekamp from SEO Amsterdam Economics. The report was reviewed by Vincent Benezech (ITF), Guillaume Burghouwt (Royal Schiphol Group), Alastair Evanson (PTV Group), Berend Onnes (Royal Schiphol Group), and Stephen Perkins (ITF). Assistance with the draft was provided by Anna Garbarczyk and Cécilia Paymon.

The project was co-ordinated by Sharon Masterson and Philippe Crist of the International Transport Forum. 


\section{Table of contents}

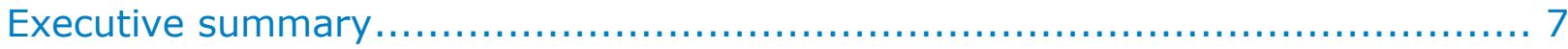

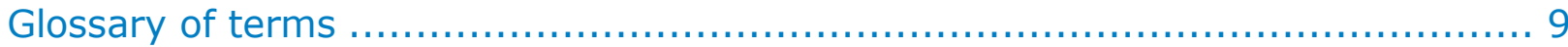

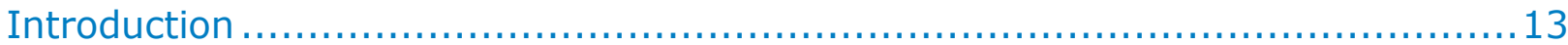

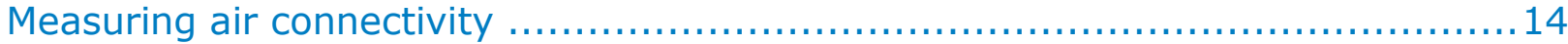

Developing network connectivity metrics.................................................................. 16

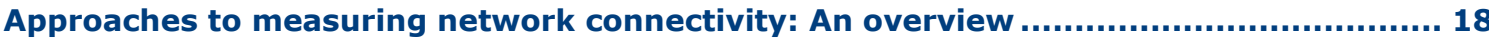

Choosing the right approach to network connectivity assessments ............................. 21

Network connectivity performance of major aviation hubs: Incheon and Schiphol 23

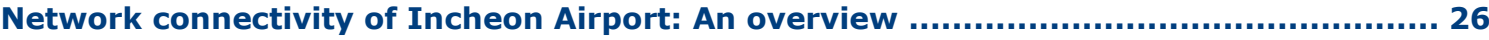

Incheon: direct, indirect, and hub connectivity outcomes..................................... 29

Network connectivity provided from Incheon against five benchmark airports.............. 36

Network connectivity of Schiphol Airport: An overview ............................................. 45

Schiphol: direct, indirect, and hub connectivity outcomes .......................................... 48

Network connectivity provided from Schiphol against five benchmark airports ............ 55

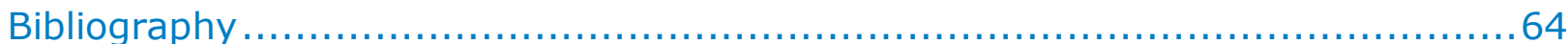

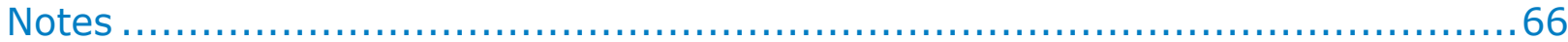

\section{Tables}

Table 1. A comparison of different approaches to measuring connectivity ....................................22

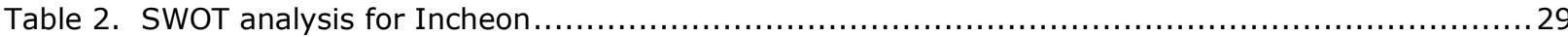

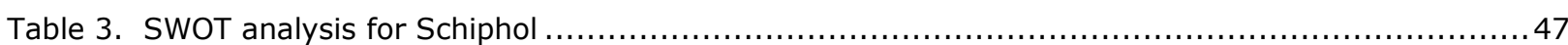

\section{Figures}

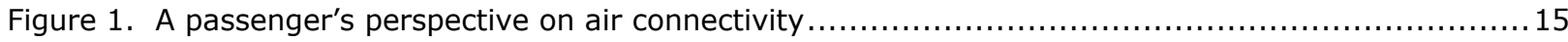

Figure 2. Components of a network connectivity assessment: An example of Incheon ........................ 16

Figure 3. Relationship between the strength of local GDP and the number of long-haul destinations for a

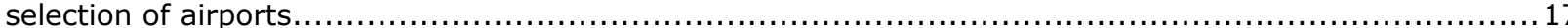

Figure 4. An example of network connectivity metrics based on flight schedule and passenger flow data.. 18 
Figure 5. Evolution of average transfer times and routing factors at Incheon and Schiphol (2007, 2012,

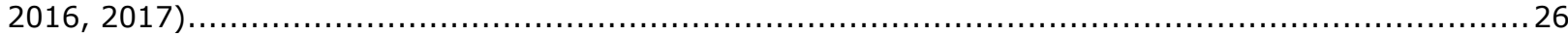

Figure 6. Level of direct connectivity from Incheon and benchmark airports $(2007,2012,2016,2017) \ldots .27$

Figure 7. Relationship between direct and hub connectivity at Incheon and benchmark airports (2007,

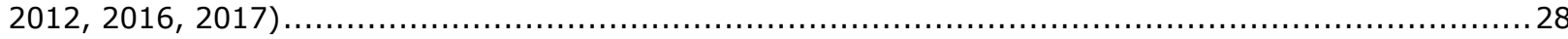

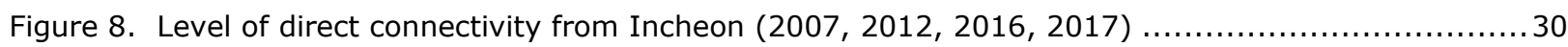

Figure 9. Share of direct connectivity from Incheon by alliance membership $(2007,2012,2016,2017) \ldots 30$

Figure 10. Level of indirect connectivity from Incheon by alliance membership (2007, 2012, 2016, 2017) 31

Figure 11. Top 10 onward hubs for connections from Incheon. .32

Figure 12. Level of indirect connectivity from Incheon for 20 most important onward hubs (2007, 2012,

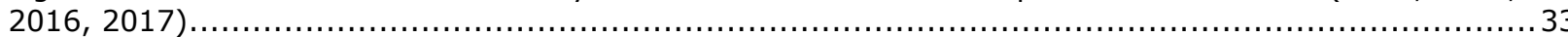

Figure 13. Level of direct and indirect connectivity from Incheon by region $(2007,2012,2016,2017) \ldots . .33$

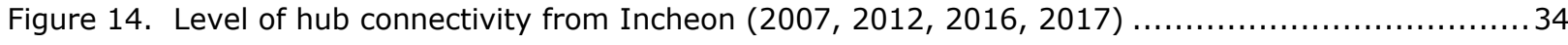

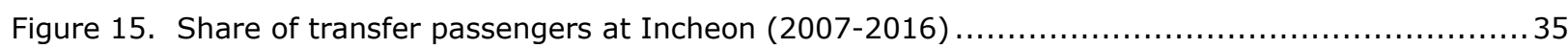

Figure 16. Share of hub connectivity from Incheon by alliance membership $(2007,2012,2016,2017) \ldots .35$

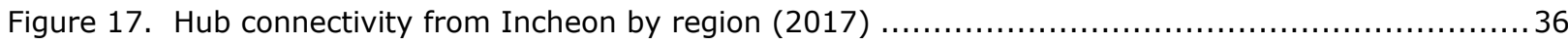

Figure 18. Degree of Incheon's hub network overlap with hub networks of other airports in the region .....37

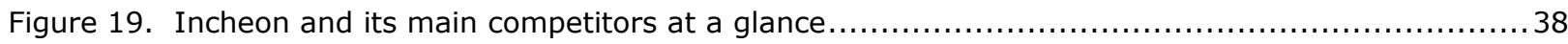

Figure 20. Level of direct connectivity from Incheon and benchmark airports (2007, 2012, 2016, 2017) .. 39

Figure 21. Share of flights operated by low-cost carriers from Incheon and benchmark airports (2007,

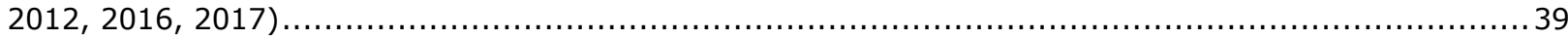

Figure 22. Share of flights operated by low-cost carriers in selected multi-airport systems (2007, 2012,

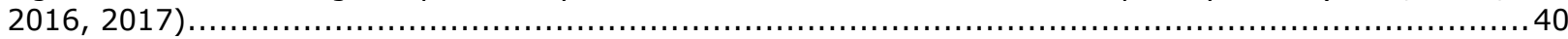

Figure 23. Level of indirect connectivity from Incheon and benchmark airports (2007, 2012, 2016, 2017)41

Figure 24. Share of direct and indirect connectivity from Incheon and benchmark airports by region ........42 Figure 25. Level of hub connectivity from Incheon and benchmark airports $(2007,2012,2016,2017) \ldots \ldots 42$ Figure 26. Share of hub connections by stage length combination from Incheon and benchmark airports . 43 Figure 27. Level of direct connectivity provided by short-haul and long-haul flights from airports for Seoul

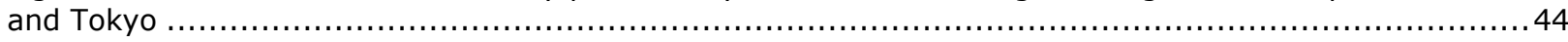

Figure 28. Degree of network overlap of benchmark airports with Incheon $(2007,2012,2016,2017) \ldots . .44$ Figure 29. Level of direct connectivity from Schiphol and benchmark airports $(2007,2012,2016,2017)$.45 Figure 30. Relationship between direct and hub connectivity at Schiphol and benchmark airports (2007,

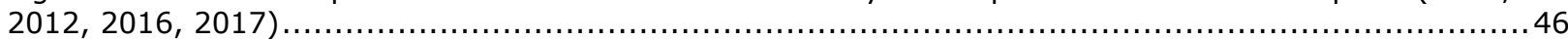

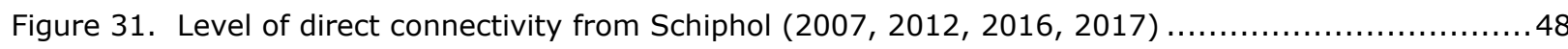

Figure 32. Share of direct connectivity from Schiphol by alliance membership (2007, 2012, 2016, 2017).49

Figure 33. Level of indirect connectivity from Schiphol by alliance membership (2007, 2012, 2016, 2017)50

Figure 34. Top 10 onward hubs for connections from Schiphol 51

Figure 35. Level of indirect connectivity from Schiphol for 20 most important onward hubs (2007, 2012, 2016, 2017)

Figure 36. Level of direct and indirect connectivity from Schiphol by region $(2007,2012,2016,2017) \ldots .52$

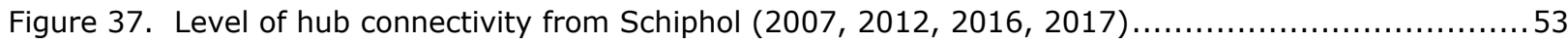

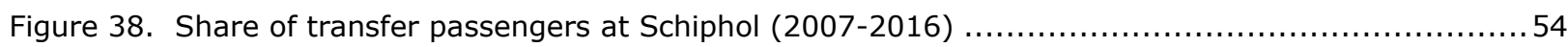




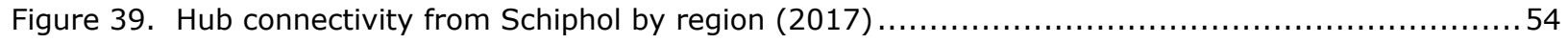

Figure 40. Degree of Schiphol's hub network overlap with hub networks of other airports in the region....55

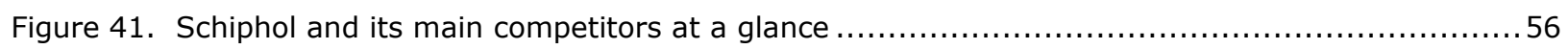

Figure 42. Level of direct connectivity from Schiphol and benchmark airports $(2007,2012,2016,2017) .57$

Figure 43. Share of flights operated by low-cost carriers from Schiphol and benchmark airports (2007,

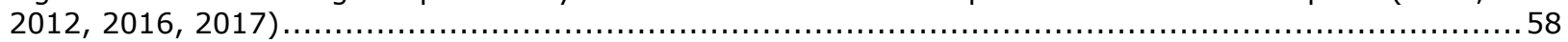

Figure 44. Share of flights operated by low-cost carriers in selected multi-airport systems $(2007,2012$,

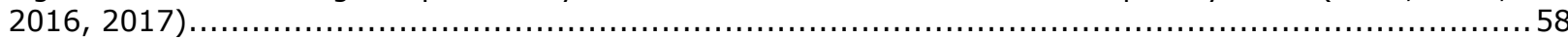

Figure 45. Level of indirect connectivity from Schiphol and benchmark airports (2007, 2012, 2016, 2017)

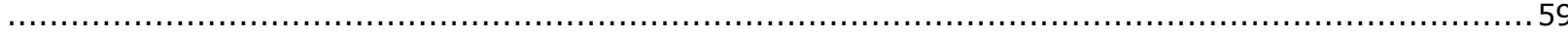

Figure 46. Share of direct and indirect connectivity from Schiphol and benchmark airports by region ......60

Figure 47. Level of hub connectivity from Schiphol and benchmark airports $(2007,2012,2016,2017) \ldots 61$

Figure 48. Share of hub connections by stage length combination from Schiphol and benchmark airports 61

Figure 49. Level of direct connectivity provided by the main hub carrier from the biggest airports in London

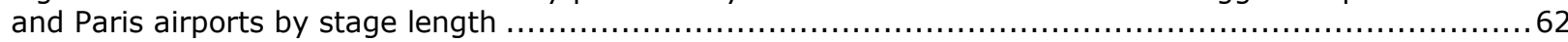

Figure 50. Degree of network overlap of benchmark airports with Schiphol $(2007,2012,2016,2017) \ldots .63$ 


\section{Executive summary}

\section{What we did}

Air connectivity can be broadly defined as ability and ease with which passengers and freight can reach destinations by air. Increasingly, governments recognise that air connectivity plays a crucial role in enhancing economic growth by facilitating tourism and inward foreign direct investment and supporting trade in goods and services. The potential of air connectivity to deliver socio-economic benefits increases as air travel becomes less expensive and more accessible - thanks to progressive aviation liberalisation, the rise of low-cost carriers, and technological developments that made air transport more efficient.

Aviation stakeholders, including airports and airlines, undertake air connectivity analysis to plan their commercial strategies. Governments are interested in air connectivity more broadly to understand the impacts of their policies and in some cases because of their ownership of airports or airlines. They are particularly concerned with the effects of connectivity on the local and national economy, and the benefits of air travel to citizens.

This report provides a review of approaches to measuring air connectivity, and applies one of them to assess the air connectivity performance of two hub airports on different continents, Incheon International Airport in Korea and Amsterdam Airport Schiphol in the Netherlands.

\section{What we found}

There is no single best approach to defining and measuring air connectivity. The approaches range from simple metrics that are relatively easy to obtain from schedule or traffic data to more complex metrics that rely on modelling techniques, multiple data sets, and expert judgment.

Simple connectivity metrics provide easy-to-interpret information about the characteristics of an airport system, but they are not suitable for analysing the connectivity impacts of any endogenous or exogenous changes to the route network. For this reason, they are not particularly useful in helping airports and airlines plan their business strategies, or in assisting policy makers with policy design.

For example, tracking the share of transfer traffic in total traffic over time provides information on the extent to which hubbing takes place at an airport. It, however, provides no insight into how any changes to airport operations, such as increased operational efficiency, or co-operation between carriers, may affect the hub connectivity levels.

More complex connectivity metrics based on modelling can provide such insights. This is a particularly important feature nowadays, when most of the most profound connectivity changes are induced by expansion of low-cost carriers and co-operation agreements between airlines. Network quality models, like the one used in this report, can be particularly useful tools for understanding how an airport links passengers and freight to the rest of the world.

These models can account for both direct connectivity and connectivity via other airports, hence reflecting the destination choices that passengers have. Indirect connections are weighted according to their quality, based on connecting time and detour involved in the indirect routing. Network quality models also provide a measure of hub connectivity of an airport, by including the number of connecting flights that can be facilitated by the hub airport in question, taking into account minimum and maximum connecting times, and weighting the quality of connections by connecting times and the detour involved. 


\section{What we recommend}

Adapt the use of connectivity metrics to specific policy challenges.

The decision on the scope of the study ultimately needs to be tailored to the policy objectives at hand. For example, if the objective is to measure the extent to which an airport or a network of airports connects the users of aviation to the outside world, the most important dimension of air connectivity to investigate is the degree to which airports are connected to one other. If the objective is to improve passenger experience and maximise the benefits of connectivity, the impact of policies on door-to-door connectivity needs to be analysed. A comprehensive air connectivity picture would entail an assessment of how easy it is to get to an airport (surface access), how efficiently passengers can get onto their flight (landside and airside considerations inside the airport), and, ultimately, to their chosen destination.

Use a combination of approaches to assess potential knock-on effects that policy or strategy changes may have on air connectivity.

This can help decision-makers get the full picture of how aviation policy or aviation business strategies impact the industry and the users of aviation. Air connectivity metrics based on network quality models and generalised travel cost models seem particularly useful in assisting policy makers. The former can provide insights into the quality of the available route network to passengers, while the latter asses the welfare implications of any changes to the route network or landside accessibility. Micro-simulation of passenger flows can shed light on how to deal with increased passenger activity within an airport that may result from connectivity improvements to the route network, hence enabling an assessment of the knock-on impacts on the entire trip chain.

Involve all aviation stakeholders in the policy process of developing air connectivity metrics.

It is crucial for governments to involve aviation stakeholders - aircraft and airport operators, air transport users, and local communities in the vicinity of the airport - and aviation experts in developing air connectivity metrics. This can help ensure that the metrics include important considerations, such as any possible impacts of a policy on commercial viability of flights from an airport, and that they are correctly interpreted. Expert judgment can also help identify important trends that need to form part of connectivity analysis.

Make systematic use of air connectivity metrics to evaluate the performance of the national aviation sector and improve decision-making.

Air connectivity metrics can be useful in shedding light on the performance of the aviation sector at a national, regional, and airport level. They can also provide valuable insights into potential consequences of changes to policy. In order to use these capabilities to the full extent, governments should consider making a systematic use of a combination of different approaches to measuring air connectivity to allow for tracking air connectivity trends over time and help improve appraisal of any potential investments in air transport. 


\section{Glossary of terms}

ACI Europe - Airports Council International Europe

Air connectivity - Air connectivity is broadly defined as ability and ease with which passengers and freight can reach destinations by air. The report defines air connectivity as the availability of flights offered by an airport or a route network, the name used for this type of air connectivity throughout the report is "network connectivity".

Airside - The side of an airport terminal beyond passport and customs control.

ATAG - Air Transport Action Group

ATM - Air transport movement

Circuity time (also: detour time) - Difference between the time that the actual flight (usually connecting) takes and the time a direct flight with a jet aircraft to a given destination would take.

CNU - NetScan connectivity units. Number of direct and indirect connections weighted by their quality in terms of transfer and detour time.

CPB - Corporate Partnership Board of the International Transport Forum (ITF)

Delta - Delta Air Lines

FSC - Full-service carrier. Full-service carriers are typically current or former national carriers that operate relatively extensive route networks (which is why they are often called network carriers) and provide a range of on-board products including different seating classes, in-flight entertainment, complimentary meals and beverages, as well as ground facilities such as waiting lounges for premium class passengers or frequent flyer programme members.

Hub airport (also: hub) - An airport from which an air carrier or an alliance operate a hub-and-spoke network.

Hub carrier - An airline that operates a hub-and-spoke network.

IATA - International Air Transport Association

Incheon - Incheon International Airport

ITF - International Transport Forum at the Organisation for Economic Co-operation and Development (OECD)

KLM - Royal Dutch Airlines

Landside - The side of an airport terminal to which the general public has unrestricted access.

LCC - Low-cost carriers are airlines that compete for passengers through offering relatively low fares. Low fares are achieved through a wide range of cost-saving measures, such as point-to-point operations, utilisation of standardised aircraft fleets, or serving airports with relatively low airport charges. Low-cost carriers often offer no-frills fares i.e. they sell tickets that exclude all non-essential features, such as free drinks and meals, and usually provide these services at an additional charge.

In the analysis completed for the report, the following airlines are classified as low-cost carriers: Air India Express, Air Seoul, Air Transat, AirAsia, AirAsia X, Astra Airlines, Blue Air, Cebu Pacific Air, Condor, Corendon Dutch Airlines, Eastar Jet, EasyJet, Germanwings (Eurowings), IndiGo, Indonesia AirAsia, Jazeera Airways, Jeju Air, Jet2.com, Jetairfly (TUI fly Belgium), Jetstar, Jetstar Asia, Jetstar Pacific, Jin Air, Jubba Airways, Lion Air, Mihin Lanka, Norwegian, PAL Express, Peach, Ryanair, Scoot, Skymark Airlines, SpiceJet, Spring Airlines, SunExpress, Taban Air, Thai AirAsia, Thomson Airways (TUI Airways), Tigerair, Transavia, TUI fly Netherlands, TUIfly (TUI fly Deutschland), T'way Air, VietJet Air, Vueling, Wizz Air, WOW air, Zagrosjet. 
LH - Long-haul. In this report, a long-haul flight is a flight with a stage length over $3450 \mathrm{~km}$.

MCT - Minimum connecting time. The minimum amount of transfer time needed between connections at a given airport or within a given terminal.

OAG - airline schedules database which holds future and historical flight details for airlines and airports globally.

OD market - Origin-destination market. An OD market for a particular airport is defined as passenger demand for travelling to (the destination "D") and from (the origin "O") that particular airport.

OECD - Organisation for Economic Co-operation and Development

Routing factor - Routing factor is defined as the ratio between the actual flight distance covered by an airline to get to a given destination and the distance of a direct flight to that destination.

Schiphol - Amsterdam Airport Schiphol

Self-hubbing (also: self-connecting) - Self-hubbing occurs when passengers, instead of buying one ticket for a connecting flight, decide to buy separate tickets and make the transfer themselves, effectively taking on the risk to any disruptions in the schedule, unless the connection is facilitated by an external party, usually the airport where the self-connection is made.SH - Short-haul. In this report, a short-haul flight is a flight with a stage length equal to or shorter than $3450 \mathrm{~km}$.

Surface access - Ground and water access to airports

Transfer time (also: connecting time) - Average time passengers need to transfer between two flights at a given airport or within a given terminal.

Transfer traffic (also: connecting traffic) - Passengers who do not travel directly to their destination, but instead purchase a combination of two or more flights to get to their destination from the same carrier or within the same airline alliance.

IATA airport codes used in the report:

ABY - Southwest Georgia Regional Airport, Albany, United States of America

AMS - Amsterdam Airport Schiphol, Amsterdam, Netherlands

ATL - Hartsfield-Jackson Atlanta International Airport, Atlanta, United States of America

ATW - Appleton International Airport, Appleton, United States of America

BKK - Suvarnabhumi Airport, Bangkok, Thailand

BOG - El Dorado International Airport, Bogotá, Colombia

BVA - Paris-Beauvais Airport, Paris, France

CAN - Guangzhou Baiyun International Airport, Guangzhou, China

CDG - Paris Charles de Gaulle Airport, Paris, France

CGK - Soekarno-Hatta International Airport, Jakarta, Indonesia

CJU - Jeju International Airport, Jeju, Korea

cos - Colorado Springs Airport, Colorado Springs, United States of America

DFW - Dallas Fort Worth International Airport, Dallas, United States of America

DMK - Don Mueang International Airport, Bangkok, Thailand 


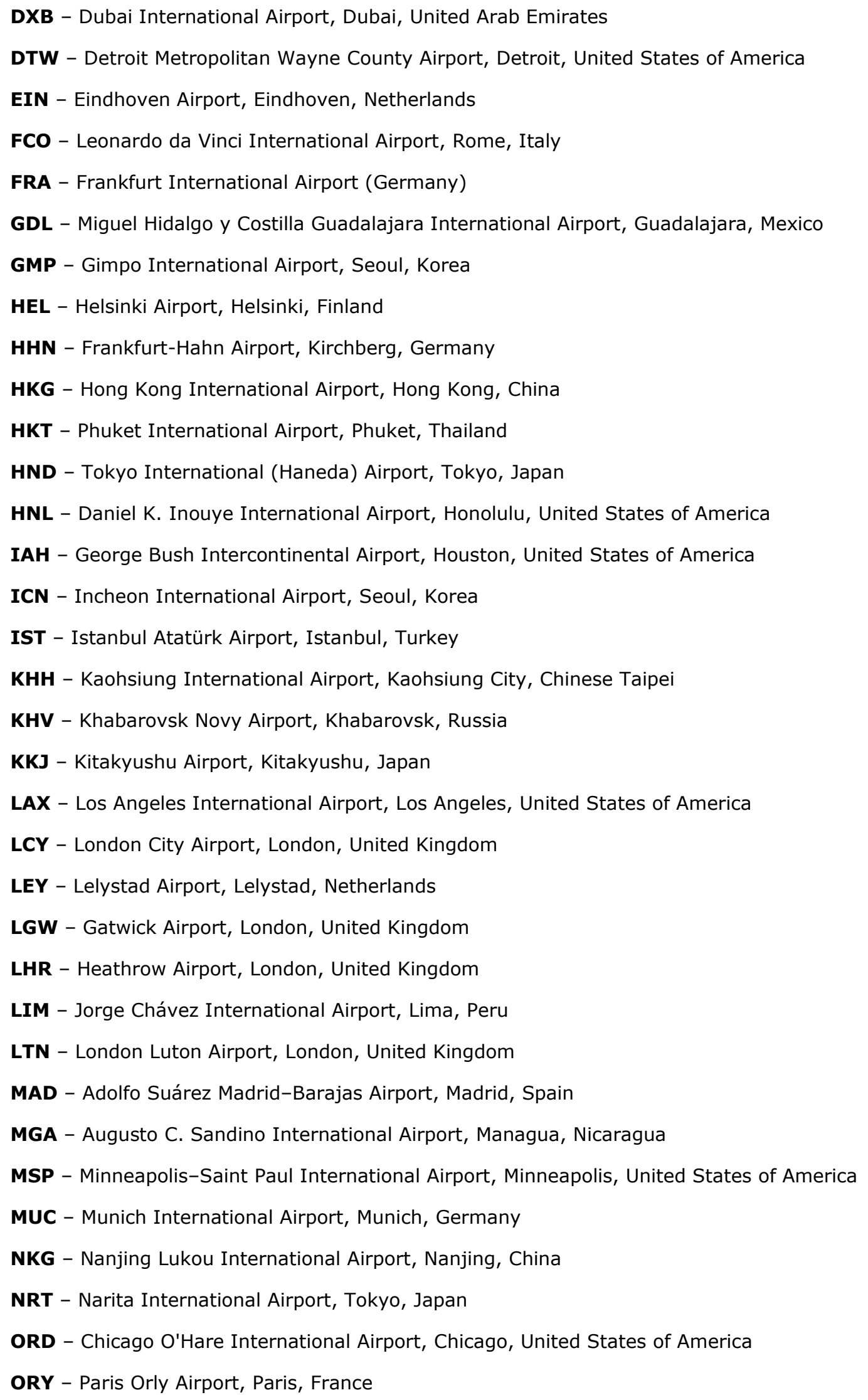


PEK - Beijing Capital International Airport, Beijing, China

PTY - Tocumen International Airport, Panama City, Panama

PUS - Gimhae International Airport, Busan, Korea

PVG - Shanghai Pudong International Airport, Shanghai, China

RTM - Rotterdam The Hague Airport, Rotterdam and the Hague, Netherlands

SAW - Sabiha Gökçen International Airport, Istanbul, Turkey

SEA - Seattle-Tacoma International Airport, Seattle. United States of America

SFO - San Francisco International Airport, San Francisco. United States of America

SHE - Shenyang Taoxian International Airport, Shenyang, China

SIN - Changi Airport, Singapore

SJC - Norman Y. Mineta San José International Airport, San Jose, United States of America

SJO - Juan Santamaría International Airport, San José, Costa Rica

SJU - Luis Muñoz Marín International Airport, San Juan, Puerto Rico

SLC - Salt Lake City International Airport, Salt Lake City, United States of America

SPN - Francisco C. Ada International Airport, Saipan, Northern Mariana Islands, United States of America

STN - London Stansted Airport, London, United Kingdom

SVO - Sheremetyevo International Airport, Moscow, Russian Federation

SZX - Shenzhen Bao'an International Airport, Shenzhen, China

TAE - Daegu International Airport, Daegu, Korea

TPE - Taiwan Taoyuan International Airport, Taipei, Chinese Taipei

UIO - Mariscal Sucre International Airport, Quito, Ecuador

VIE - Vienna International Airport, Vienna, Austria

YYZ - Toronto Pearson International Airport, Toronto, Canada

ZRH - Zurich International Airport, Zurich, Switzerland 


\section{Introduction}

Demand for aviation is driven by a need to win new business, to meet clients or suppliers face-to-face, to participate in conferences or other events, to see friends and relatives, or to enjoy the benefits of a holiday abroad. At its heart, air connectivity is about satisfying the need for long-distance travel for personal and business purposes as convenient and affordable as possible, given the separation involved.

Air connectivity can play an important role in fostering local economic development and supporting national long-term economic growth objectives. Through facilitating the movements of goods and services, people, ideas, knowledge and investment, air connectivity supports a country's integration into the global economy. By doing so, air connectivity provides direct benefits to the users of aviation and wider benefits to the entire economy through its positive impacts on productivity and economic performance. Due to these positive impacts, governments should understand the impact of their policies on air connectivity and how to foster better air connectivity outcomes.

To date, many approaches to defining and measuring connectivity have been developed to better understand how different factors affect air connectivity. For example, air connectivity metrics can help shed light on how new technologies, or changes to the airline business models, are likely to affect the experience of the users of aviation. Air connectivity metrics can help airports and airlines benchmark themselves against their competitors. Despite air connectivity having become an important tool for decision-making, systematic approaches to using air connectivity metrics in project appraisal, or in policy-making more broadly, have not yet been developed.

This report sets out the reasons why such a systematic approach to measuring air connectivity should be developed. It examines different approaches to measuring network connectivity (Chapter 2), and applies one of these approaches to assess network connectivity performance of two major aviation hubs, Incheon and Schiphol, to then combine the network connectivity assessments and an analysis of different factors influencing network connectivity outcomes to set out air connectivity prospects for the two airports (Chapter 3). 


\section{Measuring air connectivity}

The multi-dimensionality of air connectivity is the key reason why air connectivity assessments can be very challenging (see Burghouwt, 2017; Egeland and Smale, 2017). Researchers often face dilemmas with respect to the scope of air connectivity analysis and the choice of metrics to use. The scope and choice of metrics can be particularly challenging in policy studies that face multiple objectives and need to consider a wide array of impacts of government policies on the users of aviation and the wider economy.

The analysis in this report focuses on the so called "network connectivity", i.e. the extent to which an airport or a network of airports connects users of aviation to the outside world (Burghouwt and Redondi, 2013). This perspective is particularly useful to policy makers who would like to get insights into how well the national or local airport system responds to the connectivity needs of a country, and understand how to enhance air connectivity to support economic growth (Box 1).

\section{Box 1 . Why does air connectivity matter to governments?}

Governments are interested in how well their national aviation systems connect the users of aviation to different destinations, because these connections foster exchange of goods and services, investment and ideas, workers and tourists, as well as job creation, directly at airports and in businesses that depend on air transport. Aviation is particularly important to people doing business in international markets who often have no real alternative to aviation as a mode of transport.

It also matters to the wider economy. Not only does air connectivity matter to those who depend on it directly, it can also boost the productivity and growth of economies by providing better access to markets, enhancing links within and between businesses and providing greater access to resources and to international capital markets.

It is, however, methodologically challenging to establish and value the specific contribution made by aviation to a country's economy. For this reason, the estimates that are currently available should be treated with caution. Nevertheless, they send an important message about the importance of fostering air connectivity by governments. For example, according to Air Transport Action Group (ATAG), in 2014 aviation supported 62.7 million jobs and created value to the global economy equal to $3.5 \%$ of world's GDP (ATAG, 2016).

Increased air connectivity, however, imposes costs on the society as well. To help decide on airport infrastructure investment or any changes to aviation policy, governments usually conduct assessments of all positive and negative social, environmental, and economic impacts of different alternatives, and incorporate the results of these assessments into cost-benefit analysis. Air connectivity analysis is instrumental to shedding light on these important considerations. For example, network connectivity assessments can help gauge potential noise impacts from increased aviation activity on local populations.

This report defines air connectivity as the availability of flights offered by an airport or a system of airports, and calls it "network connectivity". This definition does not explicitly include airside, landside, or surface access considerations, which can also be important to policy makers. In particular, if the objective of air connectivity analysis is to focus on passenger experience, then the analysis needs to consider entire doorto-door connectivity offered to travellers (Figure 1). Ideally, such a perspective would take into account how easy it is to get to an airport (surface access), how efficiently passengers can get onto their flight (landside and airside considerations inside the airport), and, ultimately, to the destination of their choice. Affordability of the available options is usually an important part of such considerations. 
Figure 1. A passenger's perspective on air connectivity

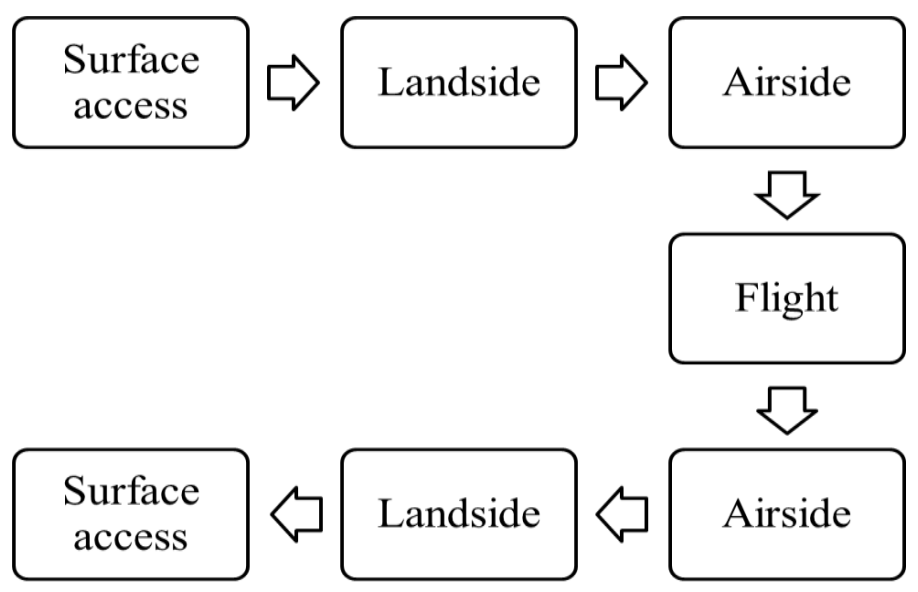

Moreover, a passenger's perspective on air connectivity can reveal the knock-on impacts of any changes to air connectivity along the entire trip chain. For example, allowing more air transport movements at an airport, holding all other factors equal, has two evident impacts on air connectivity. On the one hand, the number of seats and possibly destinations offered will increase as will frequencies, in turn improving the choice of flights offered to passengers. On the other hand, more traffic may increase airside and landside congestion, which may have negative impacts on the level of delays and resilience.

These are important considerations for airport owners and operators who are interested in where the pinch points in airport design and operations are, in order to be able to optimise the use of airport capacity. The co-ordination of movements at an airport is a logistical feat of balancing demand with precision timing, and airports use a variety of different tools to achieve better results in this regard. More recently, microsimulation modelling of land and airside operations has become a key tool to help planners inform capacity, event and operational procedures across a wide spectrum of scenarios. An example of such a tool is outlined in Box 2.

\section{Box 2. Microsimulation modelling to create a seamless airport experience: PTV Vissim}

PTV Vissim is an example of a multi-agent, multi-modal microsimulation software package that replicates and then optimises landside and airside airport operations to improve the utilisation of available airport capacity. As an operations and planning tool, it has been applied at several global hub airports to improve efficiency in vehicular and passenger flows, ground service equipment fleet size and staging areas, as well as aircraft turnaround and other airfield procedures.

Understanding and assessing dependences between different transport modes is crucial to optimising airport operations. Any factors that affect landside arrival of passengers have knock-on impacts on airside operations and vice versa. Not only does microsimulation modelling allow for testing real-life challenges to current operations, but it can also test and evaluate various design options to deal with incidents and any long-term strategies for future adaption and expansion of the airport. The flexibility of the software allows for modelling of virtually any kind of layout and testing of a wide range of possible changes to operational strategies at the airport.

With the movement of traffic and pedestrians at airports largely defined by the flight schedule, it is important to accurately replicate agents and their dependences in the simulation to identify how connectivity translates into day-to-day operations and how it affects airport capacity. All aspects of airport operations can be simulated; these include: vehicular movements at landside car parks, public transport, pick up and drop off operations, airside ground support equipment scheduling and flight turnaround, and pedestrian interactions inside the terminal. The model can be developed for the entire "eco-system" of the airport. As such, it can serve as a useful tool to help make decisions on new infrastructure investment, maximise existing capacity, and plan for future connectivity improvements. 


\section{Developing network connectivity metrics}

Network connectivity assessments are being extensively used by aviation industry to measure network connectivity performance of airports against one another (Burghouwt and Redondi, 2013, ACI Europe, 2017). Comprehensive network connectivity assessments capture the following components:

- Direct connectivity: The level (number and quality) of connections offered from the assessed airport.

- Indirect connectivity: The level (number and quality) of reasonable connections offered from the assessed airport indirectly through other airports.

- Hub connectivity: The level (number and quality) of reasonable indirect connections offered through the assessed airport.

Figure 2 provides an illustration of different components of network connectivity for Incheon.

Figure 2. Components of a comprehensive network connectivity assessment: An example of Incheon
Origin
$\mathrm{Hub}(\mathrm{s})$
Destination

ICN

Direct connections
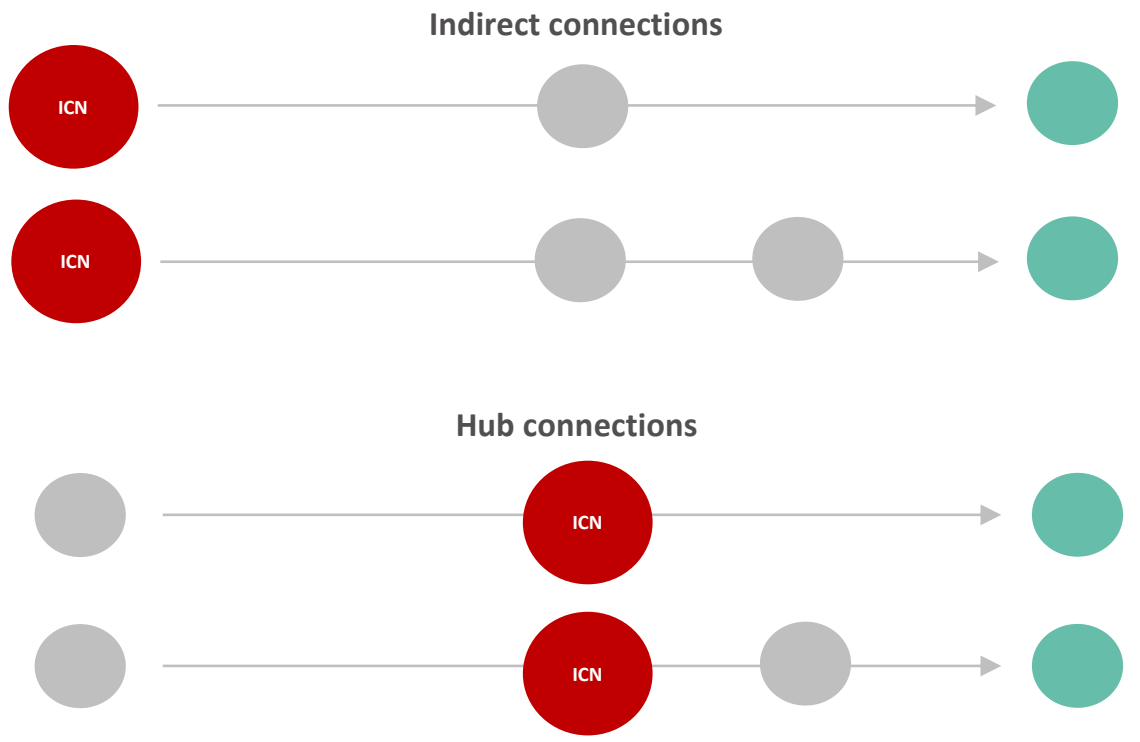

Source: SEO Amsterdam Economics

Tracking these connectivity components over time can help airlines, airports, and governments (1) analyse the evolution of network connectivity over time, (2) benchmark network connectivity performance against main airport/airline competitors, and (3) perform scenario analyses to estimate the possible impacts of business or policy decisions on the route network. The network connectivity metrics can also be used as key performance indicators (KPIs) by airports. For example, Schiphol Airport has more recently used direct and hub connectivity metrics as KPIs in its latest Annual Report. ${ }^{1}$ 
Measuring direct and indirect connectivity provides insights into all reasonable connections available to passengers and freight shippers. This is an important consideration for policy-makers as higher levels of direct and indirect connectivity improve social welfare by diminishing the generalised cost of travel. Shorter travel times, more convenient schedules, and lower air fares translate into lower travel costs, which benefit the users of aviation.

Measuring an airport's hub connectivity, on the other hand, provides insight into the scale of connecting flights that can be provided by the airport. Transfer traffic improves direct connectivity by increasing demand for direct routes from the hub. This enables a hub carrier and its partners to offer more destinations and higher frequencies than it would otherwise be possible. Figure 3 demonstrates that airports with hub operations offer many more destinations than other airports with comparable catchment areas. The additional direct connectivity resulting from hub operations is called a connectivity premium.

Figure 3. Relationship between the economic strength of a catchment area and the number of longhaul destinations for a selection of airports

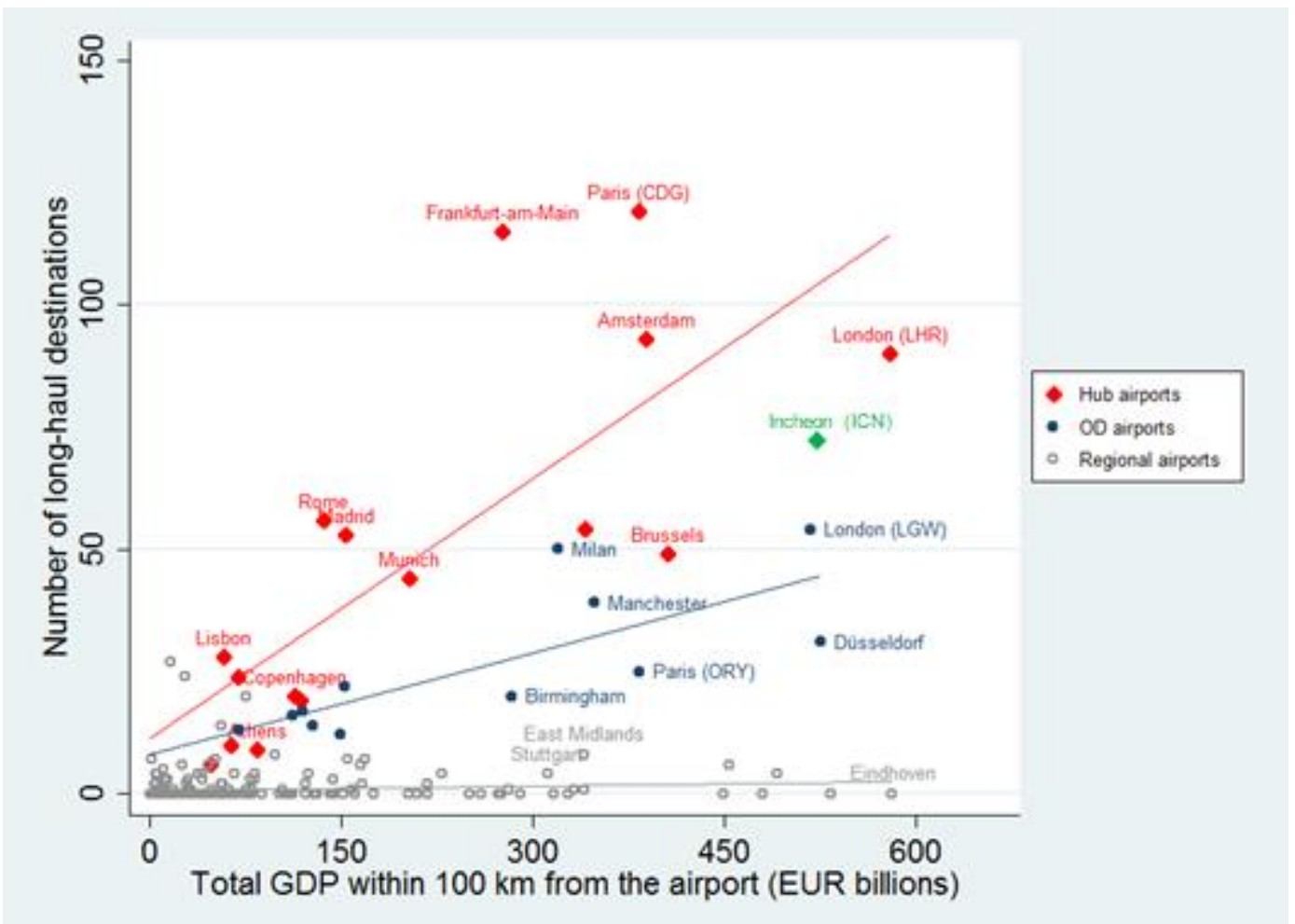

Source: SEO Airport Catchment Area Database

Note: The proxy for the economic strength of a catchment area is the GDP level within $100 \mathrm{~km}$ radius from each depicted airport. Hub airports are defined as airports where one or more carriers operate a hub network. Origin-destination (OD) airports are airports that serve more than 10 million passengers per year with a limited share of transfer passengers $(<10 \%)$. Regional airports serve fewer than 10 million passengers per year. Long-haul destinations are flights that have a stage length of more than 3,450 $\mathrm{km}$.

While direct and indirect connectivity can help airports and airlines monitor their competitive position in the origin-destination (OD) markets that they serve, an assessment of hub connectivity provides insight into the competitive position of an airport or airline vis-à-vis competitors serving the same connecting markets. 


\section{Approaches to measuring network connectivity: An overview}

A review of different approaches to measuring network connectivity reveals that there are at least three that account for all three components of connectivity mentioned above and are capable of assessing changes to the route network from different exogenous factors, such as changes to government policy or airline business models serving the network. These are:

- $\quad$ Network quality models,

- $\quad$ Quickest path length models, and

- $\quad$ Generalised travel cost models.

Most network connectivity studies conducted by governments, however, do not rely on such modelling techniques. Instead, the most common connectivity metrics used by policy makers are derived from statistics on flight schedules, as well as passenger and cargo flows data. Figure 4 provides an example of such statistics compiled by the UK Airports Commission to assess the network connectivity of the UK airport system.

Figure 4. An example of network connectivity metrics based on flight schedule and passenger flow data

\section{Total number of destinations served dailv from UK airborts}

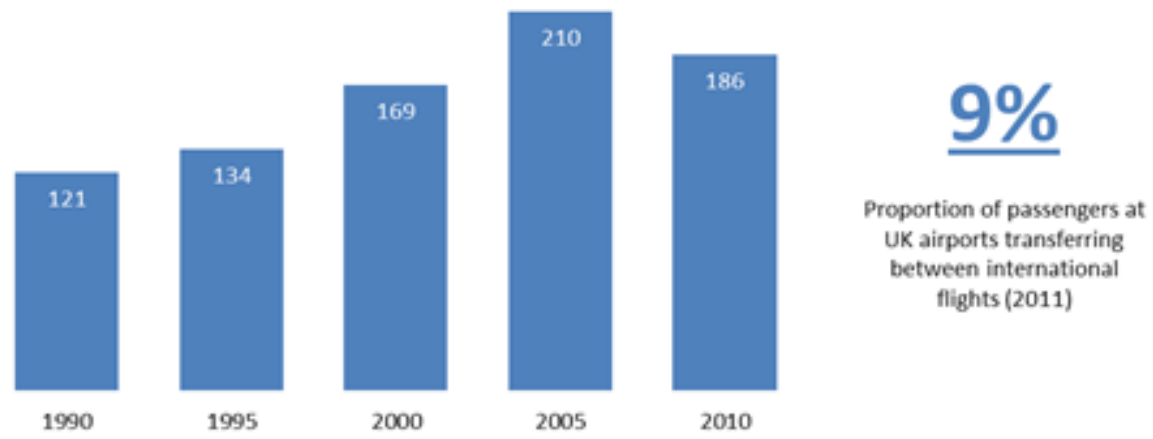

Top 10 destination countries served by UK airports (millions of passengers)

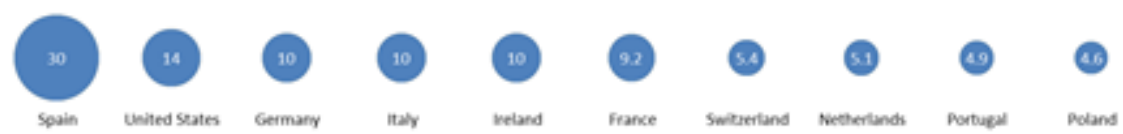

Top 10 destination countries accessed via a hub outside of the UK (millions of passengers)

\begin{tabular}{|c|c|c|c|c|c|c|c|c|c|}
\hline 4.2 & 3 & 15 & 0.8 & $a x$ & 0.6 & 0.6 & 0.6 & os & 05 \\
\hline & P & • & - & $\bullet$ & - & - & - & - & - \\
\hline United States & Australia & inds & Thaland & South Atrika & New Zealand & China & italy & Germany & anuda \\
\hline
\end{tabular}


The most common metrics derived from such statistics include the number of available destinations, flight frequencies, seat capacity, seat-kilometres, cargo-hold capacities, passenger and cargo volumes, and market shares (for example, of transfer traffic in total traffic). Such metrics can provide insights into how the route network has developed over time, across different passenger segments (business, leisure, visiting friends and relatives) or sector lengths (domestic, short-haul, long-haul).

The advantage of such metrics is that they are easy to interpret, and comparable over time and across different airports or network systems. They are, however, not particularly useful for policy or business analysis and can often be misleading. For example, some airports use the share of transfer traffic in total traffic to estimate hub capability of an airport. The share of transfer traffic is, however, only a relative measure: a decreasing share may simply mean that an airport is becoming more successful in providing point-to-point connections while preserving its hub function.

The shortcoming of single-metric measurement of hub connectivity is illustrated by the results of the analysis of the hub function at Incheon and Schiphol. Although Incheon has experienced a decreasing transfer share since 2013, the airport's hub connectivity has been in fact increasing since 2007 - by over $9 \%$ per year on average when measured as the total number of connecting passengers using the airport. At Schiphol, where transfer traffic has overall been on a declining trend since the economic and financial crisis of 2008, hub connectivity has also been on the rise, at a rate of about 5\% per year since 2007 .

\section{Network connectivity based on network quality models}

Network quality models identify all direct and all reasonable indirect and hub connections that are available for the investigated network for a defined period of time. To make the three dimensions of network connectivity additive and comparable, network quality models rely on valuations of the relative quality of connections.

The simplest network quality models incorporate routing factor thresholds ${ }^{2}$ as well as minimum and maximum connecting times (Dennis, 1994; Doganis and Dennis, 1989) to weed out unreasonable connections from the analysis. More complex network quality models classify indirect connections as "poor", "good" or "excellent" depending on the time they take relative to the shortest possible flight (Bootsma, 1997), while the most sophisticated models, such as NetScan (Box 3), apply weights to each connection to reflect on its quality on a continuous scale. The weights are based on the connection's circuity and the length of transfer time for indirect routes. ${ }^{3}$

\section{Box 3. NetScan air connectivity model}

The NetScan model developed by SEO Amsterdam Economics is an example of a sophisticated network quality model that can be used to estimate the connectivity impacts of any government or business decisions affecting the route network (see Burghouwt and Veldhuis, 2006; Burghouwt and de Wit, 2005; Burghouwt et al., 2009;

Lieshout and Burghouwt, 2013). Thanks to these capabilities the model has been applied, for example, to monitor national air connectivity for the Dutch Ministry of Transport (SEO, 2016a) or to track connectivity developments in Europe (ACI Europe, 2017).

The model identifies all direct and all reasonable indirect and hub connections including one transfer that are available for all airport pairs for a representative week of airport operations. Indirect connections are created within the model by connecting two direct flights. The model only allows indirect connections between flights of the same airline and of airlines that are members of the same alliance or that have a codeshare agreement.

NetScan uses OAG data to determine the available connections and the minimum connecting times (MCTs) for each transfer airport. Depending on whether the connection is a domestic or an international one (or a domestic international one), different MCTs are applied. If no data on MCTs is available, the model applies an MCT of 60 minutes to international-to-international and international-to-domestic connections, and 20 minutes to domestic connections. 
Like every other network quality model, it assesses the quality of connections to make direct, indirect, and hub connections comparable. A direct, non-stop flight operated by a jet aircraft is given the maximum quality weight of one. The weights applied to indirect routes are smaller than one to account for the fact that indirect connections are less attractive to the passenger than direct ones, due to the inconvenience of having to transfer through an airport and the time penalty involved. Some direct routes also have a quality weight smaller than one. This applies to, for example, direct flights operated by a turboprop, as passengers on such flights face a relatively longer travel time. All unfeasible connections are given the weight of zero.

Once weights are applied to all feasible connections, their values are aggregated to estimate the direct, indirect, and hub connectivity metrics. The connectivity scores are expressed in CNUs (Connectivity Units). 1 CNU is equivalent to one direct connection offered by a jet aircraft. CNU values are compiled for a representative week in the schedule, usually the third week of September.

Network connectivity metrics based on network quality modelling require significant resources in terms of modelling capacity, data collection, and expert judgment. In particular, computing sufficiently accurate minimum and maximum connecting times at different airports requires both expert knowledge of airport operations and obtaining information on the actual duration of flights.

Apart from providing comprehensive coverage of all connectivity dimensions, network connectivity metrics can be used to assess potential impacts resulting from changes to factors that can affect route networks. For example, in this report the NetScan network quality model is used to estimate the impacts of a joint venture between Korean Air and Delta Air Lines (Box 4). The model can be applied to estimate network connectivity impacts of route expansion or rationalisation by carriers, airline mergers or bankruptcies, change in the minimum connecting times at hub airports, or changes to government aviation policy. Moreover, network quality modelling captures the availability of connections provided by an airport or a system of airports, hence providing valuable insights for policy makers interested in fostering aviation connections for leisure and business purposes. Such insights can be valuable to airports and airlines as well, and there may be value in using network connectivity metrics as KPIs, to track airport performance against competitors.

\section{Network connectivity metrics based on quickest path length models}

Network connectivity metrics based on quickest path length models estimate direct and indirect connectivity by measuring the average travel time along the quickest path to reach all other airports in a network within a certain time threshold. Hub connectivity is estimated by calculating the number of all connections lying on the quickest OD path ${ }^{4}$ (Malighetti et al., 2008; Nieße and Grimme, 2015; Paleari et al., 2010). For example, Cattaneo et al. (2017) employed a quickest path length model to understand the evolution of selfconnecting in the intra-European market.

While network quality models usually exclude the connections including more than one transfer to reduce complexity, quickest path length models take indirect connections with multiple stops into account. Routing factor thresholds are always applied as such models only consider the quickest available connections within a certain distance or time limit. The minimum and maximum connecting times can also be included.

Although the coverage of such models includes direct, indirect, and hub connectivity, the estimates include only the fastest connections. Moreover, such models do not account for route frequencies. As a result, they are not particularly well suited to assessing connectivity implications of policy changes, or due to other factors that may affect the route network.

\section{Network connectivity metrics based on generalised travel cost models}

Generalised travel cost models assess the generalised travel cost of reaching a selection of destinations (or all reasonable destinations) in a network. The better connected an airport is, the lower generalised travel costs incurred by the users of aviation. The generalised travel cost includes cost of tickets (average air fare, 
and sometimes average charges related to getting to the airport), as well as the monetised value of time spent travelling. Some generalised cost estimates include costs due to delays or schedule delays. ${ }^{5}$

Aggregate air connectivity estimates based on generalised cost of travel are often challenging to interpret. This is due to the fact that one of the key drivers of the value of generalised travel cost is the average sector length of flights included in the estimate. This implies that airports with a larger share of long-haul connections tend to be characterised by a higher generalised travel cost than airports serving predominantly short-haul traffic. For that reason, if such metrics are to facilitate a comparison, they have to be computed for comparable sets of direct and indirect destinations for each airport.

As with network quality models, identifying all feasible direct and indirect connections involves specifying the minimum and maximum connecting times and routing factors. In addition, ticket prices and the monetised value of time spent travelling must be estimated, which makes this modelling technique relatively resource-intensive.

Metrics based on generalised travel cost models produce monetary estimates reflecting welfare impacts of connectivity changes on the users of aviation. The modelling results can thus be fed directly into the costbenefit analysis of any prospective policy intervention. This approach is particularly useful for investigating the welfare implications of changes to the supply-side of the air travel market (for example, from increasing ticket prices), but it can also test any other factors affecting the route network. For example, SEO Amsterdam Economics' generalised travel cost model, NetCost, was applied to measuring welfare impacts of European airspace modernisation (SEO, 2016b).

\section{Choosing the right approach to network connectivity assessments}

Table 1 provides and overview of the advantages and disadvantages of the selection of comprehensive approaches to measuring network connectivity that are described above.

This report applies the NetScan network quality model to assess network connectivity of Incheon and Schiphol against several benchmark airports. The reason behind the choice of this particular approach the superiority of network quality models over quickest path length models in terms of capturing all significant connections. While generalised travel cost models also cover all significant connections, they are better suited for welfare (not network) impact analysis - which is beyond the scope of this report.

The overview of a selection of different approaches to measuring network connectivity revealed that it is crucial to involve aviation stakeholders - aircraft and airport operators, air transport users, and local communities in the vicinity of the airport - and aviation experts in the process of developing air connectivity metrics. This can help ensure that the metrics include important considerations, such as any possible impacts of a policy on commercial viability of flights from an airport, and are correctly interpreted. Expert judgment can also help identify important trends that need to form part of connectivity analysis. 
Table 1. A comparison of different approaches to measuring connectivity

\begin{tabular}{|c|c|c|c|}
\hline & $\begin{array}{l}\text { Metrics based on } \\
\text { network quality } \\
\text { models }\end{array}$ & $\begin{array}{l}\text { Metrics based on } \\
\text { quickest path length } \\
\text { models }\end{array}$ & $\begin{array}{l}\text { Metrics based on } \\
\text { generalised travel } \\
\text { cost models }\end{array}$ \\
\hline What they estimate & $\begin{array}{l}\text { Number of direct, } \\
\text { indirect, and hub } \\
\text { connections weighted by }\end{array}$ & $\begin{array}{l}\text { Average travel time to } \\
\text { reach all other airports } \\
\text { in a network. }\end{array}$ & $\begin{array}{l}\text { The welfare impacts (in } \\
\text { monetary terms) of } \\
\text { connectivity changes. }\end{array}$ \\
\hline
\end{tabular}

their quality in terms of

transfer and detour

Number of markets

connected within a

certain time limit.

$\begin{array}{ll}\text { Scope } & \text { Comprehensive: Direct, } \\ & \text { indirect, and hub } \\ \text { connectivity. }\end{array}$

Comprehensive: Direct, indirect, and hub connectivity.

Comprehensive: Direct, connectivity.

Airline schedule data.

indirect, and hub

Data requirements

Airline schedule data.

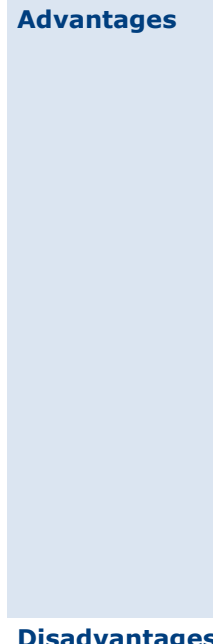

Provide a

comprehensive

connectivity overview as

all significant

connections are included

in the estimates.

Capture the availability

of connections provided

from an airport or a

system of airports.

Enable analysis of

changes to the route

network and scenario

analysis.

Enable analysis of

changes to the route

network and scenario analysis. connectivity

Airline schedule data ticket price database (or estimates of ticket prices), detailed data of passenger demand (possibly door-to-door).

Provide a comprehensive connectivity overview as all significant connections are included in the estimates.

Enable analysis of changes to the route network and scenario analysis.

Provide analysis of welfare impacts of changes to the route network - results can be used in government's

Relatively easy to interpret and communicate. cost-benefit analysis.

\section{Disadvantages}

Require complex modelling.
Require highly complex modelling.

Do not take all significant routes or route frequencies into account.

Account for connections for which there is very little or no demand, obscuring the true connectivity picture.
Require highly complex modelling.

Require collecting data from multiple datasets.

Using ticket price data creates challenges as it can be unreliable for particular markets.

Relatively difficult to interpret and communicate. 


\section{Network connectivity performance of major aviation hubs: Incheon and Schiphol}

This chapter sets out the findings from network connectivity assessments of two major global hub airports, Incheon International Airport (Incheon) and Amsterdam Airport Schiphol (Schiphol). Network connectivity levels were estimated for the years 2007, 2012, 2016 and 2017, which allowed for a comparison between the connectivity levels before the aftermath of the financial crisis (2007) to the post-crisis connectivity levels: just after the crisis (2012), as well as more recently (2016 and 2017). Each of the assessed airports is also compared against a selection of five benchmark airports in the region. The chapter also outlines the future air connectivity prospects for both airports.

The findings provide insights into the strengths and weaknesses of the route network provided by Incheon and Schiphol and shed light on the factors that affect air connectivity at the investigated airports and, in turn, what air connectivity prospects the two airports are likely to offer in the future. A wide range of findings demonstrates the versatility of air connectivity metrics based on network quality modelling in delivering useful insights for aviation stakeholders. For example, Box 4 demonstrates how network quality modelling can help shed light on connectivity impacts from a trans-Pacific joint venture between Korean Air and Delta Air Lines. ${ }^{6}$ Such insights can be useful to the policy makers as well: network quality models provide insights into the availability of connections to the users of aviation, a perspective that is particularly useful in determining the capacity of the national (and local) aviation systems in providing connections to faraway destinations for citizens to enjoy their free time or do business.

Box 4. A network connectivity case study: A joint venture between Korean Air and Delta Air Lines

Network connectivity metrics can be used to assess how any changes to airline business models or airline strategies - for example, from an increased presence of low-cost carriers at hub airports, or further consolidation or co-operation between carriers to provide connecting flights - may affect the route network.

This case study applies the NetScan network quality model to assess the potential network connectivity impacts of a trans-Pacific joint venture between Korean Air and Delta Air Lines. This joint venture is expected to contribute to network connectivity growth at Incheon through an increased number of flights provided between Incheon and Delta's hubs in the USA and improved schedule co-ordination. The study assumes that the joint venture will result in one additional daily service between Incheon and Atlanta (Delta's largest hub). Korean Air and Delta Air Lines operate wave systems at their respective hubs. These waves of incoming and outgoing traffic are depicted below, in red and grey respectively. The blue bars indicate the flights currently operated by either of the two hub carriers. 


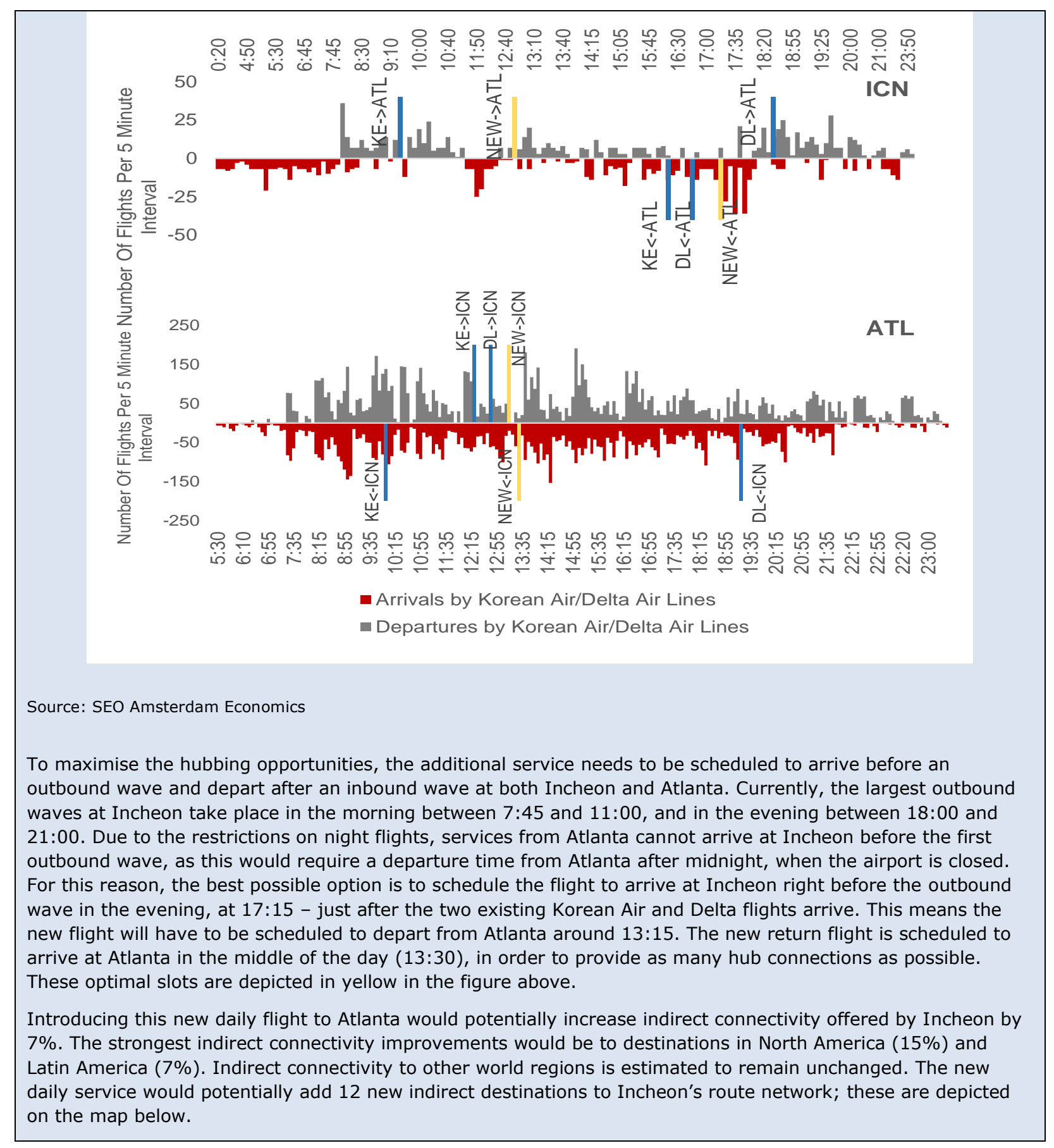




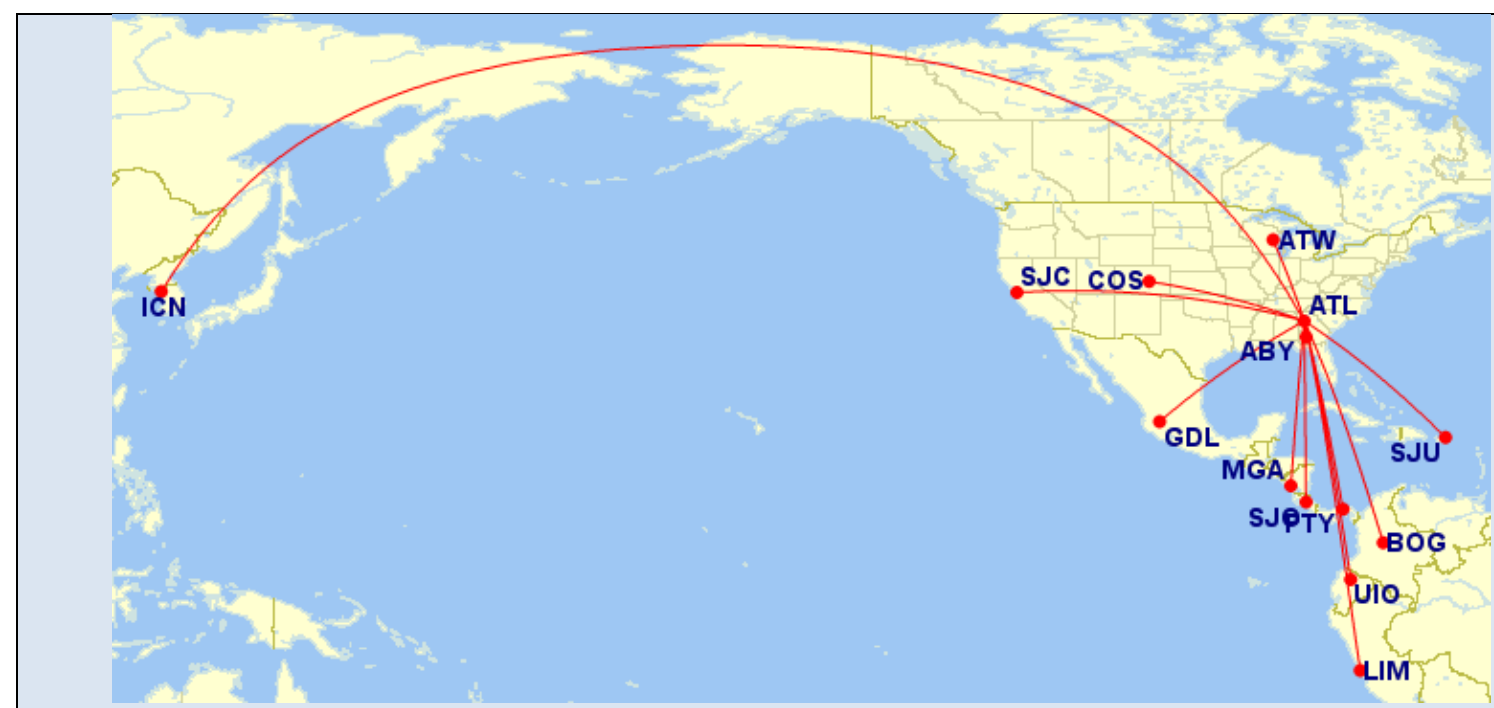

Source: SEO Amsterdam Economics

Note: The 12 new destinations that can be reached indirectly with a single stop are:

Southwest Georgia Regional Airport (ABY), Albany, United States of America; Appleton International Airport (ATW), Appleton, United States of America; El Dorado International Airport (BOG), Bogotá, Colombia; Colorado Springs Airport (COS), Colorado Springs, United States of America; Miguel Hidalgo y Costilla Guadalajara International Airport (GDL), Guadalajara, Mexico; Jorge Chávez International Airport (LIM), Lima, Peru; Augusto C. Sandino International Airport (MGA), Managua, Nicaragua; Tocumen International Airport (PTY), Panama City, Panama; Norman Y. Mineta San José International Airport (SJC), San Jose, United States of America; Juan Santamaría International Airport (SJO), San José, Costa Rica; Luis Muñoz Marín International Airport (SJU), San Juan, Puerto Rico; Mariscal Sucre International Airport (UIO), Quito, Ecuador.

The new service between Incheon and Atlanta would also increase Incheon's hub connectivity by around $2 \%$, mostly between destinations in Asia Pacific and North America. The new inbound flight from Atlanta to Incheon could provide onward connections to a number of previously unavailable destinations. These include Daegu, as well as new destinations in China, Japan, Thailand and Russia.

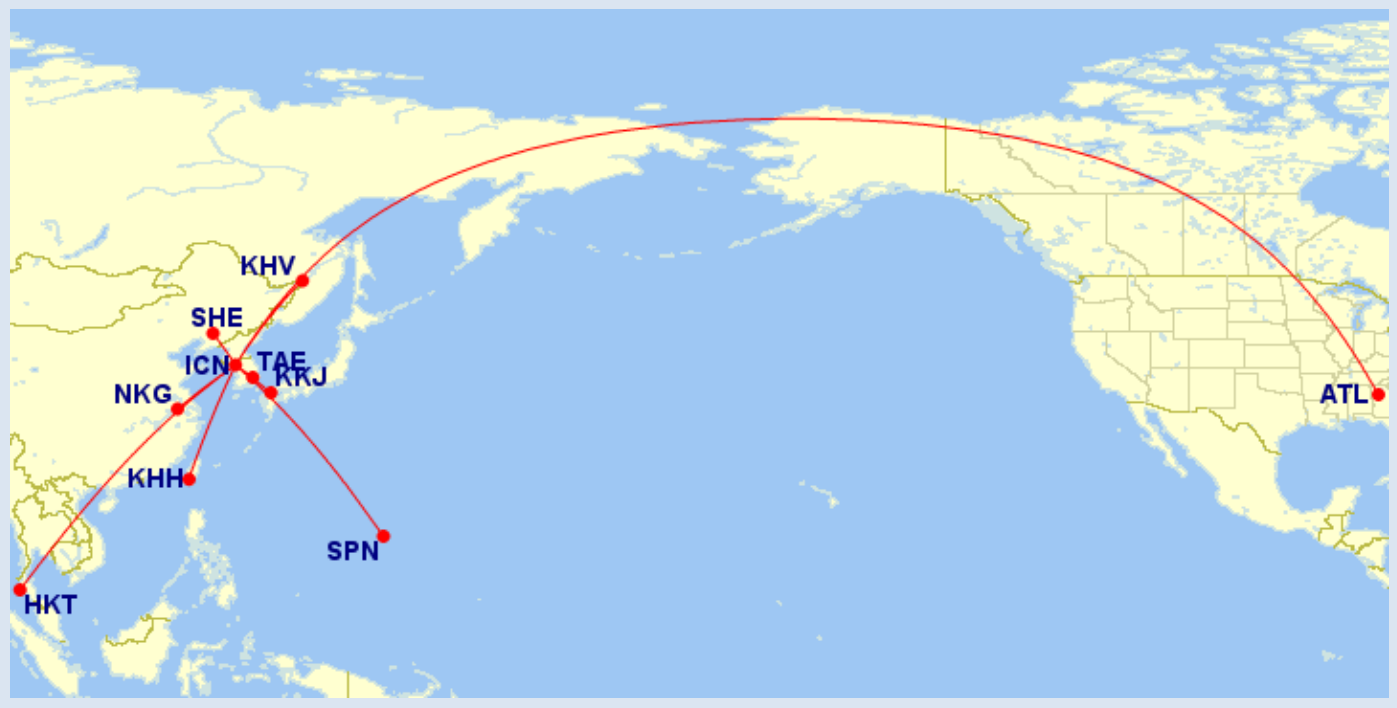

Source: SEO Amsterdam Economics

Note: The 8 new hub markets via Incheon are the markets between Hartsfield-Jackson Atlanta International Airport (ATL), Atlanta, United States of America and: Phuket International Airport (HKT), Phuket, Thailand; Kaohsiung International Airport (KHH), Kaohsiung City, Chinese Taipei; Khabarovsk Novy Airport (KHV), Khabarovsk, Russia; Kitakyushu Airport (KKJ), Kitakyushu, Japan; Nanjing Lukou International Airport (NKG), Nanjing, China; Shenyang Taoxian International Airport (SHE), Shenyang, China; Francisco C. Ada International Airport (SPN), Saipan, Northern Mariana Islands, United States of America; Daegu International Airport (TAE), Daegu, Korea. 
In terms of interpreting the results, like in the case of all other connectivity metrics, to produce robust results, a comparative analysis of different airports or points in time should be carefully considered using expert judgment and against other data on route networks, airport operations, as well as any relevant global and local socio-economic developments. For example, Schiphol has higher hub connectivity levels than Incheon. This is due to relatively extensive hub operations of KLM and its SkyTeam partners at the airport. The hub connectivity scores, however, also depend on transfer times and routing factors. For example, hub connectivity scores, which represent the availability of hub connections via the investigated hub airport, depend on both the transfer times and routing factors ${ }^{7}$.

Figure 5 demonstrates that the hub connectivity scores for Schiphol also benefit from relatively shorter average transfer times and smaller routing factors. The relatively smaller routing factors at Schiphol benefit from its convenient geographical position to serve connections between Europe and Asia as well as North America. Incheon's routing factors are higher due to the airport's position slightly off the main flight paths for many intra-Asian connections and connections between Asia and Europe. Since routing factors largely depend on geography, airports cannot really influence them. What both airports can improve, however, is the average transfer times at their hubs. Micro-simulation modelling of airside and landside can shed light on how that could be achieved in practice.

Figure 5. Average transfer times and routing factors at Incheon and Schiphol (2007, 2012, 2016, 2017)

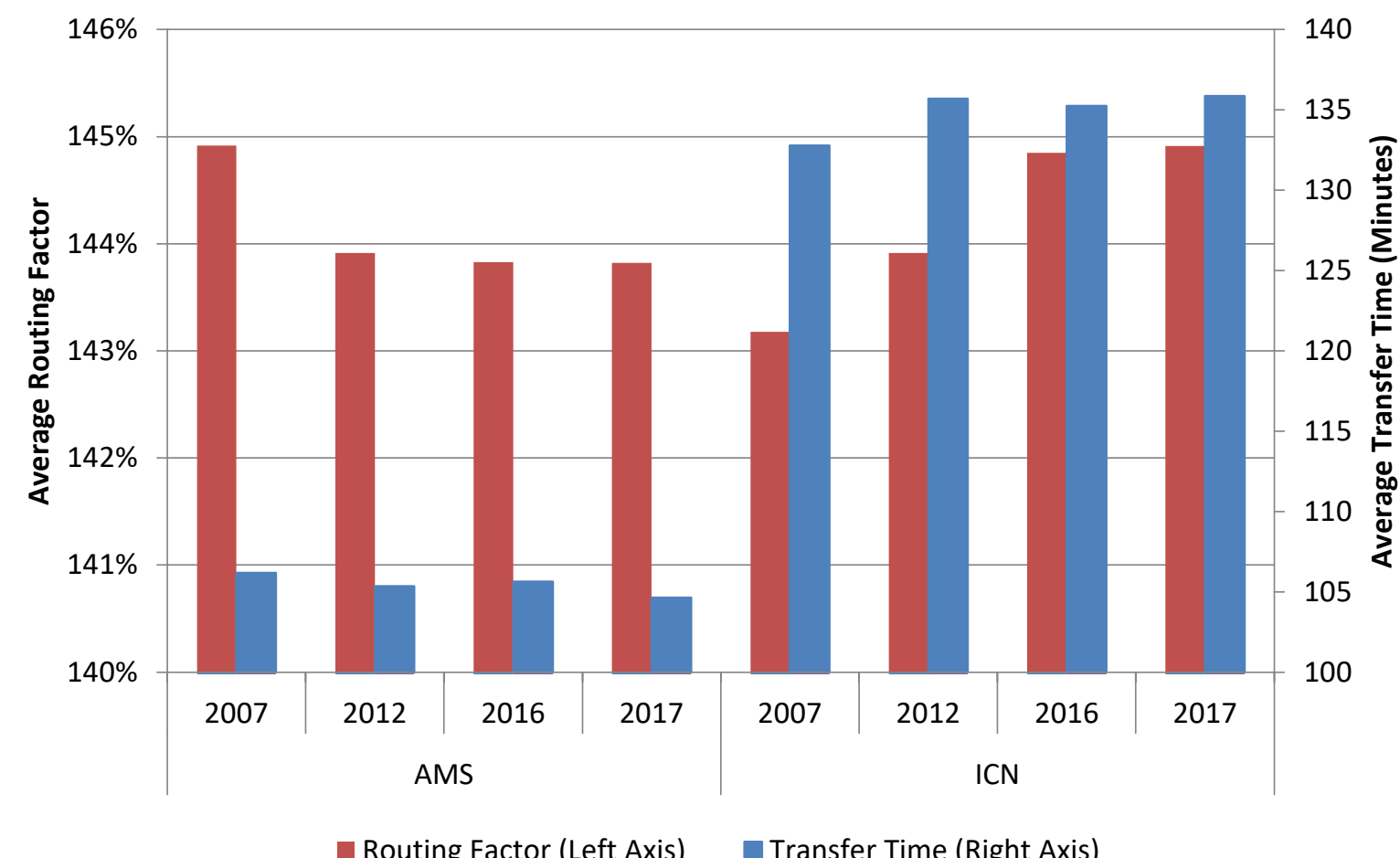

Source: SEO NetScan

\section{Network connectivity of Incheon Airport: An overview}

Direct connectivity at Incheon (ICN) has increased on average by about $6 \%$ per year over the past decade. This growth rate was higher than at the benchmark airports of Beijing (PEK), Hong Kong (HKG), Tokyo Narita (NRT), Singapore (SIN), and Bangkok (BKK). Despite the impressive growth in direct connectivity, 
the airport provides only about half of the direct connections offered from the Beijing hub (Figure 6). The airport has nevertheless surpassed the connectivity of Tokyo's Narita and its direct connectivity is currently on par with that of Bangkok, Hong Kong, and Singapore.

Figure 6. Level of direct connectivity from Incheon and benchmark airports $(2007,2012,2016,2017)$

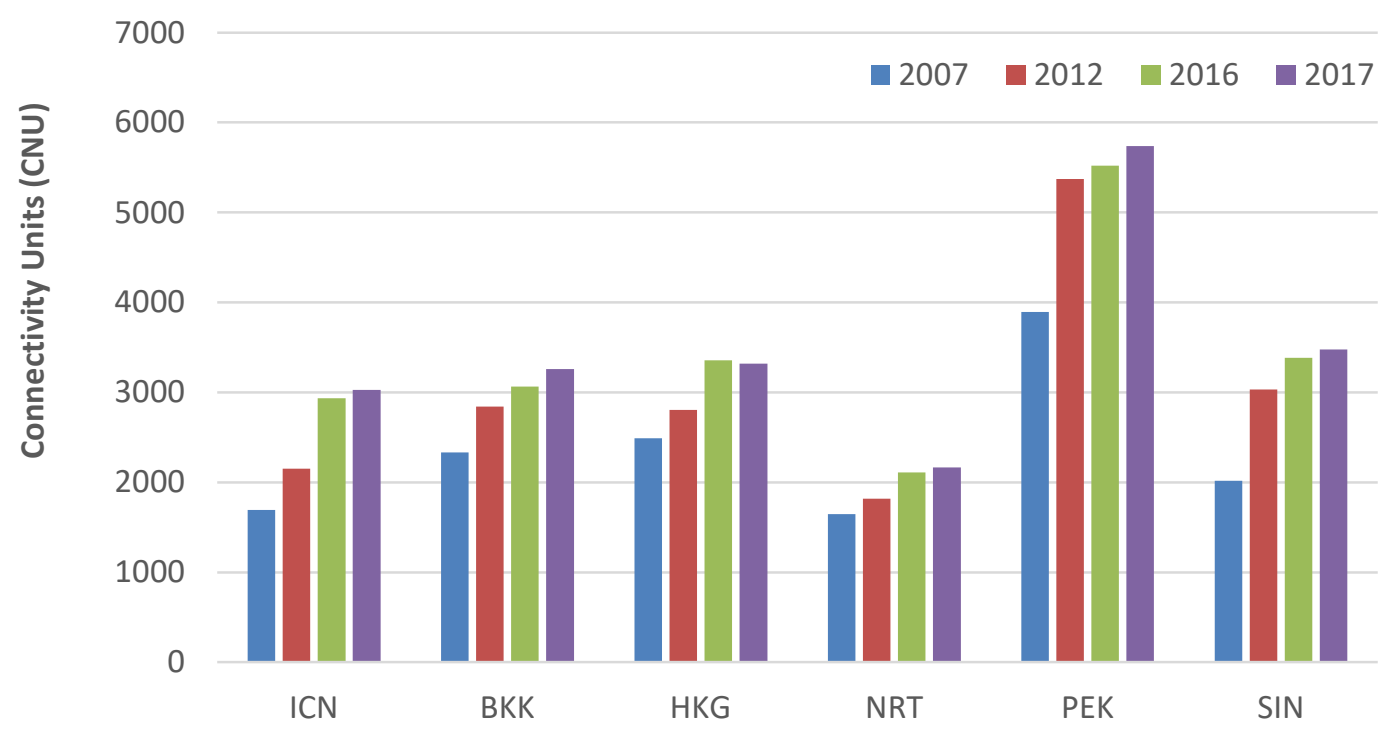

Source: SEO NetScan

Most of the growth in direct connectivity can be explained by the rapid rise of low-cost carrier presence at the airport. Until 2012, the growth in direct connectivity at Incheon mainly came from Korean Air, which significantly expanded its network between 2007 and 2012. After 2012, the growth in direct connectivity was mainly due to the rapid expansion of low-cost carriers. In 2007, Cebu Pacific was the only LCC operating at Incheon, offering 15 flights per week. As of 2017, five of the 10 largest carriers in terms of direct connectivity provided at Incheon have been LCCs. Jeju Air currently is the third largest airline operating at Incheon, followed by Jin Air, T'way Air and Eastar Jet. These four carriers have been delivering double-digit growth rates over the past year. The share of low-cost carriers in direct connectivity increased from $1 \%$ in 2007 to $29 \%$ in 2017 . Of the benchmark airports only Singapore has a larger low-cost penetration. In Bangkok, the opening of Don Mueang Airport led to a shift of low-cost traffic from Suvarnabhumi Airport to Don Mueang Airport. The slowdown of the direct connectivity growth rate over the past couple of years occurred mainly due to lower direct connectivity growth rates in the networks provided by Incheon's hub carriers - Korean Air and Asiana Airlines.

The vast majority of direct connectivity from Incheon is provided to airports in the Asia Pacific region ( $82 \%$ share of the total). The second and third most important destination regions in terms of direct connections are North America and Europe ( $8 \%$ and $5 \%$ respectively). Compared to the benchmark airports in the region, Incheon offers relatively many connections to other continents. Only Tokyo Narita has a larger share of direct connections to airports outside Asia Pacific.

Unsurprisingly, most of Incheon's indirect connectivity is provided by the carriers that operate a hub-andspoke model, Korean Air and Asiana Airlines. While Korean Air has outpaced the average annual growth in indirect connectivity at the airport over the past decade (4.3\%), Asiana Airline's share of the indirect network from the airport diminished. Most of Incheon's indirect connectivity is provided by Korean Air and Delta's flights to US hubs in Atlanta and Dallas. Indirect connectivity is likely to receive a strong boost from the recently signed trans-Pacific joint venture between Korean Air and Delta. One additional daily flight 
between Incheon and Atlanta could potentially increase indirect connectivity from Incheon by $7 \%$ and hub connectivity by $2 \%$.

Hub connectivity provided from Incheon has experienced an impressive average annual growth rate of 9.4\% over the past decade. Growth in hub connectivity was strongest between 2007 and 2014 when Korean Air significantly expanded its network at the airport. Korean Air and its partners currently provide just over $70 \%$ of all hub connections at Incheon. The benchmark airports have also experienced impressive growth levels (apart from Tokyo Narita). Incheon mainly provides connections between different Asian airports and between Asia Pacific and North America. In terms of competition level with other hubs, the share of contested markets between Incheon and the benchmark airports has decreased in all cases, except for Beijing.

Over the past decade, each additional direct connection at Incheon has led to an average increase of 4.5 connectivity units (CNU) in terms of hub connectivity (which is illustrated by the angle of the trend in Figure 7). This relationship is similar to that of Singapore. The other benchmark airports have experienced a much stronger relationship, with Hong Kong's direct connectivity corresponding to $9.9 \mathrm{CNU}$ in terms of hub connectivity. The relatively weaker generation of hub connectivity per unit of direct connectivity at both Incheon and Singapore can be explained by the fact that most of the traffic increase at the airports has been thanks to the expansion of low-cost carriers.

Figure 7. Relationship between direct and hub connectivity at Incheon and benchmark airports (2007, 2012, 2016, 2017)

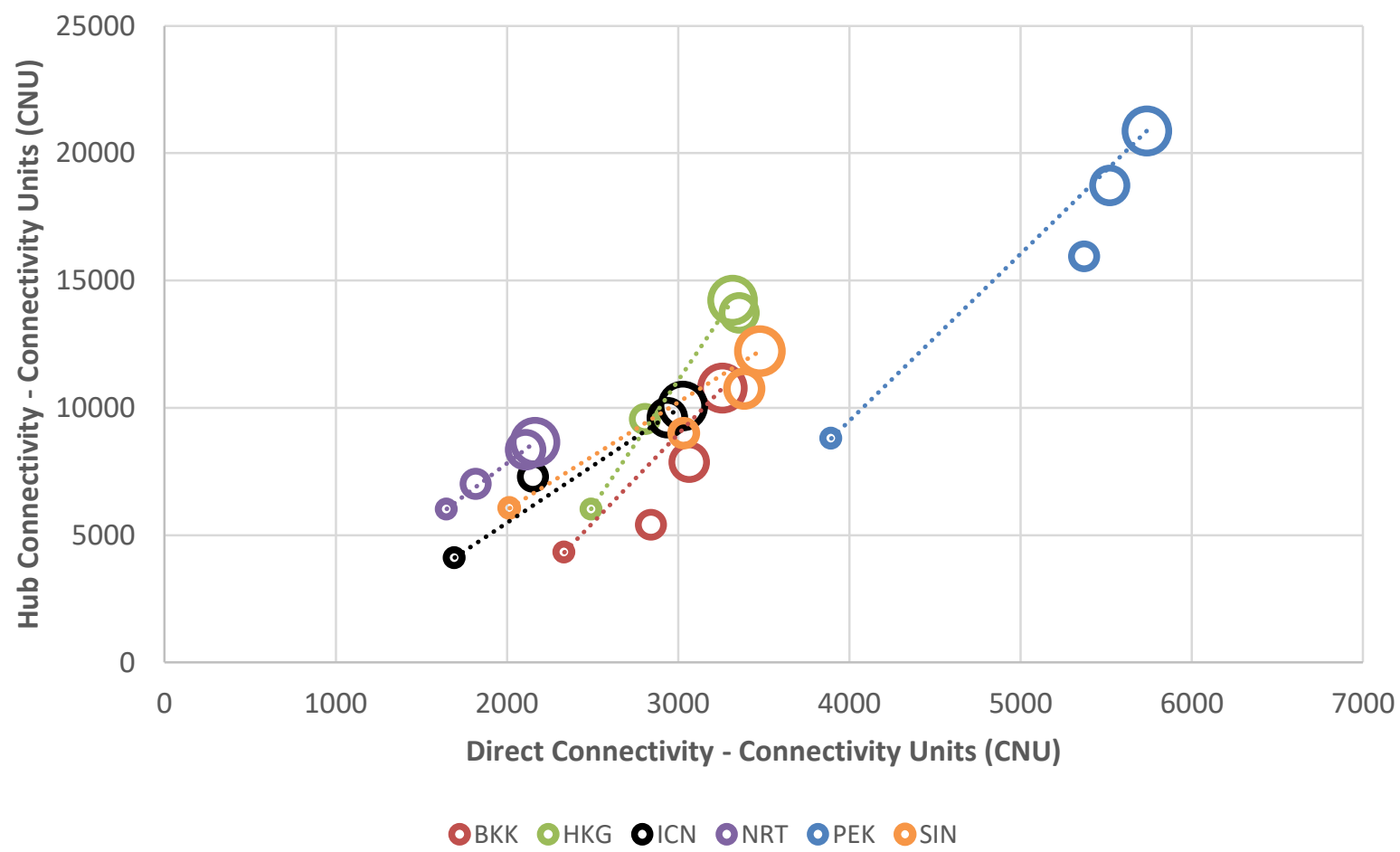

Source: SEO NetScan

Note: The figure depicts the relationship between direct and hub connectivity for a selection of airports in the years 2007, 2012, 2016, and 2017. The largest circle indicates data for the most recent year (2017) and the smallest circle indicates the most dated point in time (2007). For each airport, the dotted line connects the most dated and the most recent points in time - the steeper the gradient, the stronger the relationship between direct and hub connectivity has been in the period 2007-2017. 
The future air connectivity prospects of Incheon look promising. The airport enjoys unrestricted capacity to grow its connectivity, and the traffic growth projections for the region are well above the projected average global rates. The success of the hub at Incheon, however, will depend on how well it will be able to compete with other hubs, particularly in China, and on how well further growth in LCC presence will be accommodated into Incheon's route network. One of the challenges for the hub at Incheon is the fact that traffic for Seoul is served from two airports, Gimpo and Incheon. Like in other multi-airport city systems, e.g. London or Tokyo, split operations by the hub carrier and its partners may be a hurdle to maximising the benefits of hub connectivity (ITF, 2014). The SWOT analysis for Incheon is summarised in Table 2.

\section{Table 2. SWOT analysis for Incheon}

Strengths Weaknesses

- $\quad$ Premium airport facilities contribute to the airport's attractiveness as a transfer point.

- $\quad$ Strong growth of low-cost carriers has significantly increased direct connectivity at the airport as well as competition between carriers at the airport, hence possibly reducing fare levels and making the airport more attractive to passengers.

- $\quad$ Strong reliance on OD market and a big catchment area make the airport less vulnerable to competition from other hubs.

- Lack of restrictions on night operations enables more flexible scheduling of flights and increases the attractiveness of the airport for carriers.

\section{Opportunities}

- $\quad$ Noise considerations are not a significant factor so carriers do not face the risk of airport utilisation caps in the future.

- Ample spare capacity allows airlines to grow their connectivity to and via the airport.

- Strong growth in air traffic is foreseen for the region, making the airport an attractive expansion site.

- Advancement of aviation liberalisation enables expansion through adding new destinations to Incheon's route network.

- Co-operation between the two hub carriers may significantly enhance hub connectivity, making Incheon more attractive to transfer passengers.

- Increasing share of LCCs at Incheon may enhance competition at the airport and provide new opportunities for passengers to arrange their own connections (selfconnecting), hence improving the overall connectivity levels.
- $\quad$ Split hub operations between Incheon and Gimpo limit the hub connectivity potential at Incheon.

- $\quad$ Single hub carrier operations would also allow for a more efficient scheduling of flights.

- Incheon's location limits its ability to efficiently serve certain markets, in particular Southeast Asia.
Threats

- Growth of low-cost operations may threaten feeder traffic of the hub carriers, hence weakening hub operations.

- Advancement of aviation liberalisation and growth of Chinese hubs may increase competition for connecting markets, and possible weaken the hub at Incheon.

- $\quad$ Aviation liberalisation may lead to increased competition in existing markets, jeopardising hub connectivity provided at Incheon.

- Climate change considerations may result in more stringent restrictions on $\mathrm{CO}_{2}$ emissions, increasing costs for airlines, hence reducing demand for aviation and overall connectivity.

Source: SEO Amsterdam Economics

\section{Incheon: direct, indirect, and hub connectivity outcomes}

\section{Direct connectivity}

Over the past decade, Incheon's direct connectivity level has doubled (Figure 8). This rising trend, however, has recently slowed down - while the average annual growth rate since 2007 was at around $6 \%$, direct connectivity between 2016 and 2017 increased only by around 3\%. 
Figure 8. Level of direct connectivity from Incheon $(2007,2012,2016,2017)$

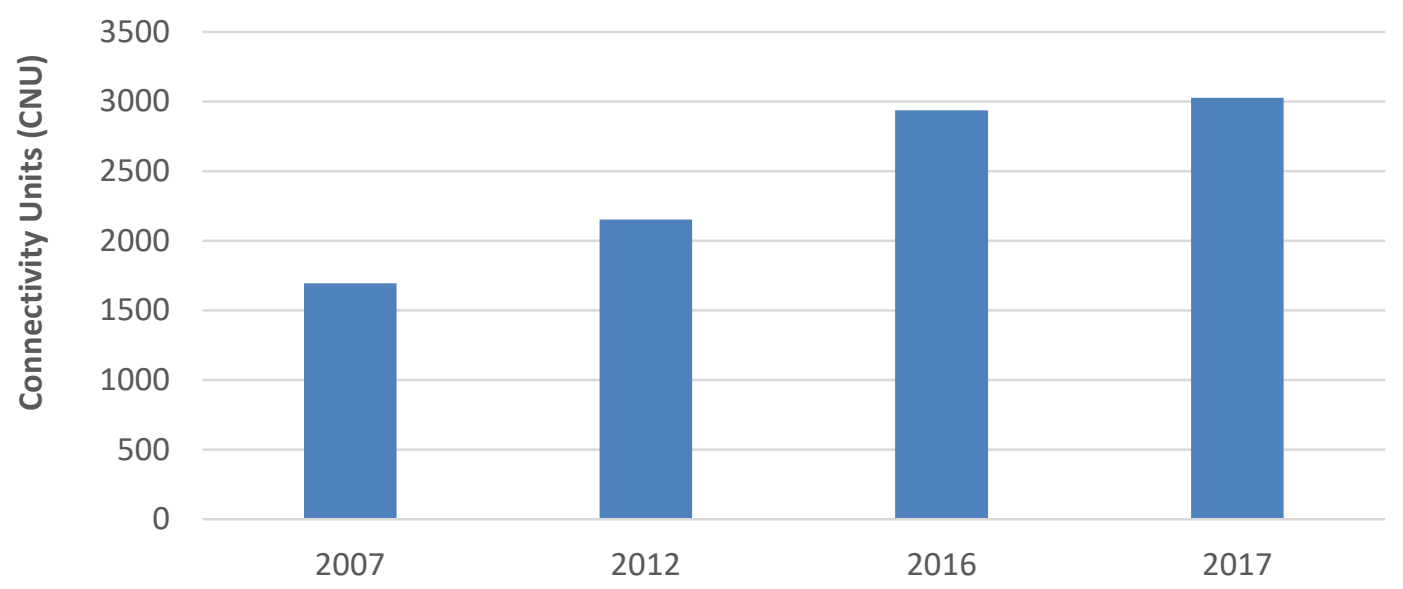

Source: SEO NetScan

The doubling of direct connectivity over the past decade can be explained by the rapidly increasing low-cost operations at Incheon (Figure 9). In 2007, Cebu Pacific was the only low-cost carrier (LCC) operating at Incheon, offering 15 flights per week. As of 2017, five of the 10 largest carriers in terms of direct connectivity provided from Incheon have been LCCs. Jeju Air currently is the third largest airline operating at Incheon, followed by Jin Air, T'way Air and Eastar Jet. These four LCCs have been delivering double-digit growth rates over the past year: Jeju Air's direct connectivity grew by $20 \%$, Jin Air's by $33 \%$, T'way's by $34 \%$, and Eastar Jet's by $50 \%$.

The slowdown of growth in direct connectivity from 2016 to 2017 occurred due to changes to the route networks of the two hub carriers operating at Incheon. Over this period, direct connectivity of Korean Air and Asiana Airlines has decreased by $2.5 \%$ and $11.7 \%$ respectively. Asiana Airlines transferred over 60 of its weekly flights to its low-cost subsidiary Air Seoul, while Korean Air has reduced its route network to destinations in Asia, notably to Japan (-12\%) and China (-4\%).

Figure 9. Share of direct connectivity from Incheon by alliance membership $(2007,2012,2016,2017)$

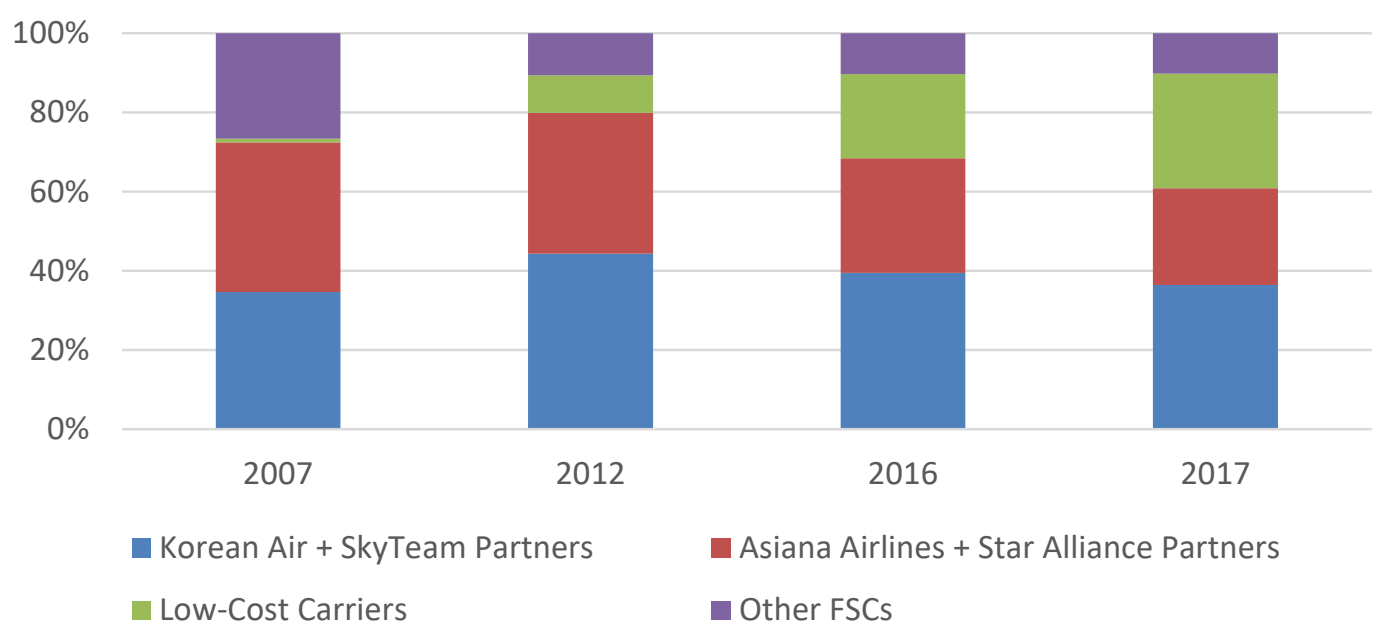

Source: SEO NetScan

Note: The list of carriers that were assigned to the low-cost category can be found in the glossary of terms. Other FSCs category comprises those full-service carriers that have not joined any of the three airline alliances. 


\section{Indirect connectivity}

Over the past decade, indirect connectivity at Incheon has increased by an average annual rate of $4.3 \%$. Between 2016 and 2017, indirect connectivity increased by $8.8 \%$, hence outpacing the growth of direct connectivity. The vast majority of indirect connectivity at Incheon is provided by airline alliances: SkyTeam, Star Alliance, and Oneworld (Figure 10). This relatively faster growth rate of indirect connectivity available from the airport may, however, be underestimated. The rapid growth of LCC presence at Incheon has created many opportunities for self-hubbing of passengers, hence increasing the indirect and hub connectivity potential.

SkyTeam (of which Korean Air is a member) has increased its indirect connectivity by an average $4.8 \%$ per year over the past 10 years. The growth of indirect connectivity provided by Star Alliance (of which Asiana Airlines is a member) over the same period was relatively lower, on average $1.4 \%$ per year, which led to a reduction of Star Alliance's share in indirect connectivity by $10 \%$ over the past decade. Indirect connectivity provided by Oneworld (of which Japan Airlines is a member) experienced the strongest growth, $12.8 \%$ on average per year. Its share of indirect connectivity at the airport, however, has recently substantially decreased. This decline can be mainly attributed to Japan Airlines' decision to phase out flights between Incheon and Narita, and focus on serving connections between Gimpo and Haneda.

Figure 10. Level of indirect connectivity from Incheon by alliance membership (2007, 2012, 2016, 2017)

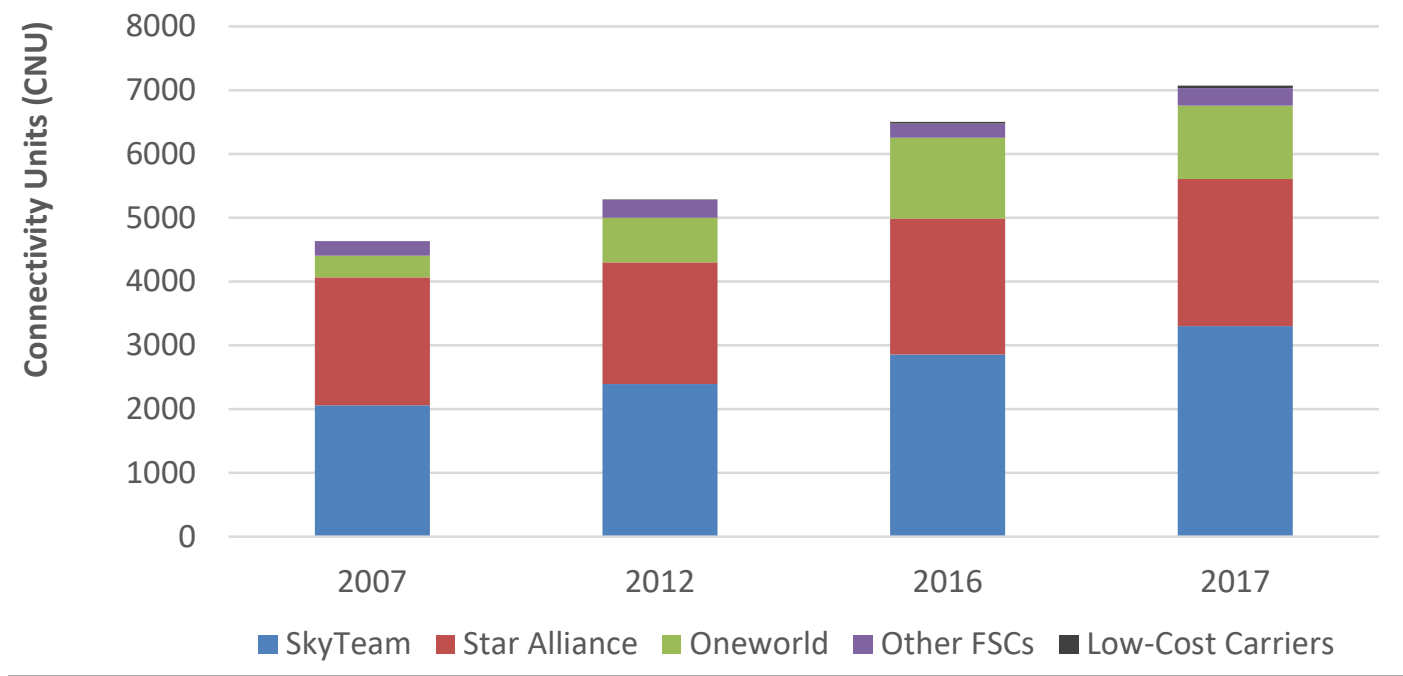

Source: SEO NetScan

Note: The list of carriers that were assigned to the low-cost category can be found in the glossary of terms. Other FSCs category comprises those full-service carriers that have not joined any of the three airline alliances.

\section{Onward connections from Incheon}

North American and European airports are the most important hubs for providing onward connections from Incheon. The top 10 airports for providing highest levels of indirect connectivity for Incheon are all located in North America and Europe (Figure 11). The highest ranked Asian hub, Hong Kong, is only in $12^{\text {th }}$ place (Figure 12). Tokyo Narita currently occupies the $16^{\text {th }}$ position - a stark decline since 2007 when Narita was the fourth most important hub for proving indirect connectivity for Incheon. This decline can be mainly attributed to Japan Airlines having curbed their operations between the biggest airport in Seoul (Incheon) and the biggest airport in Tokyo (Narita), to focus instead on serving smaller airports closer to the city centre of Seoul and Tokyo (Gimpo and Haneda respectively). 
The most important onward hub for Incheon is Atlanta: 13 weekly direct flights operated by Delta Air Lines and Korean Air provide numerous onward connections to reach cities in the USA. Between 2016 and 2017 the indirect connectivity provided via Atlanta increased substantially (Figure 12) as Delta reinstated its flights between the airport and Incheon. Delta also provides a substantial share of Incheon's indirect connectivity through its hubs in Detroit and Seattle.

American Airlines connects Incheon to its network via Dallas-Fort Worth. Almost 500 weekly onward connections provided for Incheon made Dallas the second most important onward hub for Incheon in 2017.

Istanbul Atatürk is another airport which has gained importance as an onward hub for Incheon over the past decade. Flights provided by Turkish Airlines and Asiana Airlines connect Incheon to the network of Star Alliance members at Istanbul, a hub which experienced tremendous growth over the past years.

The third and fourth most important onward hubs for Incheon are Frankfurt and Schiphol respectively. Flights operated by Asiana Airlines and Lufthansa provide connections to the Star Alliance route network at Frankfurt, while Korean Air and KLM connect passengers from Incheon to the SkyTeam network at Schiphol.

Figure 11. Top 10 onward hubs for connections from Incheon (2017)

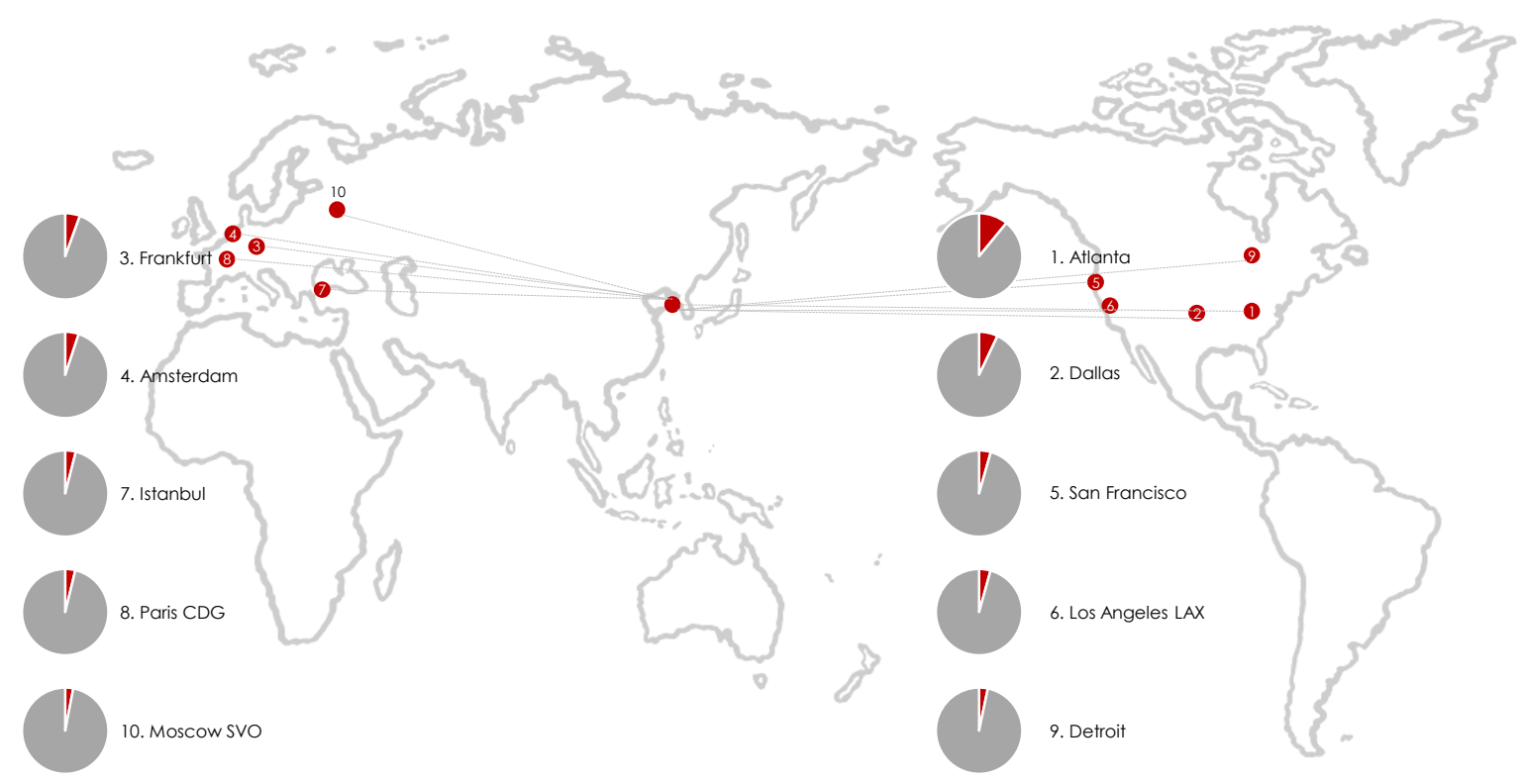

Source: SEO NetScan

Note: The red slice of each pie chart indicates the share of Incheon's indirect connectivity facilitated by a given hub. 
Figure 12. Level of Incheon's indirect connectivity by onward hubs providing the connection (2007, 2012, 2016, 2017)

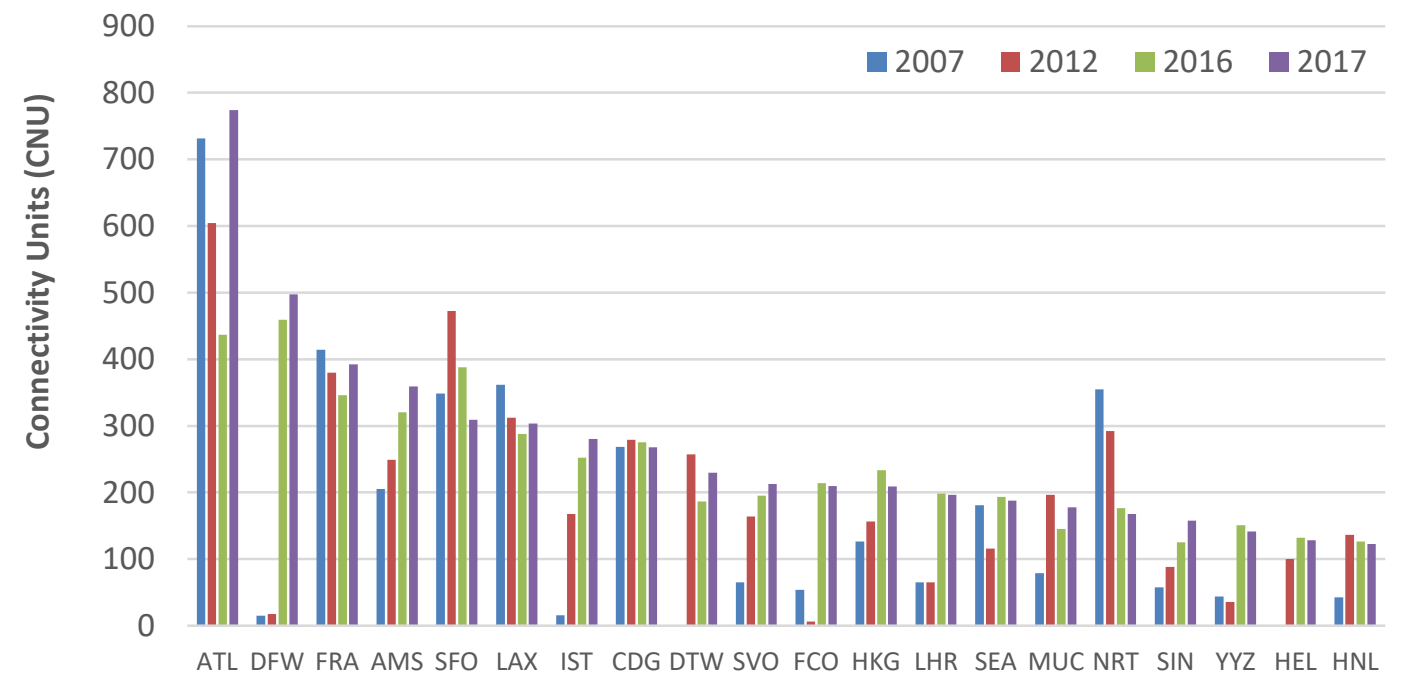

Source: SEO NetScan

\section{Direct and indirect connectivity by region}

The lion's share of direct connections available from Incheon is to the Asia Pacific (82\%) (Figure 13). The relatively low levels of direct connectivity to North America $(8 \%)$ and Europe $(5 \%)$ are compensated by high levels of indirect connectivity mostly provided by SkyTeam and Star Alliance members. Indirect connectivity from Incheon is mostly to North America (44\%) and Europe (34\%). Indirect connections to Asia Pacific constitute $13 \%$ of Incheon's indirect connectivity.

Figure 13. Level of direct and indirect connectivity from Incheon by region $(2007,2012,2016,2017)$

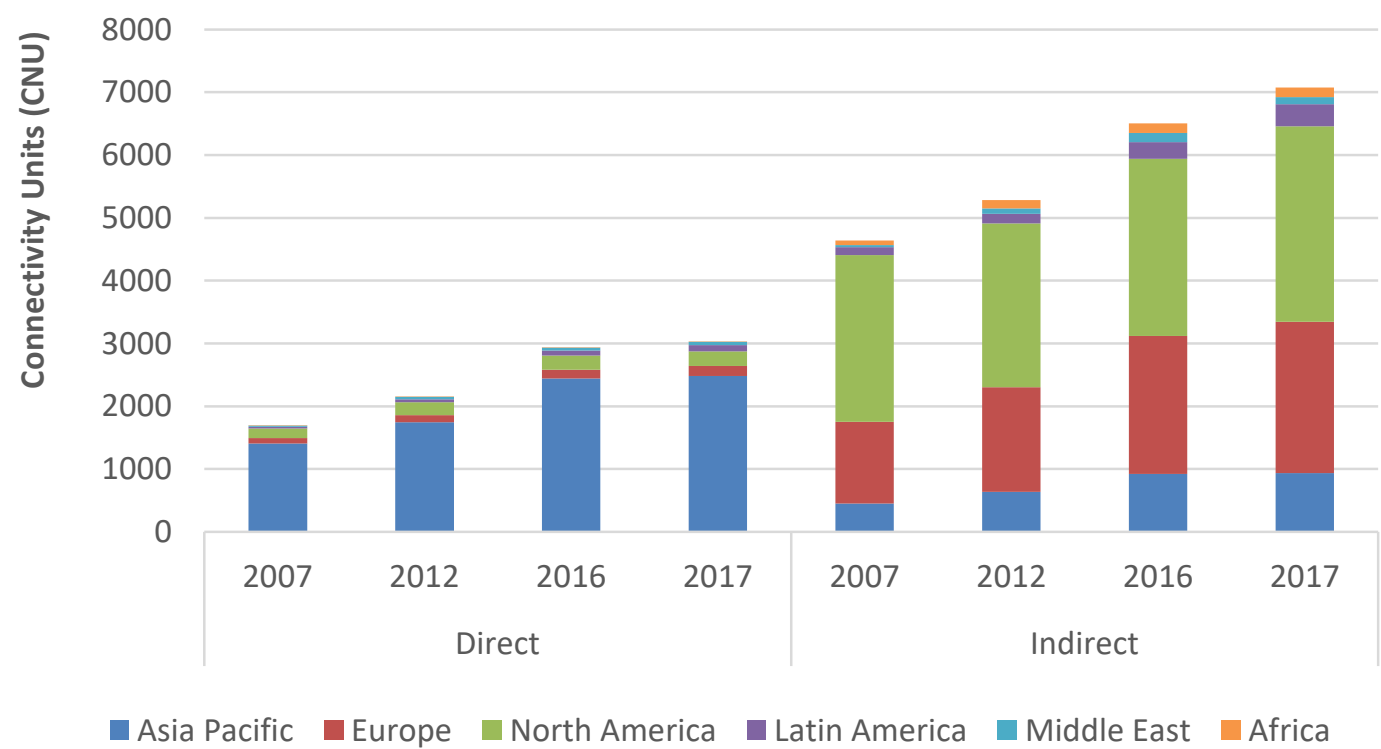

Source: SEO NetScan 


\section{Hub connectivity}

Incheon has experienced very strong growth in hub connectivity over the past 10 years, by an average annual rate of $9.4 \%$ (Figure 14). The growth of hub connectivity was highest during the period 2007-2012 (over 12\% growth per year). It then slowed down to just under 5\% between 2016 and 2017.

The most important factor behind rapidly growing hub connectivity levels was Korean Air's expansion of its route network from Incheon. Hub connectivity also increased due to Korean Air's improved offer on domestic destinations from Incheon. While most domestic flights in Korea are operated from Gimpo Airport, between 2007 and 2012 Korean Air significantly increased the number of flights from Incheon to Jeju, Busan and Daegu. Korean Air served the latter two destinations 27 and 14 times per week respectively in 2017. Establishing these services fuelled hub connectivity already offered from the airport.

Figure 14. Level of hub connectivity from Incheon $(2007,2012,2016,2017)$

12000

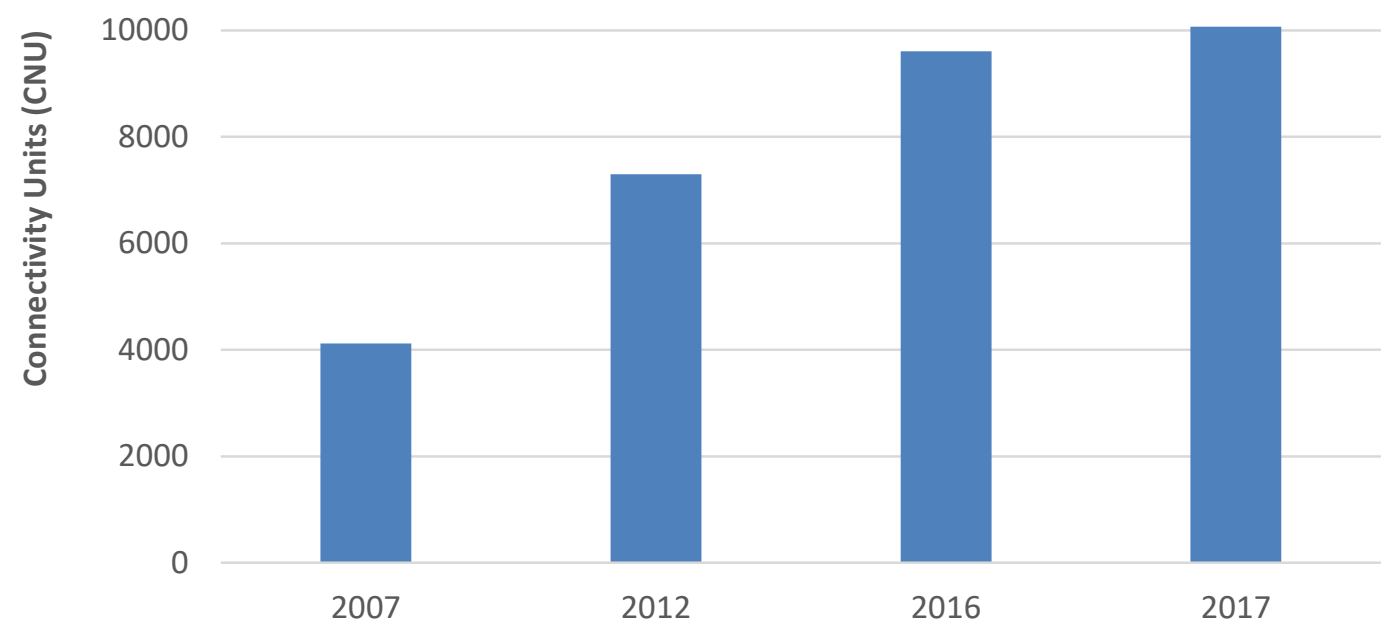

Source: SEO NetScan

While the level of hub connectivity currently offered from Incheon is 2.5 times larger than a decade ago, the share of transfer passengers in total traffic at the airport in 2007 and 2016 (i.e. for the most recent available data point) was around $12 \%$ (Figure 15). As such, transfer shares do not reflect the hub connectivity levels provided by Incheon. 
Figure 15. Share of transfer passengers in total traffic at Incheon (2007-2016)

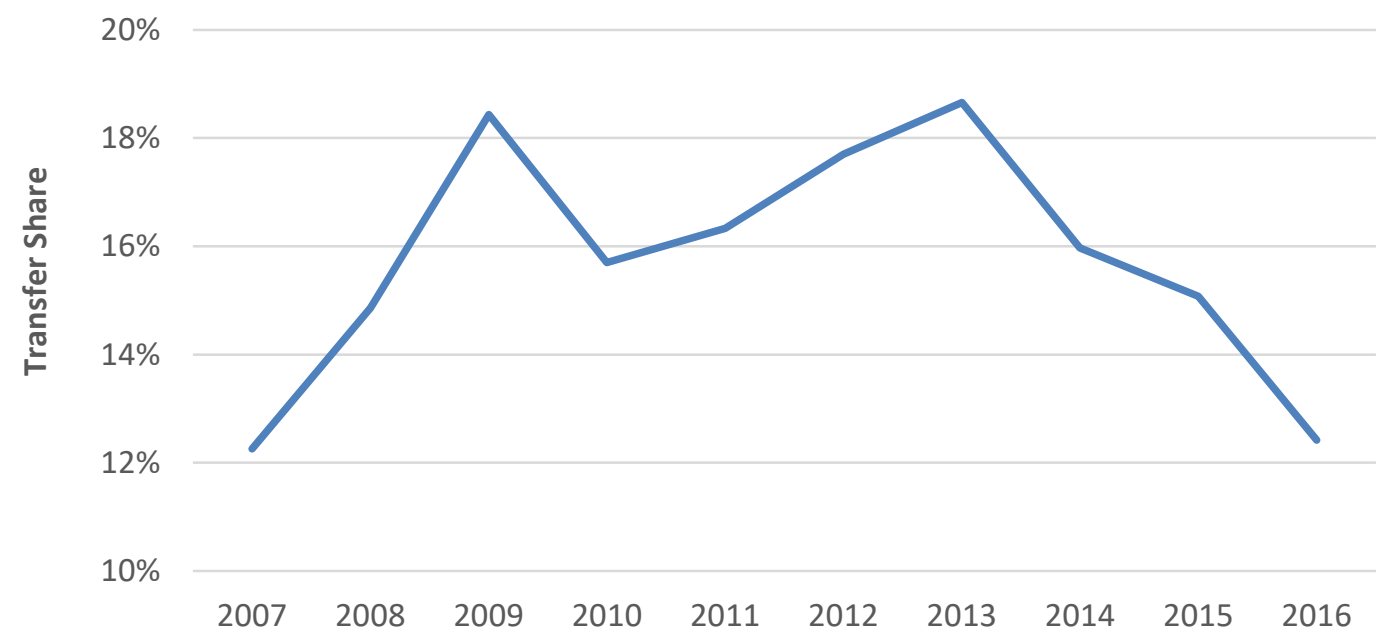

Source: Incheon Airport Statistics

The share of Korean Air and its SkyTeam partners' contribution to hub connectivity provided from Incheon has been steadily increasing since 2007, at the expense of the share of Asiana Airlines and its Star Alliance partners (Figure 16). This trend is directly linked to the stronger growth of Korean Air relative to Asiana Airlines over the same period. In 2017, Korean Air and its SkyTeam partners provided over $70 \%$ of all hub connectivity from Incheon.

Figure 16. Share of hub connectivity from Incheon by alliance membership $(2007,2012,2016,2017)$

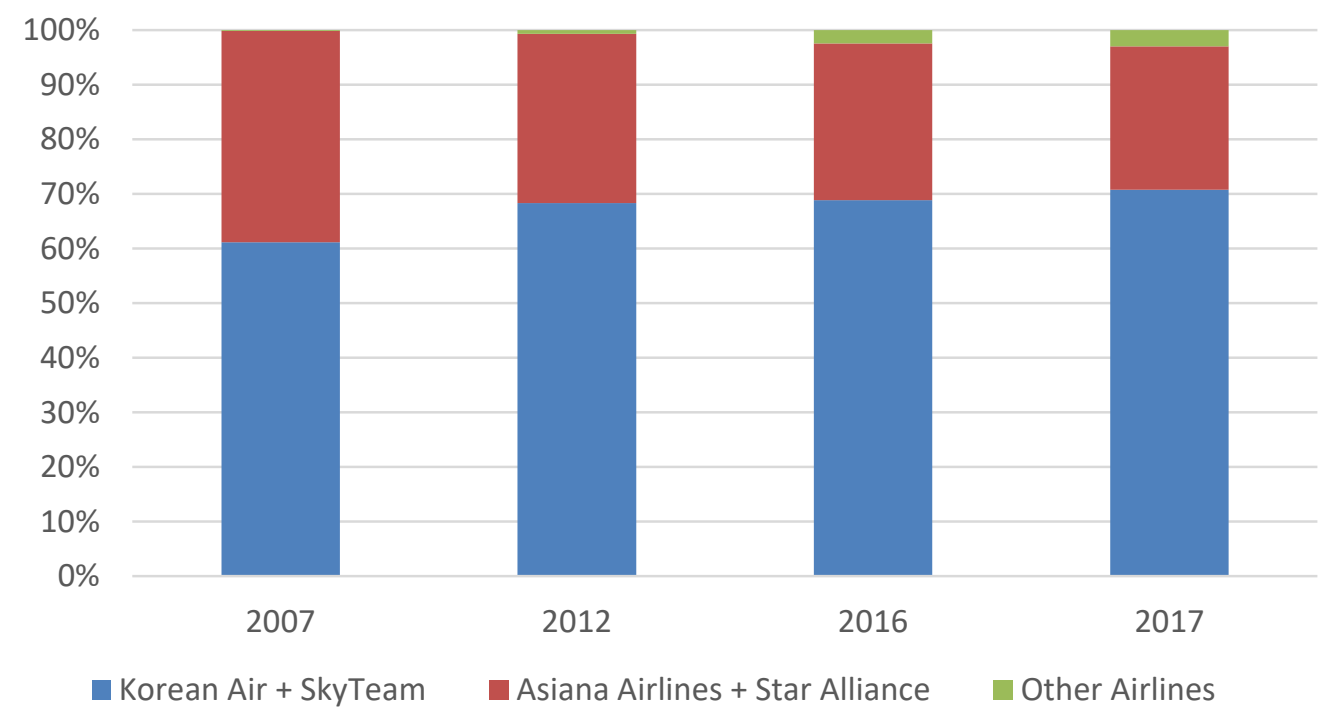

Source: SEO NetScan

Hub connectivity by world region

As Figure 17 demonstrates, Incheon operates as a connecting hub mainly for airports in the Asia Pacific region (47\%). It is also a connecting point for Asia Pacific - North America and Asia Pacific - Europe traffic ( $23 \%$ and $21 \%$ respectively). The remaining $8 \%$ of Incheon's hub connections are between intercontinental flights. 
Figure 17. Hub connectivity from Incheon by region (2017)

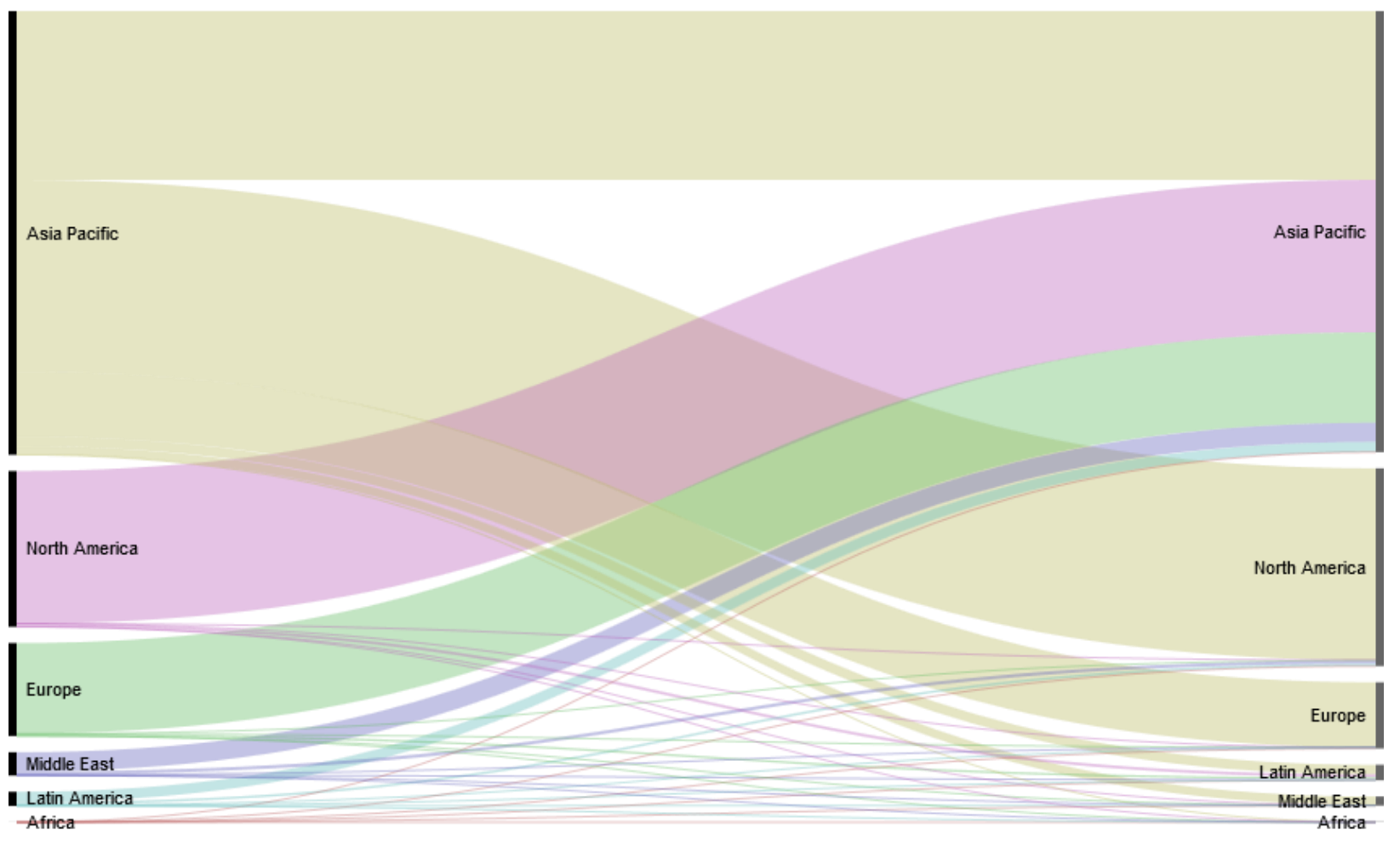

Source: SEO NetScan

\section{Network connectivity provided from Incheon against five benchmark airports}

Network connectivity metrics can serve as useful means of comparing route networks of different airports. The analysis below compares Incheon against five benchmark airports in Beijing, Hong Kong, Tokyo Narita, Singapore, and Bangkok. The selection of benchmark airports was based on (a) an analysis of the extent to which the hub network of the selected airport is contested by other hubs in the region and (b) internal discussions held with the airport operator.

The analysis of the extent to which Incheon's hub network is contested by other large hub airports included the following steps. The first step was to identify all connecting markets served by network carriers at Incheon. The second step was to estimate the level of hub connectivity offered in each of these markets. The third step was to determine which connecting markets served via Incheon are contested by other large hub airports in the region. The final step included estimating Incheon's hub connectivity share contested by other hub airports. This share demonstrates the extent to which other hub networks overlap with Incheon's hub network (Figure 18). 
Figure 18. Degree of Incheon's hub network overlap with hub networks of other airports in the region

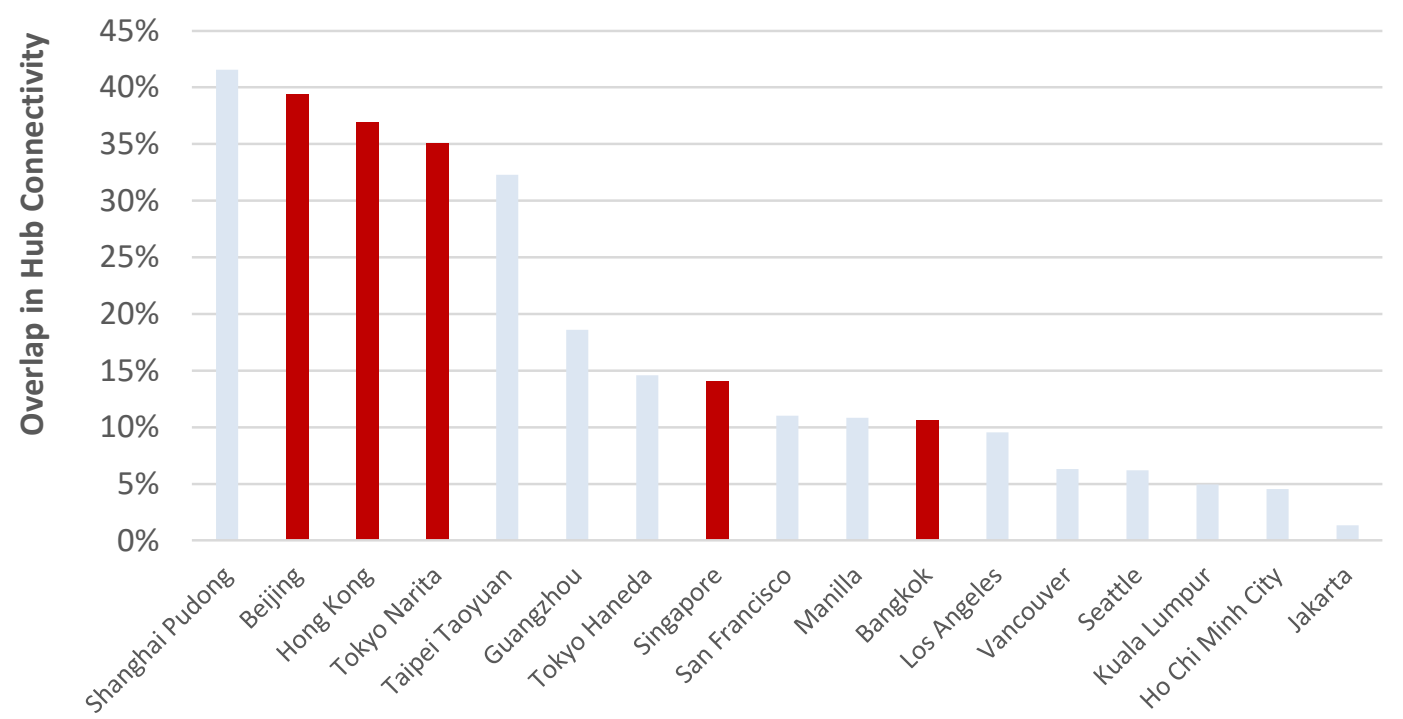

Source: SEO NetScan

Note: The five benchmark airports included in the comparative network connectivity analysis are depicted in red.

The five airports which show the largest overlap in their hub networks with Incheon are:

1. Shanghai Pudong International Airport (PVG), Shanghai, China: $42 \%$

2. Beijing Capital International Airport (PEK), Beijing, China: 39\%

3. Hong Kong International Airport (HKG), Hong Kong, China: $37 \%$

4. Narita International Airport (NRT), Tokyo, Japan: 35\%

5. Taiwan Taoyuan International Airport (TPE), Chinese Taipei: $32 \%$.

These five airports clearly stand out in terms of hub network overlap. Due to their geographical proximity, they are able to serve many of the connecting markets served by Incheon, which mainly consist of transfer markets between Asia and North America, Asia and Europe, and intra-Asia traffic. Hong Kong, although located further away than for instance Guangzhou and Tokyo Haneda, has a large intercontinental network similar to Incheon's. Guangzhou and Haneda to a larger extent serve domestic markets and therefore exhibit lower levels of overlap with Incheon's hub network.

North American hubs show significantly less overlap with Incheon's hub traffic - from $11 \%$ at San Francisco to $6 \%$ at Seattle. This can be explained by their geographical location which allows them to effectively compete with Incheon only for the Asia-North America market.

Incheon Airport chose the following five airports against which to benchmark its network connectivity performance:

1. Beijing Capital International Airport (PEK), Beijing, China

2. Hong Kong International Airport (HKG), Hong Kong, China

3. Narita International Airport (NRT), Tokyo, Japan

4. Changi Airport (SIN), Singapore

5. Suvarnabhumi Airport (BKK), Bangkok, Thailand. 
Although the share of network overlap of Bangkok is lower than for the other chosen benchmark airports, Bangkok is a relevant case to investigate against Incheon's. Just like Seoul, Bangkok operates a multiairport system. The secondary airport for Bangkok is a hub for low-cost, mainly short-haul traffic, while Seoul's Gimpo hosts a large number of (mainly) domestic flights operated by Asiana Airlines and Korean Air.

The main characteristics of Incheon against its five benchmark airports are presented in Figure 19.

Figure 19. Incheon and its main competitors at a glance

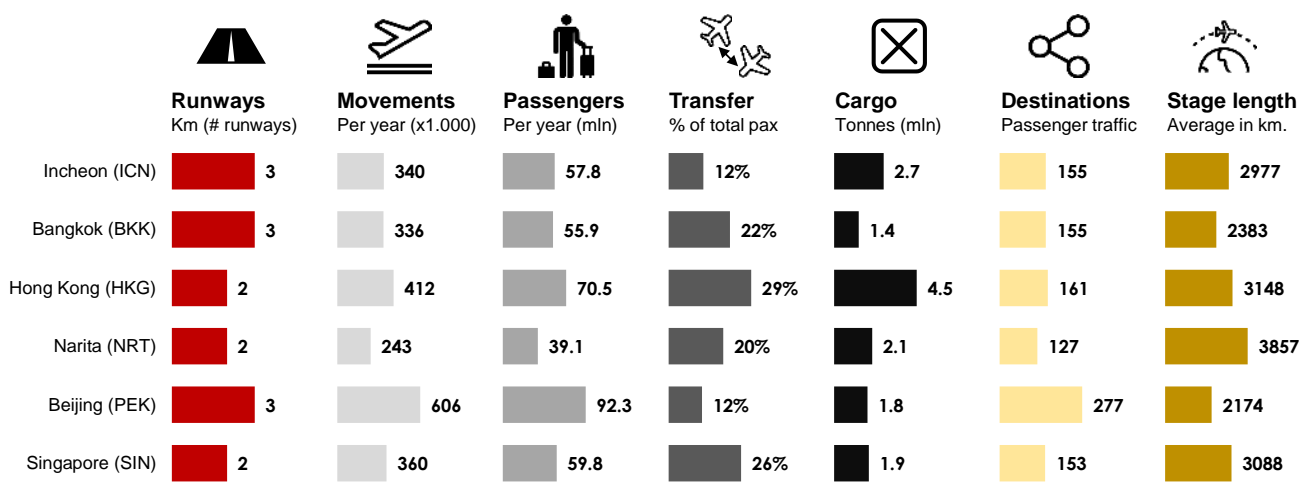

Source: SEO Analysis based on ACI, OAG airport statistics

Note: Movements, passengers, cargo and transfer statistics (2016). Average stage length and number of destinations (third week of September 2017).

\section{Direct connectivity}

Over the past 10 years, Incheon's direct connectivity has grown by around 6\% per year, outperforming its main competitors. Singapore has shown a similar but lower annual average growth rate of $5 \%$. Other airports have experienced lower average direct connectivity increases, ranging from $2.8 \%$ (Tokyo Narita) to $4.0 \%$ (Beijing). All of the surveyed airports, apart from Narita, have started from higher direct connectivity levels than Incheon, particularly the hub in Beijing (Figure 20). Incheon has rapidly increased its direct connectivity over the past decade and is now almost on par with Bangkok and Hong Kong, which it used to trail. Tokyo Narita, on the other hand, now lags behind Incheon even though both airports used to have very similar levels of direct connectivity in 2007. 
Figure 20. Level of direct connectivity from Incheon and benchmark airports $(2007,2012,2016,2017)$

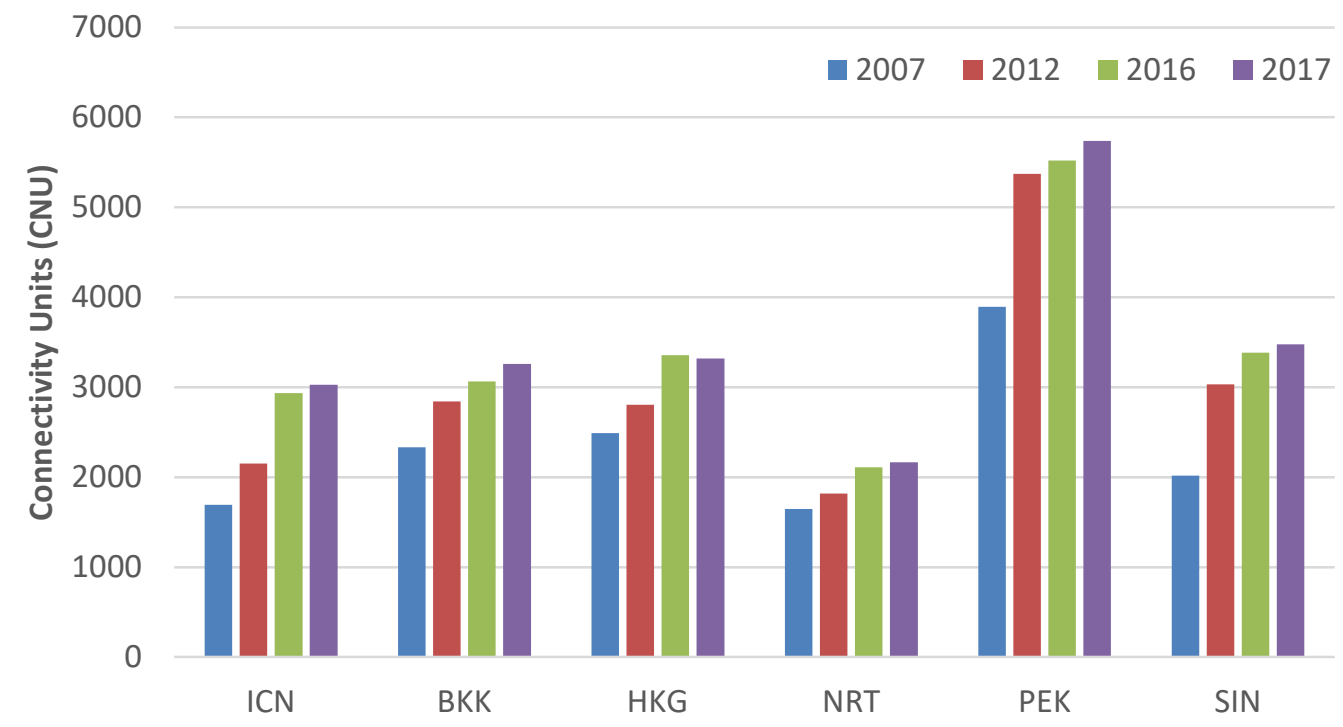

Source: SEO NetScan

The rise of direct connectivity at Incheon occurred mostly due to increased LCC operations from $1 \%$ to $29 \%$ share in total traffic over the past decade. Only Singapore has a higher LCC penetration rate than Incheon (Figure 21). Singapore has seen the share of LCC operations double over the past 10 years. This trend has mainly been driven by growth of Singapore Airlines' LCC subsidiaries Tiger and Scoot, as well as the increasing presence of LCCs such as AirAsia and Jetstar. Bangkok's LCC share has decreased due to the reopening of Don Mueang airport in 2007, which now facilitates the lion's share of LCC operations serving Bangkok (Figure 22).

Figure 21. Share of flights operated by low-cost carriers from Incheon and benchmark airports (2007, 2012, 2016, 2017)

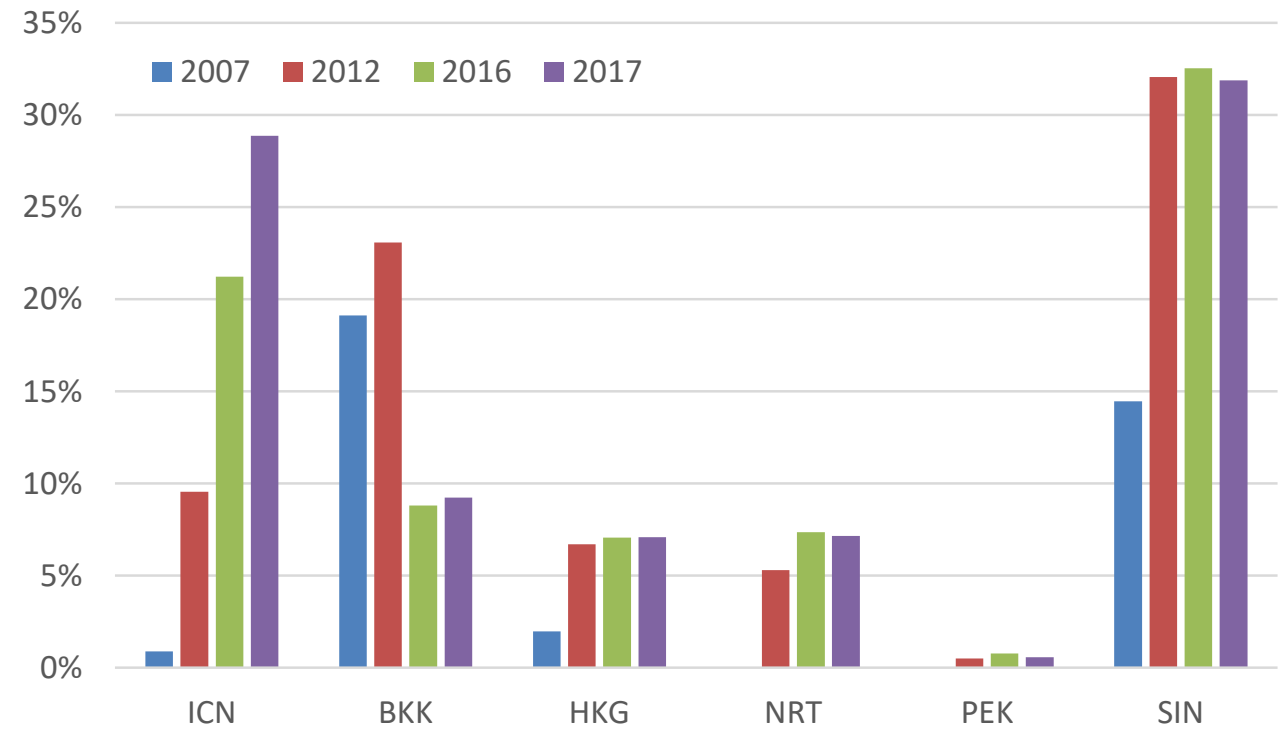

Source: SEO NetScan

Note: The list of carriers that were assigned to the low-cost category can be found in the glossary of terms. 
Figure 22 presents LCC penetration rates for the selected airports, as well as for secondary airports serving the same metropolitan areas. In Seoul, the share of LCC traffic at Incheon and Gimpo is very similar. The same is observed for the two airports serving Tokyo, and for the two Pearl River Delta airports - Hong Kong and Shenzhen. In Seoul and Tokyo, the two airports located closest to the city centres - Gimpo and Haneda - are mainly used for domestic traffic, whereas their hub counterparts - Incheon and Narita - cater mainly for international and long-haul flights. In Bangkok hub operations are concentrated at Suvarnabhumi Airport, while Don Mueang hosts most of the LCC traffic. The split of carriers at Bangkok airports is thus more "traditional" than at airports in Seoul and Tokyo, where LCCs are now serving passengers from airports which used to be exclusively used by full-service carriers.

Figure 22. Share of flights operated by low-cost carriers in selected multi-airport systems (2007, 2012, 2016, 2017)

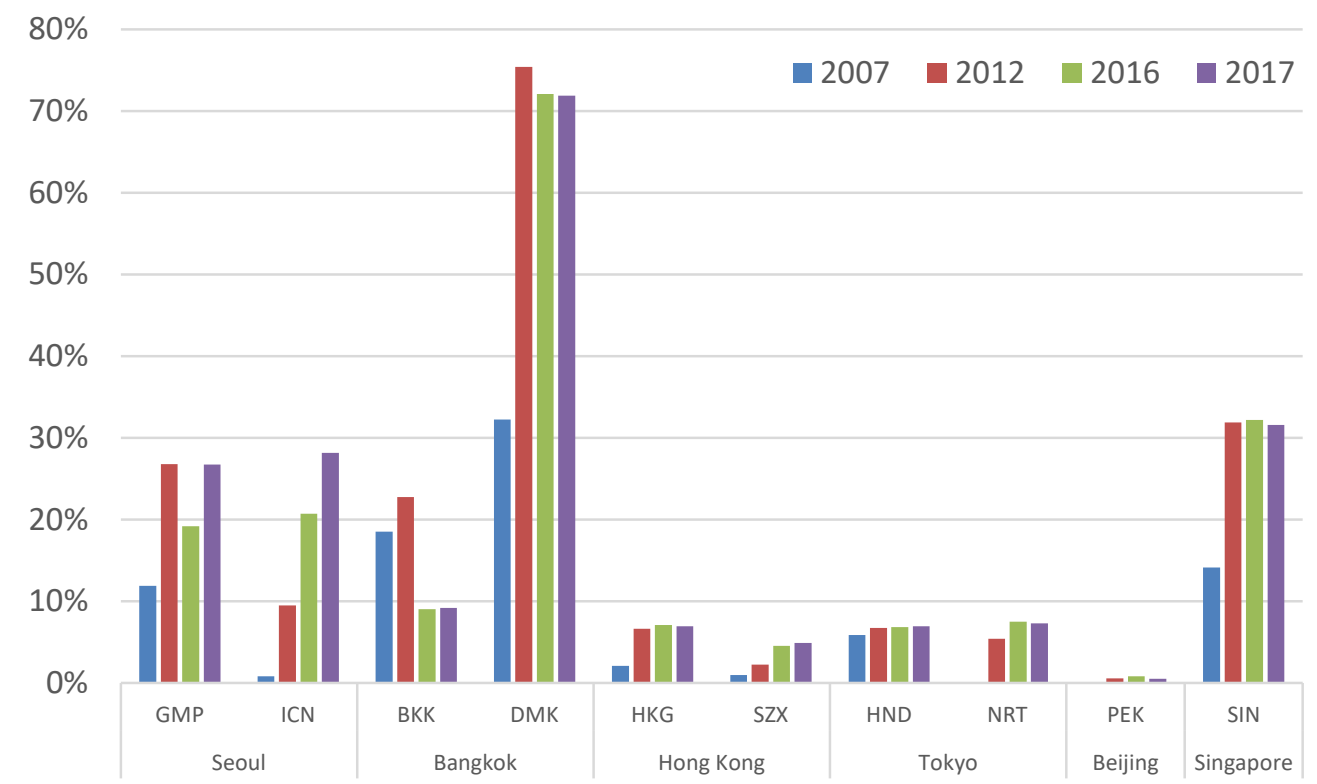

Source: SEO NetScan.

Note: The list of carriers that were assigned to the low-cost category can be found in the glossary of terms.

\section{Indirect connectivity}

Incheon's indirect connectivity is lower than that provided by the five benchmark airports (Figure 23). In 2017, Beijing had the highest indirect network connectivity score, followed by Singapore and Narita. Over the past 10 years, indirect connectivity from Beijing has grown very strongly (on average by 6\% per year), followed by Singapore (4.6\%) and Incheon (4.3\%). The average growth rate of indirect connectivity per year since 2012, however, was highest for Incheon (6\%), as was the growth rate over the past year $(8.8 \%)$.

Tokyo Narita is the only airport that now offers less indirect connectivity than a decade ago. The airport's indirect connectivity plummeted by $2.4 \%$ on average per year since 2007 . This is mainly due to some services having been moved to Haneda, located more closely to Tokyo's city centre. Haneda was previously used for domestic flights, but started operating short-haul international services in 2010 and long-haul services in 2014. As a result, some services to large hubs in Chicago, Los Angeles, Paris, Detroit, Frankfurt, and London were moved from Narita to Haneda, leading to a significant loss in indirect connectivity available from the hub airport. 
While Beijing is by far the largest airport in terms of direct connectivity, its indirect connectivity level is comparable to those of Narita and Singapore. As Beijing is one of the most important aviation hubs for China, it offers a large number of connections to domestic destinations, most of which, however, do not provide any onward connections. Airports such as Tokyo Narita and Singapore, on the other hand, are well connected to the world's largest hubs, offering significant indirect connectivity.

Figure 23. Level of indirect connectivity from Incheon and benchmark airports (2007, 2012, 2016, 2017)

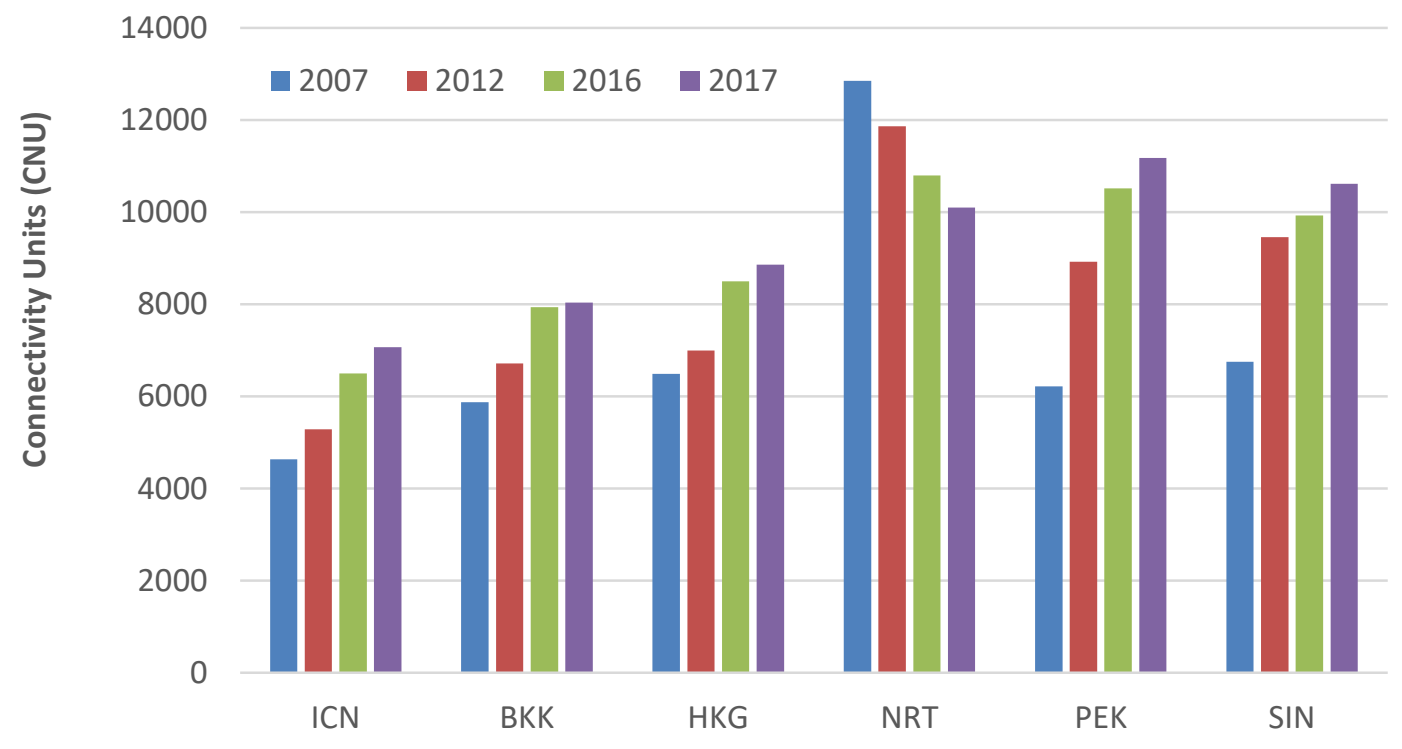

Source: SEO NetScan

In line with the results for Incheon, Figure 24 demonstrates that direct connectivity provided by all selected airports is mostly to Asia Pacific, while indirect connectivity is mainly to Europe and North America. Narita has the largest share of flights to destinations outside of Asia Pacific (26\%), followed by Incheon (18\%). The route networks of Beijing and Singapore are largely focused on Asia Pacific ( $91 \%$ in both cases). While this result for Beijing is mostly due to its large domestic network, Singapore's central location in the Asia Pacific region makes the airport an important gateway for southeast Asia and Australia. 
Figure 24. Share of direct and indirect connectivity from Incheon and benchmark airports by region

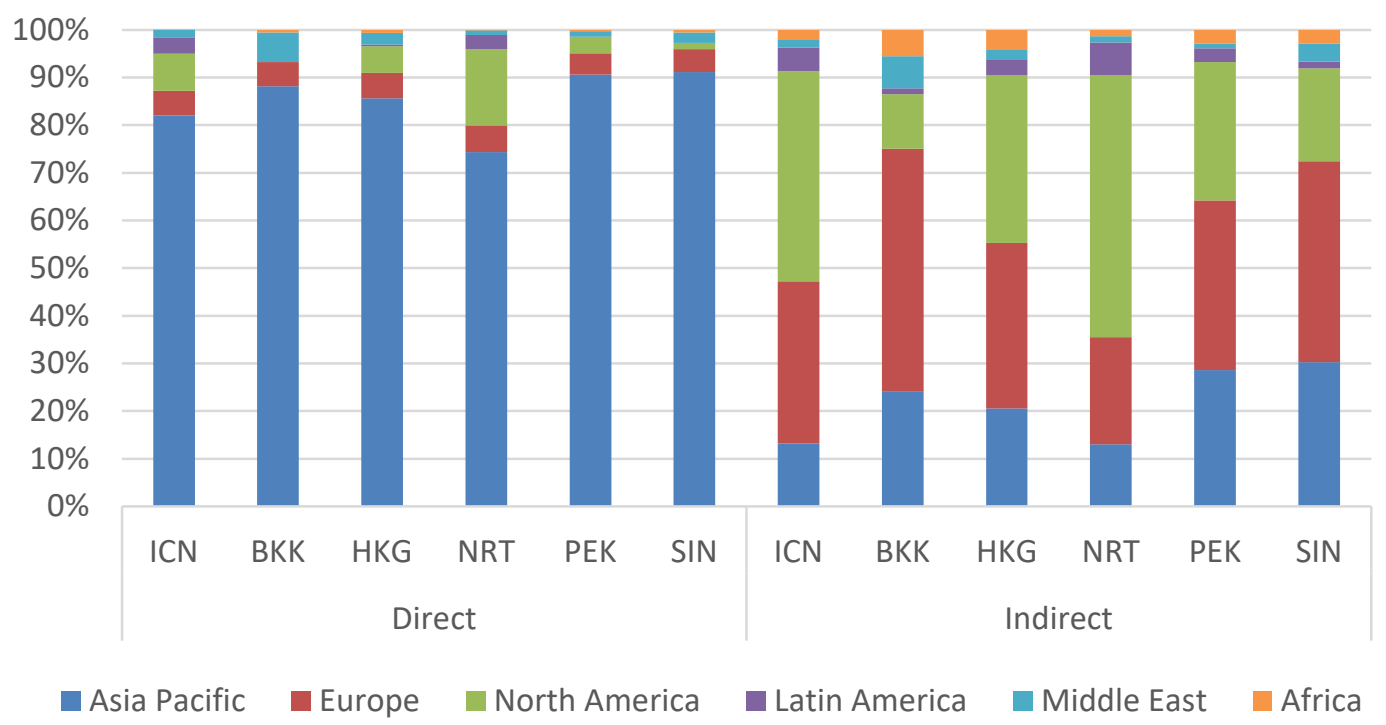

Source: SEO NetScan

\section{Hub connectivity}

Incheon's hub connectivity in terms of its strength is comparable to that of Bangkok, Tokyo Narita and Singapore (Figure 25). Hub connectivity of Beijing is substantially higher, due to its role in connecting Chinese cities to the rest of the world.

Over the past 10 years, Incheon's hub connectivity has grown substantially, in line with hub connectivity growth rates of Bangkok, Hong Kong and Beijing. Last year, Bangkok recorded a very strong growth in hub connectivity (37\%), overtaking Incheon. This extraordinary level of growth occurred mainly due to a new codeshare agreement between Thai Airways and Bangkok Airways ${ }^{8}$, which accounted for around $80 \%$ of the increase of Bangkok's hub connectivity.

Figure 25. Level of hub connectivity from Incheon and benchmark airports $(2007,2012,2016,2017)$

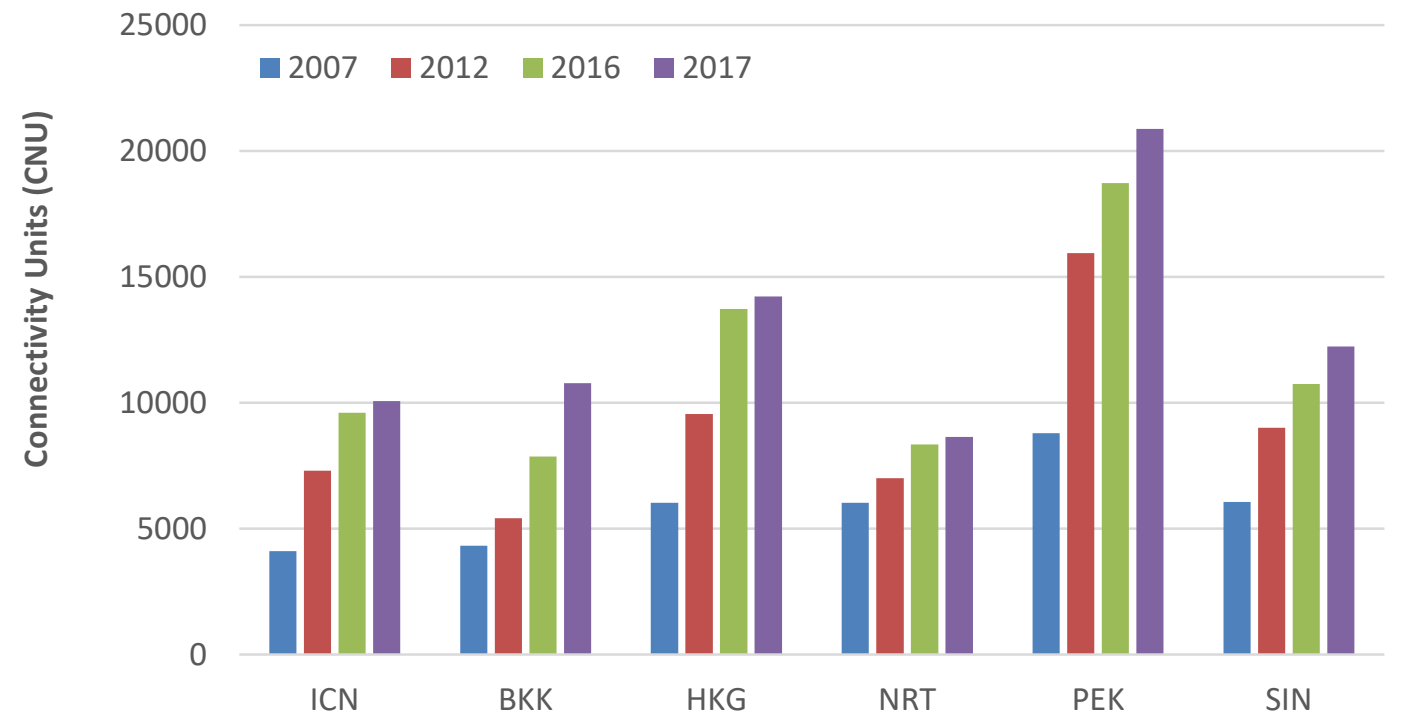

Source: SEO NetScan 
Figure 26 breaks down the share of hub connections into long-haul to long-haul (LH-LH), short-haul to long-haul (SH-LH; and vice versa), and short-haul to short-haul (SH-SH) market segments. Tokyo Narita has the largest share of long-haul to long-haul connections (26\%). Incheon has a relatively high share of long-haul to long-haul connections (16\%), while at Hong Kong, Beijing, and Bangkok this share is lower than $10 \%$. On the other hand, the share of hub connections consisting of two short-haul flights is relatively high for these airports (19\%-20\%). Incheon provides a relatively small share of short-haul to short-haul connections ( $8 \%$ of its hub connectivity), due to Seoul's domestic network being mostly served from Gimpo (Figure 27).

Figure 26. Share of hub connections by stage length combination from Incheon and benchmark airports (2017)

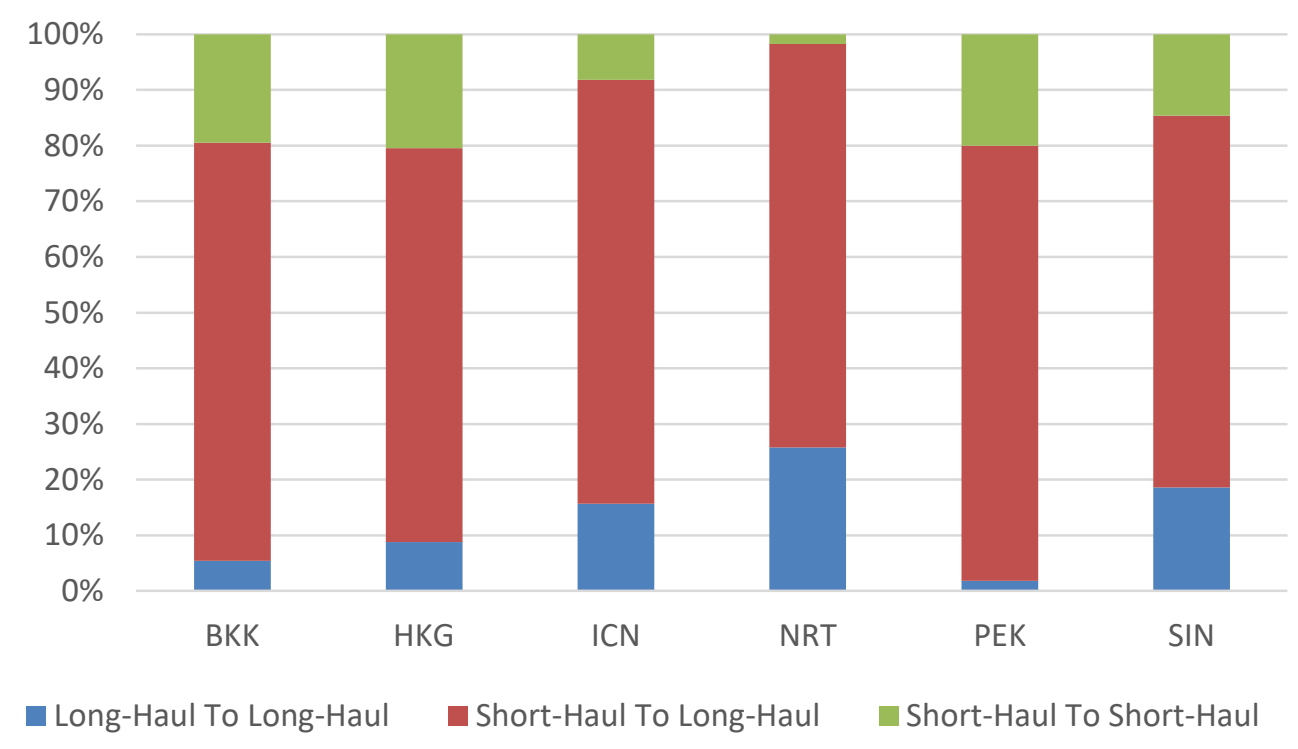

Source: SEO NetScan

Note: A long-haul (short-haul) flight is a flight with a stage length over (below or equal to) $3450 \mathrm{~km}$.

The relatively high share of long-haul to long-haul connections can be explained by the fact that hub carriers serving Seoul (Korean Air and Asiana Airlines) and Tokyo (All Nippon Airways and Japan Airlines) operate in a multi-airport system (see Figure 27). Korean Air and Asiana Airlines operate their short-haul flights from both Gimpo (678 weekly) and Incheon (869 weekly), while all long-haul flights are operated from Incheon. In Tokyo, All Nippon Airways and Japan Airlines operate the lion's share of their short-haul flights from Haneda. The long-haul networks are also distributed over the two airports, with Narita hosting $65 \%$ of the hub carriers' long-haul flights. 
Figure 27. Level of direct connectivity at airports in Seoul and Tokyo by stage length

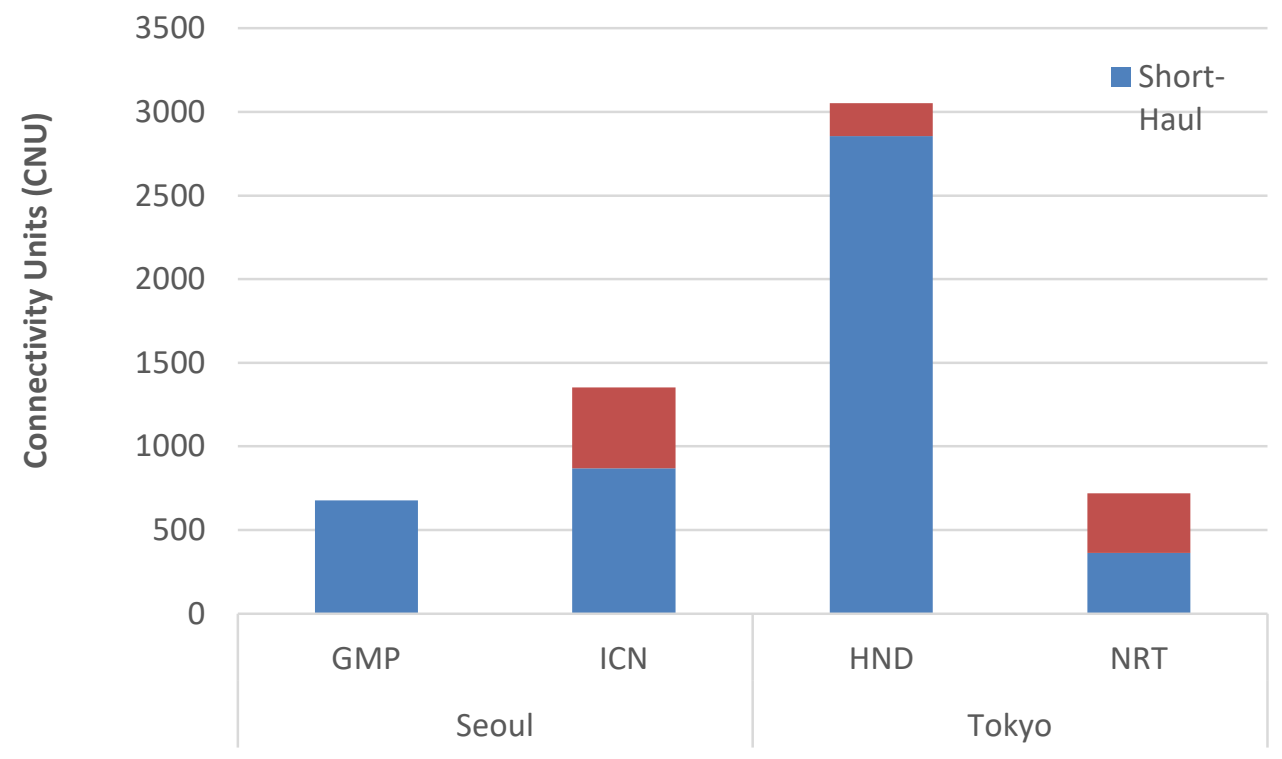

Source: SEO NetScan

Note: The main hub carriers for Seoul are Korean Air and Asiana Airlines, and All Nippon Airways and Japan Airlines for Tokyo airports. A long-haul (short-haul) flight is a flight with a stage length over (below or equal to) $3450 \mathrm{~km}$.

Figure 28 presents developments in the share of Incheon's hub connections that are also served via the respective benchmark airports. As seen in the overlap analysis, the networks of Beijing, Hong Kong and Tokyo Narita have the largest overlap with Incheon's hub network. Unlike for other analysed airports, the hub network overlap with Beijing has increased over the past decade. This increase can be explained by an increase in operations of Korean Air and Asiana Airlines to China (2\% per year since 2017), as well as due to the substantial hub connectivity growth at Beijing of hub markets also served via Incheon.

Figure 28. Degree of network overlap of benchmark airports with Incheon's hub connectivity (2007, 2012, 2016, 2017)

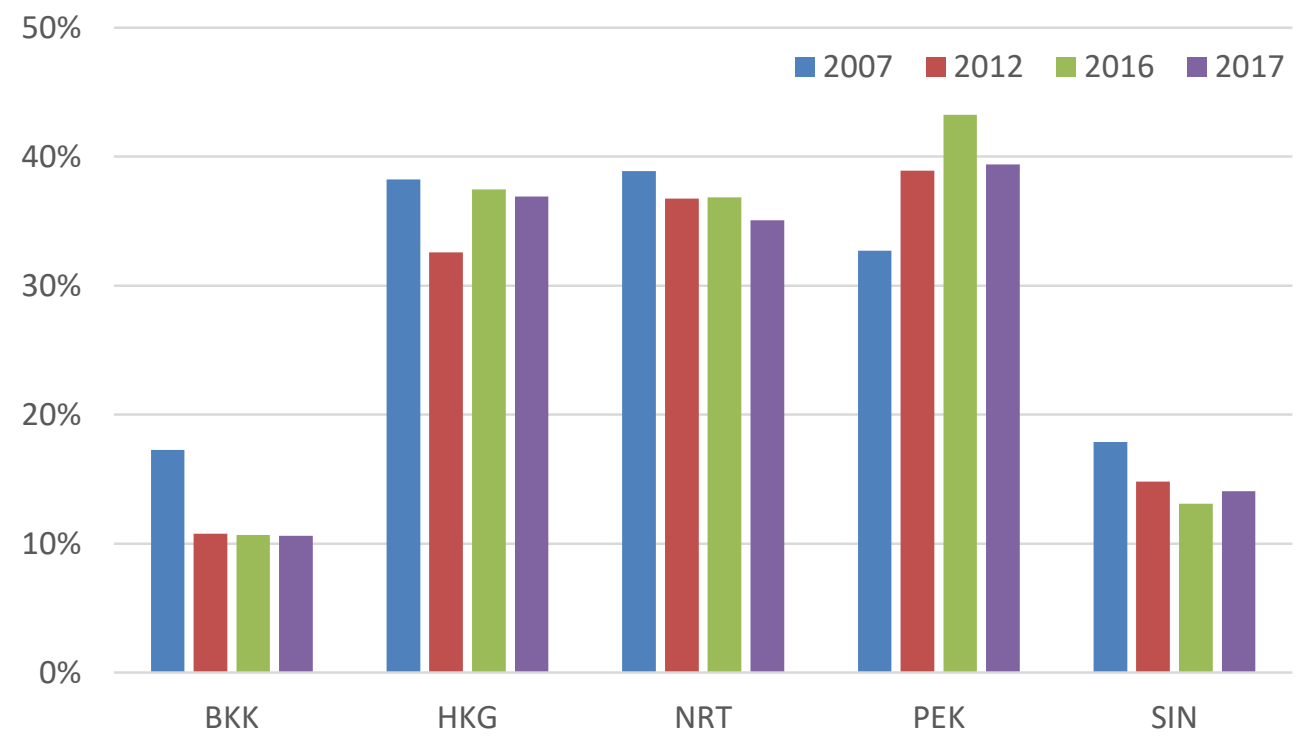

Source: SEO NetScan 


\section{Network connectivity of Schiphol Airport: An overview}

Direct connectivity at Schiphol (AMS) has increased by over $2 \%$ per year on average over the past decade, despite the adverse impact of aviation from the global financial crisis. While network carriers were rationalising their route networks in the aftermath of the financial crisis, low-cost carriers at Schiphol were on the rise. Direct connectivity recovered to pre-crisis levels in 2012. Over the past year, the growth in direct connectivity accelerated to $4.5 \%$ due to a combination of global and airport-specific factors. The global economic recovery and low oil price contributed to the growth of direct connectivity. This was reinforced by decreased airport charges and strong growth of low-cost carriers at the airport. These developments injected more competition into Schiphol. Competition at the airport was further increased by airlines' anticipation of possible capacity shortages from 2018, due to the policy cap at the airport.

Schiphol currently offers more direct connectivity than any other European hub (Figure 29). In terms of Schiphol's benchmark airports, the hub in Istanbul (IST) has experienced an extremely strong growth in direct connectivity since 2007, despite a terrorist attack and political instability in the country. Direct connectivity levels have been relatively stable at both Heathrow (LHR), mostly due to capacity constraints, and Paris Charles the Gaulle (CDG), the only benchmark airport that has not yet recovered its direct connectivity to the pre-crisis levels.

Figure 29. Level of direct connectivity from Schiphol and benchmark airports $(2007,2012,2016,2017)$

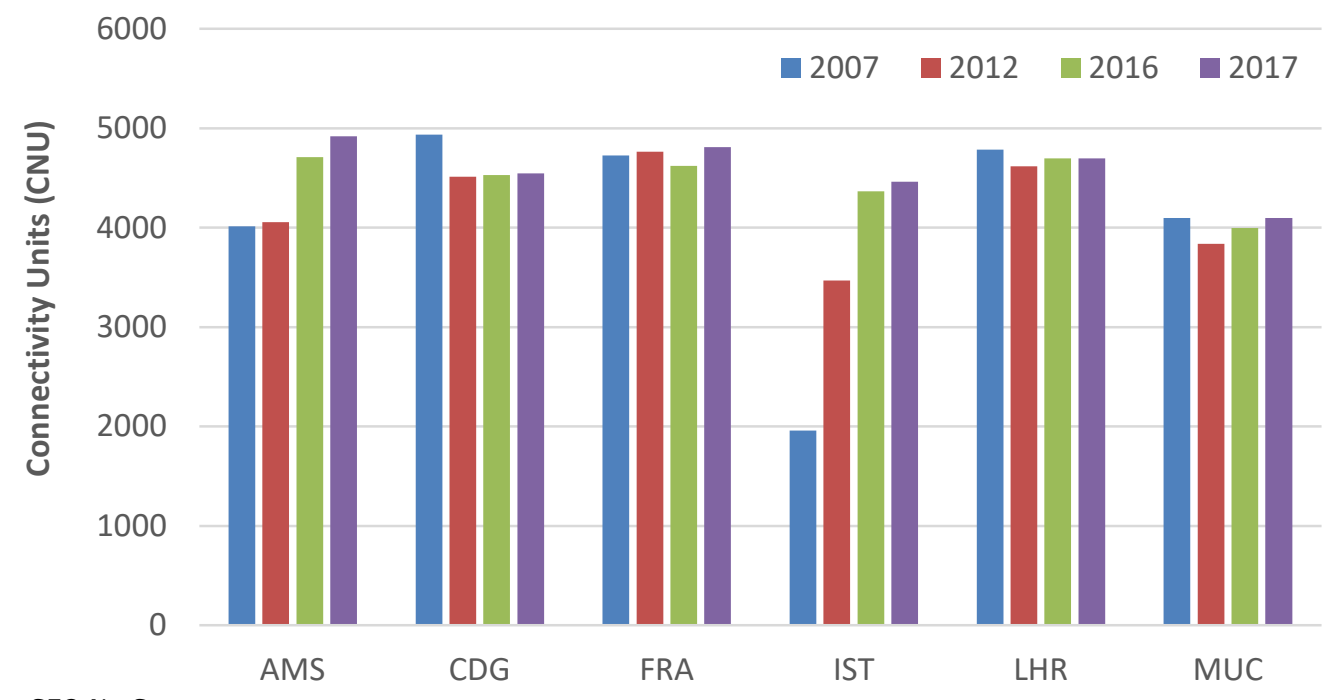

Source: SEO NetScan

With $20 \%$ of direct connections offered by low-cost carriers, Schiphol has a relatively large presence of LCCs compared to the benchmark airports. London Heathrow and Istanbul Atatürk, on the other hand, have very limited low-cost operations. Amsterdam, Paris, Frankfurt and London are also served by secondary airports focusing predominantly on low-cost traffic.

Indirect connectivity at Schiphol decreased during the financial crisis due to route network rationalisation by network carriers to then recover after the crisis, in line with the global aviation markets. Apart from the revival of connectivity to major hubs in Europe and the USA (in particular, Frankfurt, Minneapolis, Moscow Sheremetyevo and Salt Lake City), the hub in Amsterdam benefitted from increased operations of Gulf carriers (particularly Emirates and Etihad) that connect passengers from Amsterdam onto their hubs in the Middle East. Increased presence of Gulf carriers, as well as Turkish Airlines and Chinese carriers, significantly contributed to Schiphol's expansion into the Asia Pacific market. The biggest market segments though are still Europe and North America. 
The hub in Atlanta currently serves more connections from Schiphol than any other airport. Other important onward hubs for passengers from Amsterdam are in Frankfurt and London. Schiphol's indirect connectivity levels are, however, still lower than those of the other large European hubs. This is mostly because other European hubs are better connected to large onward hubs.

Schiphol's hub connectivity has been experiencing a rapid annual average growth of $5 \%$ since 2007 , leaving other European hubs behind in terms of growth. Frankfurt, however, still has the strongest hub connectivity in Europe. Schiphol's impressive growth in hub connectivity can be attributed to the continued expansion of KLM and its partners, and a very effective wave-system at the airport. Despite the strong growth of hub connectivity levels, Schiphol's transfer share decreased from $41 \%$ in 2007 to $38 \%$ in 2017 . This reflects the stronger growth of low-cost carriers compared to the hub carrier and its partners. It also demonstrates that transfer share of total traffic alone is not a meaningful indicator of hub connectivity performance.

Over the past decade, each additional direct connection at Schiphol has led to a very substantial average increase of $27.2 \mathrm{CNU}$ in terms of hub connectivity (Figure 30). Other European hubs have also experienced very strong increases of their hub connectivity relative to their direct connectivity levels. At the German hubs in Frankfurt and Munich (MUC), the relatively dominant position of Lufthansa and other Star Alliance partners has enabled the hub carrier and its partners to grow their hub operations. At Paris Charles de Gaulle and London Heathrow, hub carriers and their partners grew their hub operations through improving the efficiency of their hub operations, possibly at the expense of other carriers serving these airports. This is reflected in sharp rise in their hub connectivity and a simultaneous decrease in direct connectivity.

Figure 30. Relationship between direct and hub connectivity at Schiphol and benchmark airports $(2007,2012,2016,2017)$

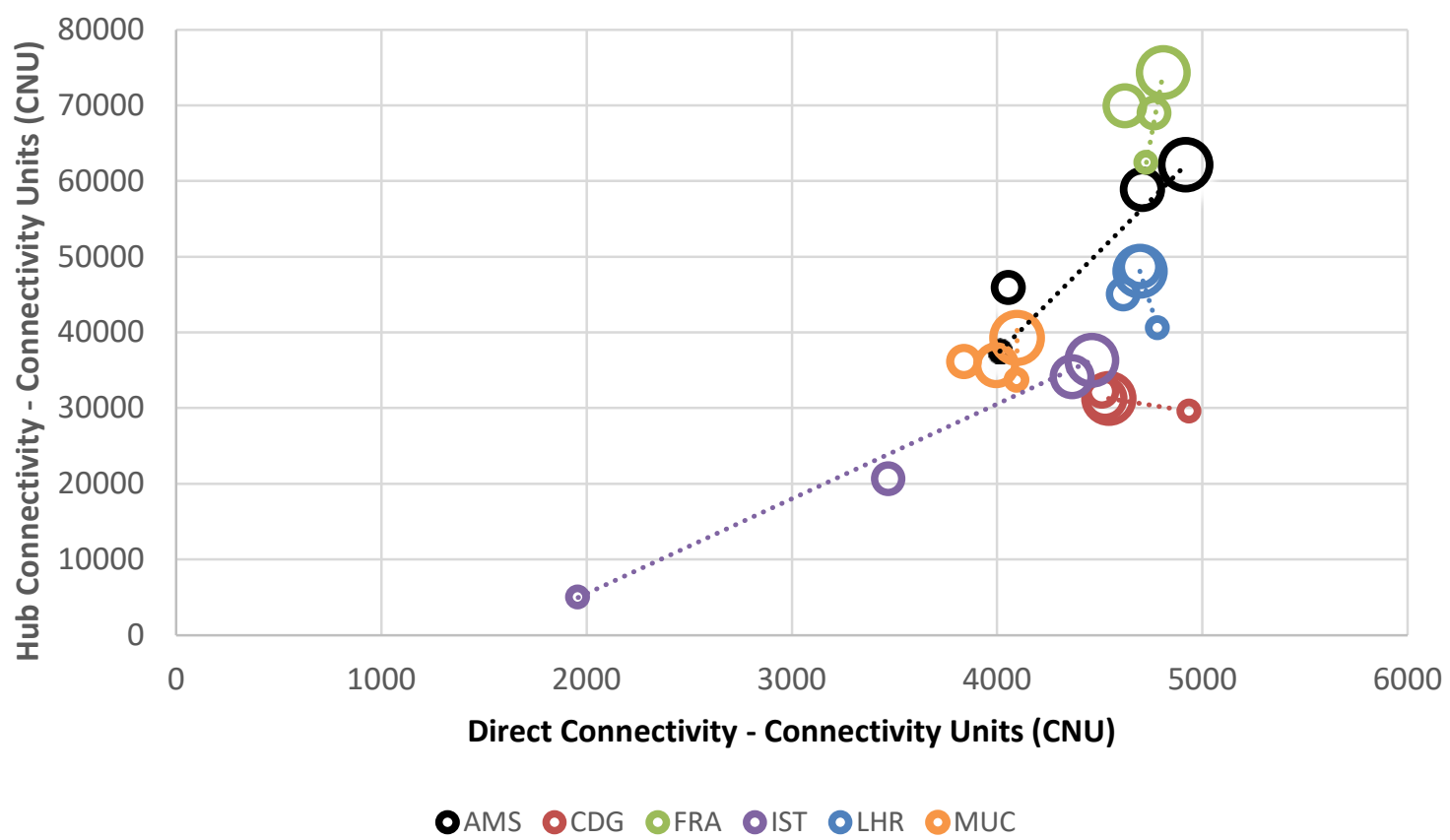

Source: SEO NetScan

Note: The figure depicts the relationship between direct and hub connectivity for a selection of airports in the years 2007, 2012, 2016, and 2017. The largest circle indicates data for the most recent year (2017) and the smallest circle indicates the most dated point in time (2007). For each airport, the dotted line connects the most dated and the most recent points in time - the steeper the gradient, the stronger the relationship between direct and hub connectivity has been in the period 2007-2017. 
Schiphol's high-quality airport facilities, the efficiency of transfers at the airport, as well as its central location as a hub for Europe are assets that make the airport well-placed to retain its position in the European market in the future. Schiphol is currently subject to an environmentally motivated policy cap of 500000 air traffic movements (ATMs). The cap will stay in place until 2020, and it is still uncertain whether the constraint on ATMs will be relaxed after that time. In order to accommodate the forecasted future demand until 2020 (which is expected to exceed the 500000 ATM cap), according to the Alders Agreement, Lelystad and Eindhoven airports are to take over a sizeable portion of flights from Schiphol, which are mostly leisure destinations to resorts in the Mediterranean, hence accommodating the excess demand at Schiphol and allowing Schiphol's operations to focus on network flights. The SWOT-analysis for Schiphol is summarised in Table 3.

Table 3. SWOT analysis for Schiphol

\begin{tabular}{|c|c|}
\hline Strengths & Weaknesses \\
\hline $\begin{array}{l}\text { - Premium airport facilities contribute to the airport's } \\
\text { attractiveness as a transfer point. } \\
\text { Diverse network of destinations offered at high } \\
\text { frequencies by KLM and its partners allows for many } \\
\text { connection possibilities, hence making the airport } \\
\text { attractive to passengers. } \\
\text { - Strong growth of LCCs has significantly increased } \\
\text { direct connectivity at the airport as well as } \\
\text { competition between carriers, hence possibly } \\
\text { reducing fare levels and making the airport } \\
\text { attractive to passengers. } \\
\text { Schiphol's location makes it well-placed to serve } \\
\text { many important aviation markets. } \\
\text { Relatively low airport charges, compared to } \\
\text { competing airports, make Schiphol attractive to } \\
\text { airlines. } \\
\text { Schiphol benefits from a strong OD market and a big } \\
\text { catchment area. }\end{array}$ & $\begin{array}{l}\text { - A policy cap on the number of ATMs limits any } \\
\text { potential network expansion. } \\
\text { Restrictions on night operations reduce scheduling } \\
\text { flexibility at the airport. } \\
\text { - The airport, although it benefits from a strong OD } \\
\text { market and a big catchment area, is more reliant on } \\
\text { transfer traffic than other European hubs, making it } \\
\text { dependent on the success of its transfer market. }\end{array}$ \\
\hline Opportunities & Threats \\
\hline $\begin{array}{l}\text { - Attractiveness of Amsterdam as a tourism and } \\
\text { business destination, and a growing importance of } \\
\text { the already economically strong Amsterdam } \\
\text { Metropolitan Area will further increase the strength } \\
\text { of Schiphol's OD market. } \\
\text { - Advancement of aviation liberalisation with non-EU } \\
\text { countries provides opportunities for carriers at } \\
\text { - Schiphol to enter new markets. } \\
\text { Additional airport capacity at regional airports, may } \\
\text { free up capacity at Schiphol, enabling its hub carrier } \\
\text { to expand hub connectivity. } \\
\text { - Positive outlook on demand for air travel in Europe. } \\
\text { Relaxation of the ATM cap beyond 2020, if it } \\
\text { becomes a reality, will create opportunities for } \\
\text { carriers to expand at the airport. } \\
\text { Increasing share of LCCs at Incheon may enhance } \\
\text { competition at the airport and provide new } \\
\text { opportunities for passengers to arrange their own } \\
\text { connections (self-connecting), hence improving the } \\
\text { overall connectivity levels. }\end{array}$ & $\begin{array}{l}\text { - Schiphol is located in a densely populated area } \\
\text { where well-organised local communities are calling } \\
\text { for retaining of the ATM policy cap beyond its } 2020 \\
\text { expiry date. } \\
\text { - Air France-KLM may decide to concentrate growth at } \\
\text { Paris Charles de Gaulle, hence weakening the hub at } \\
\text { Schiphol. } \\
\text { The negative impact of Brexit on Schiphol's hub } \\
\text { operations might be significant, given a large } \\
\text { number of connections with the UK. } \\
\text { Expansion of the currently constrained hub at } \\
\text { Heathrow may reduce Schiphol's market share for } \\
\text { services between the UK and the rest of the world. } \\
\text { Low-cost carrier development may adversely affect } \\
\text { KLM's feeder traffic, hence weakening hub } \\
\text { operations. } \\
\text { Aviation liberalisation may lead to increased } \\
\text { competition in existing markets, hence jeopardising } \\
\text { hub connectivity provided at Incheon. } \\
\text { Climate change considerations may result in more } \\
\text { stringent restrictions on cO2 emissions, increasing } \\
\text { costs for airlines and hence reducing demand for } \\
\text { aviation and overall connectivity. } \\
\text { Government may introduce tax on air tickets as of } \\
\text { 2021, making air travel more expensive, hence } \\
\text { reducing demand for aviation. }\end{array}$ \\
\hline
\end{tabular}




$\begin{array}{ll}\bullet \begin{array}{l}\text { European hubs are challenged by the global } \\ \text { economy's centre of gravity gradual move to the } \\ \text { east. }\end{array} & \begin{array}{l} \\ \hline\end{array}\end{array}$

Source: SEO Amsterdam Economics, Royal Schiphol Group (2018)

\section{Schiphol: direct, indirect, and hub connectivity outcomes}

\section{Direct connectivity}

Over the past decade, direct connectivity at Schiphol has increased by an average rate of just above $2 \%$ per year (Figure 31). The growth rate of direct connectivity has been accelerating and reached $4.5 \%$ between 2016 and 2017. The growth rate, however, is expected to stall due to a policy cap imposed on the airport of 500000 air transport movements per year. This cap will most likely remain in place until 2020. Therefore, it is expected that the level of direct connectivity will remain stable after 2017.

Figure 31. Level of direct connectivity from Schiphol $(2007,2012,2016,2017)$

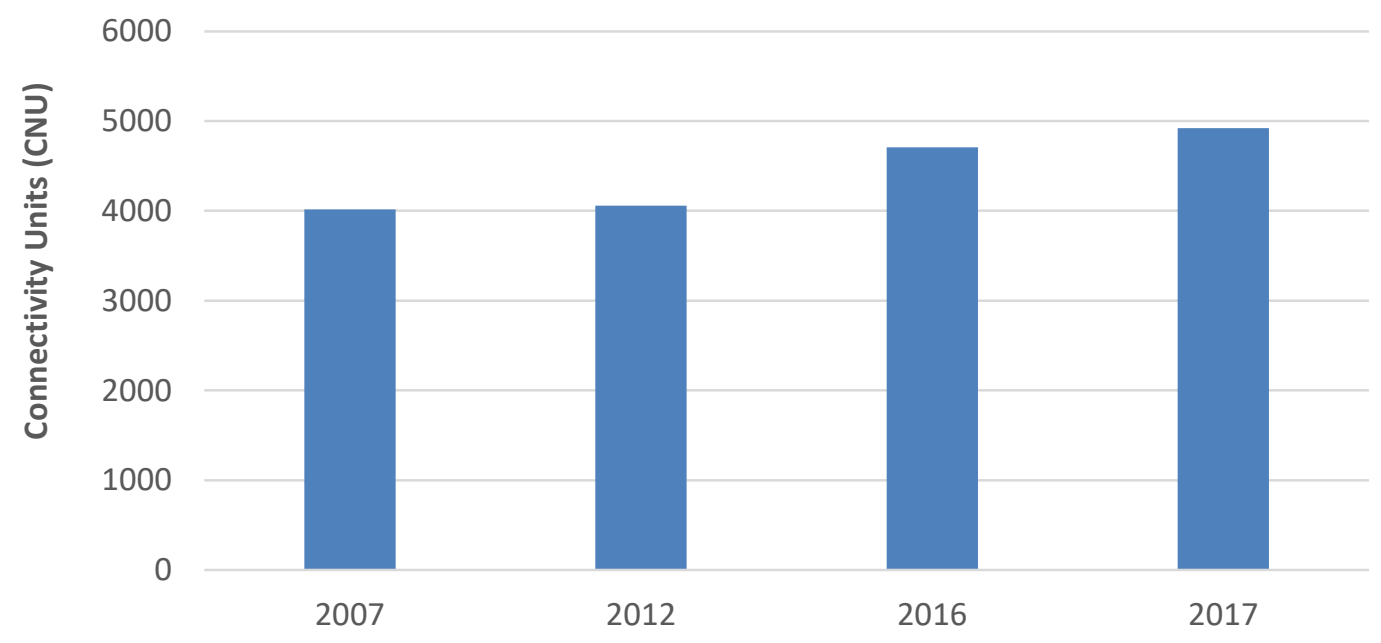

Source: SEO NetScan

The share of direct connectivity provided by LCCs at Schiphol increased from $15 \%$ in 2007 to $20 \%$ in 2017 (Figure 32). LCCs have increased their market share by an average $8.7 \%$ per year since 2012 , while direct connectivity provided by KLM and its SkyTeam partners has increased by a relatively modest annual rate of $2.6 \%$. Over the same time period, full-service carriers that are not part of the SkyTeam or Star Alliance (indicated as "Other FSCs" in Figure 32) reduced their services from Schiphol by $22 \%$. This was mostly due to the impact of the global financial crisis: to cope with declining passenger numbers, legacy carriers were forced to rationalise their networks. This market segment at Schiphol has still not recovered to its pre-crisis connectivity levels. 
Figure 32. Share of direct connectivity from Schiphol by alliance membership $(2007,2012,2016,2017)$

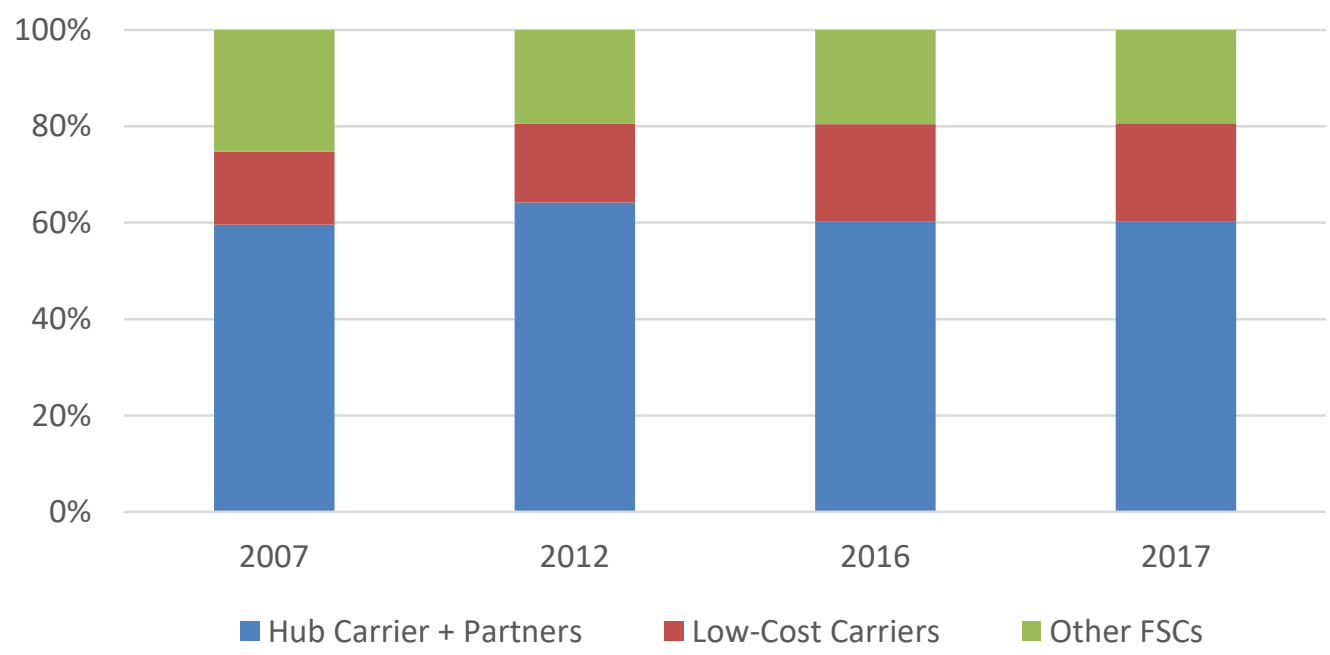

Source: SEO NetScan

Note: The list of carriers that were assigned to the low-cost category can be found in the glossary of terms. Other FSCs category comprises those full-service (not low-cost) carriers that have not joined any of the three airline alliances.

\section{Indirect connectivity}

The global financial crisis also affected Schiphol's indirect connectivity as many European and US network carriers were forced to curb their operations. The stark decline of indirect connectivity from 2007 to 2012 of $13 \%$ over five years (Figure 33 ) - was mainly caused by fewer onward connections offered from hubs in the USA. Schiphol was particularly affected by Delta's rationalisation of its route network. After 2012, the revival of US and other hubs, as well as the rise of Middle Eastern carriers, contributed to significant indirect connectivity increases, by an average rate of 5.4\% per year until 2017. Emirates and Etihad substantially contributed to this growth, generating an average annual growth rate of $17.5 \%$ between 2012 and 2017. 
Figure 33. Level of indirect connectivity from Schiphol by alliance membership (2007, 2012, 2016, 2017)

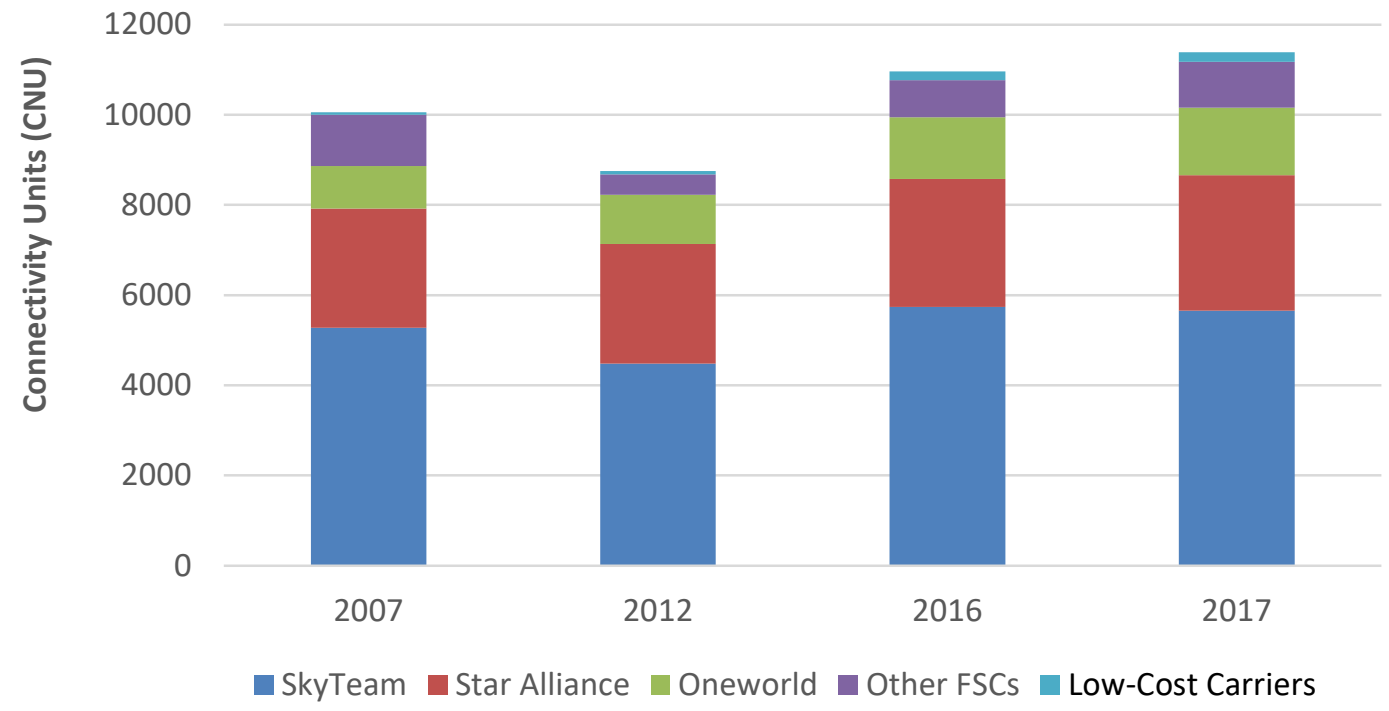

Source: SEO NetScan

Note: The list of carriers that were assigned to the low-cost category can be found in the glossary of terms. Other FSCs category comprises those full-service (not low-cost) carriers that have not joined any of the three airline alliances.

\section{Onward connections from Schiphol}

Hub airports in Europe and the USA provide the vast majority of Schiphol's indirect connectivity (Figure 34). Schiphol provides numerous indirect connections to US cities through the SkyTeam hubs in Atlanta, Detroit and Minneapolis. Prior to the merger of Continental Airlines and United Airlines in 2012, Houston was also an important onward hub for Schiphol. After the merger, the hub in Houston stopped providing onward connections for KLM and other members of the SkyTeam alliance. The three biggest European hubs in London, Paris, and Frankfurt are also of great importance to Schiphol's indirect connectivity levels. There are numerous connections provided by network carriers between Schiphol and their bases in Frankfurt, London and Paris.

Istanbul and Dubai have gained importance as onward hubs for Schiphol over the past decade, hence improving their standing as the most important onward hubs from $18^{\text {th }}$ and $25^{\text {th }}$ to $9^{\text {th }}$ and $12^{\text {th }}$ place in the ranking (Figure 35). Beijing's importance as an onward hub has also risen significantly. Currently it is the $8^{\text {th }}$ most important onward hub and Schiphol's biggest gateway to China. 
Figure 34. Top 10 onward hubs for connections from Schiphol (2017)

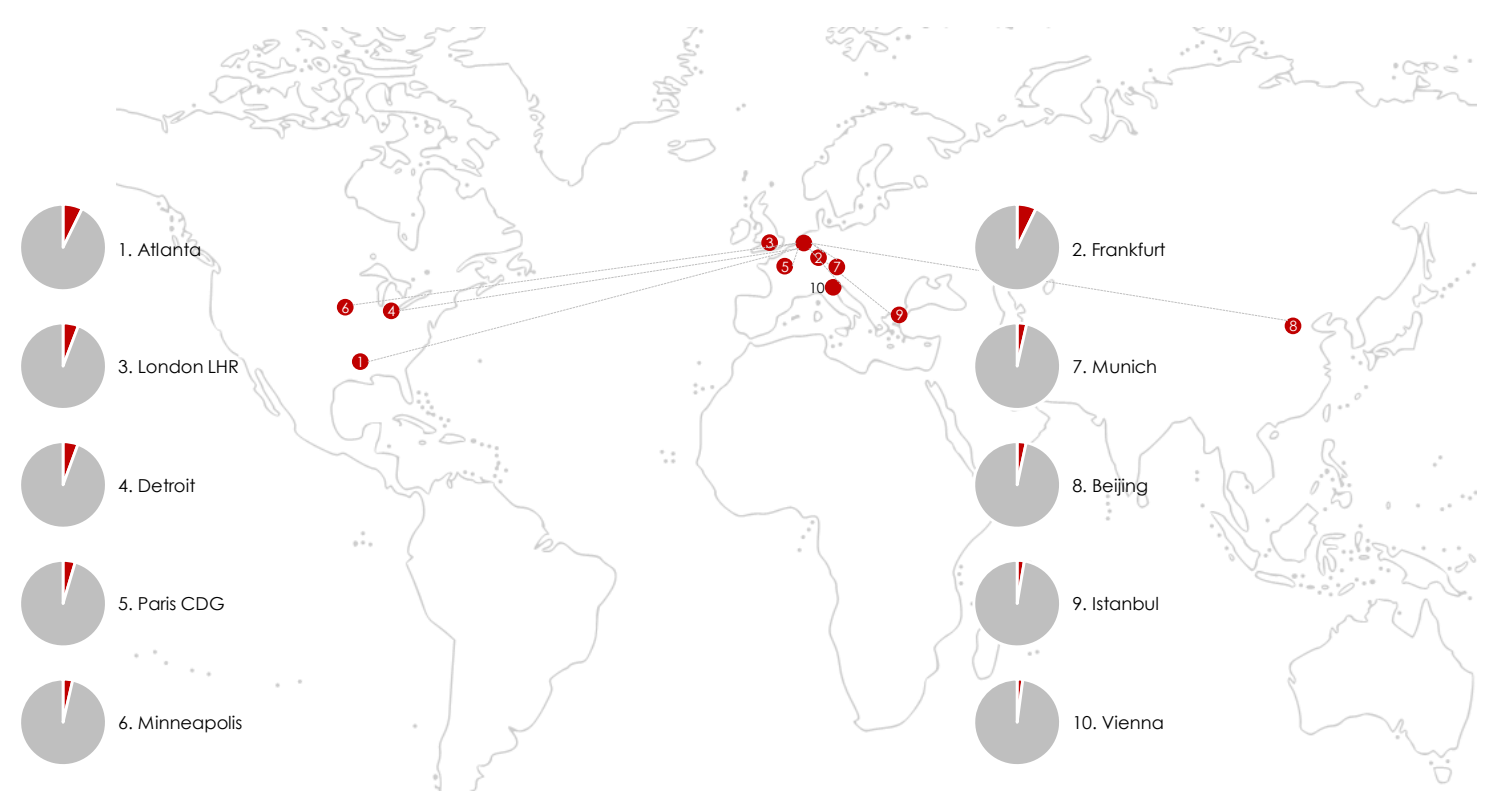

Source: SEO NetScan

Note: The red slice of each pie chart indicates the share of Schiphol's indirect connectivity facilitated by a given hub.

Figure 35. Level of Schiphol's indirect connectivity by onward hubs providing the connection (2007, 2012, 2016, 2017)

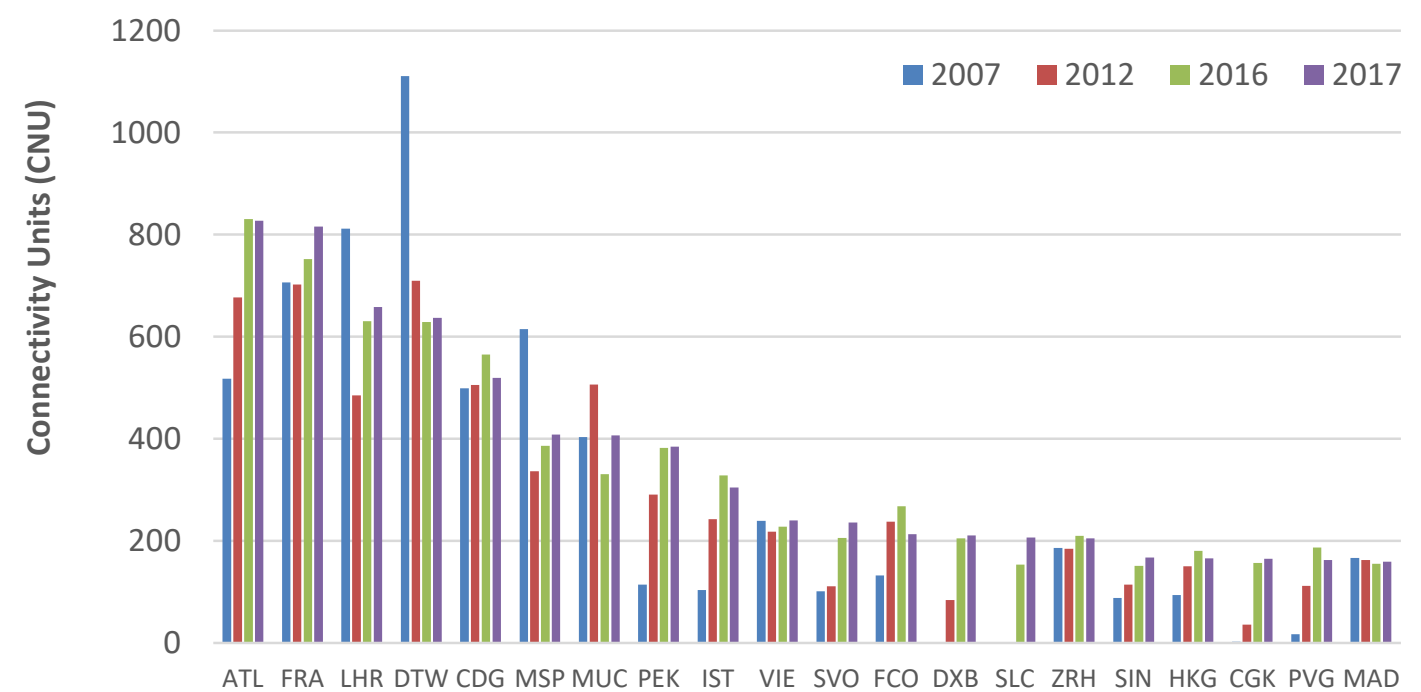

Source: SEO NetScan 


\section{Direct and indirect connectivity by region}

Schiphol's route network is strongly focused on Europe: $83 \%$ of all flights available from the airport are to European destinations. North America is Schiphol's second most important region, accounting for $6 \%$ of direct flights, while Asia Pacific accounts for $4 \%$ of Schiphol's direct connectivity. These market shares have been relatively stable over the past decade.

Indirect connectivity is mostly provided to North America (39\%), Asia Pacific (27\%) and Europe (17\%) (Figure 36). Over the past 10 years, indirect connectivity to North America has declined by an average rate of $2.1 \%$ per year, mainly due to the restructuring of US hub carriers. Indirect connectivity to Asia Pacific, on the other hand, showed the strongest rate of growth (7.4\%), which can be attributed to the rise of Gulf carriers and Turkish Airlines, as well as a substantial growth of flights operated by Asian (mainly Chinese) carriers.

Figure 36. Level of direct and indirect connectivity from Schiphol by region $(2007,2012,2016,2017)$

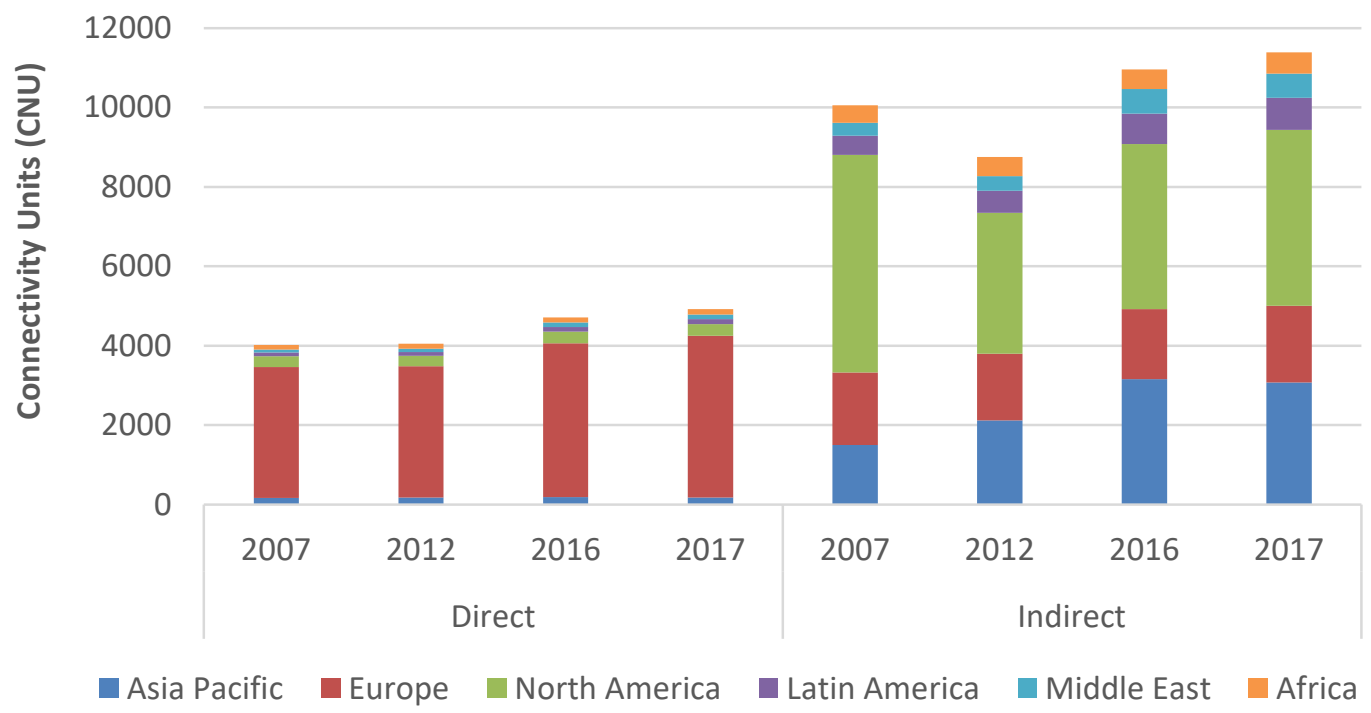

Source: SEO NetScan

Hub connectivity

Schiphol's hub connectivity has increased by an average annual rate of $5.2 \%$ over the past 10 years (Figure 37). The continuous expansion of operations of KLM and SkyTeam partners at Schiphol, in combination with an efficient wave system at the airport, has contributed to this significant increase in hub connectivity. 
Figure 37. Level of hub connectivity from Schiphol $(2007,2012,2016,2017)$

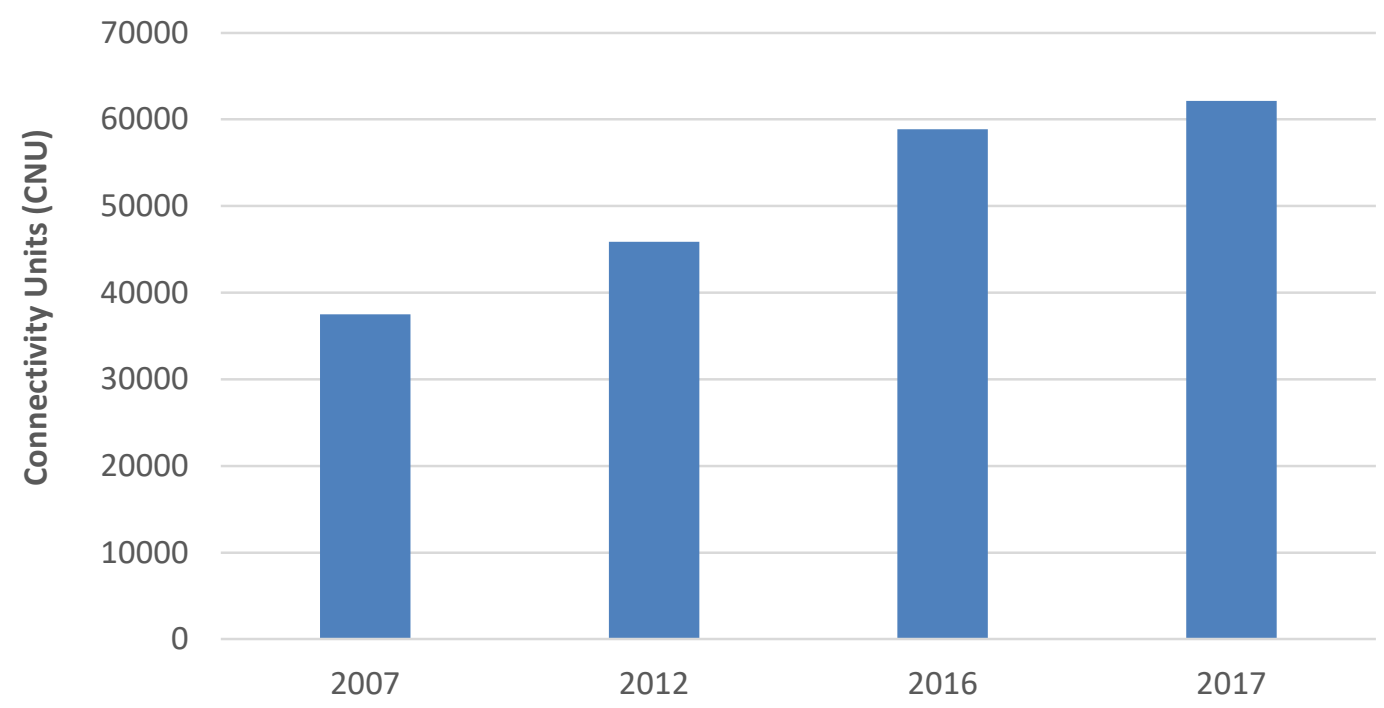

Source: SEO NetScan

While hub connectivity has been on the rise, the share of transfer passengers at Schiphol slightly decreased over the past decade, from $41 \%$ in 2007 to $38 \%$ in 2016 (Figure 38). The fall of transfer share in total traffic has mainly been caused by a strong growth of point-to-point connections provided by low-cost carriers.

There is a question of whether the growth of point-to-point traffic can indeed facilitate a significant increase in self-hubbing potential at airports with extensive route networks, where there are many opportunities for passengers to facilitate their own connections. With an increasing volume of low-cost operations, this is an area of research worth pursuing (although beyond the scope of this report). On the one hand, there are some indications that airports like Schiphol may have a significant self-hubbing potential. ${ }^{9}$ On the other hand, self-hubbing may never become a significant portion of the market for air travel, due to its complexity and inconvenience to passengers, particularly due to the lack of insurance provision to passengers for an eventuality that they miss their connection ${ }^{10}$ and of facilities to handle passenger luggage without the need for passengers to check it in again at their transfer airport. 
Figure 38. Share of transfer passengers in total traffic at Schiphol (2007-2016)

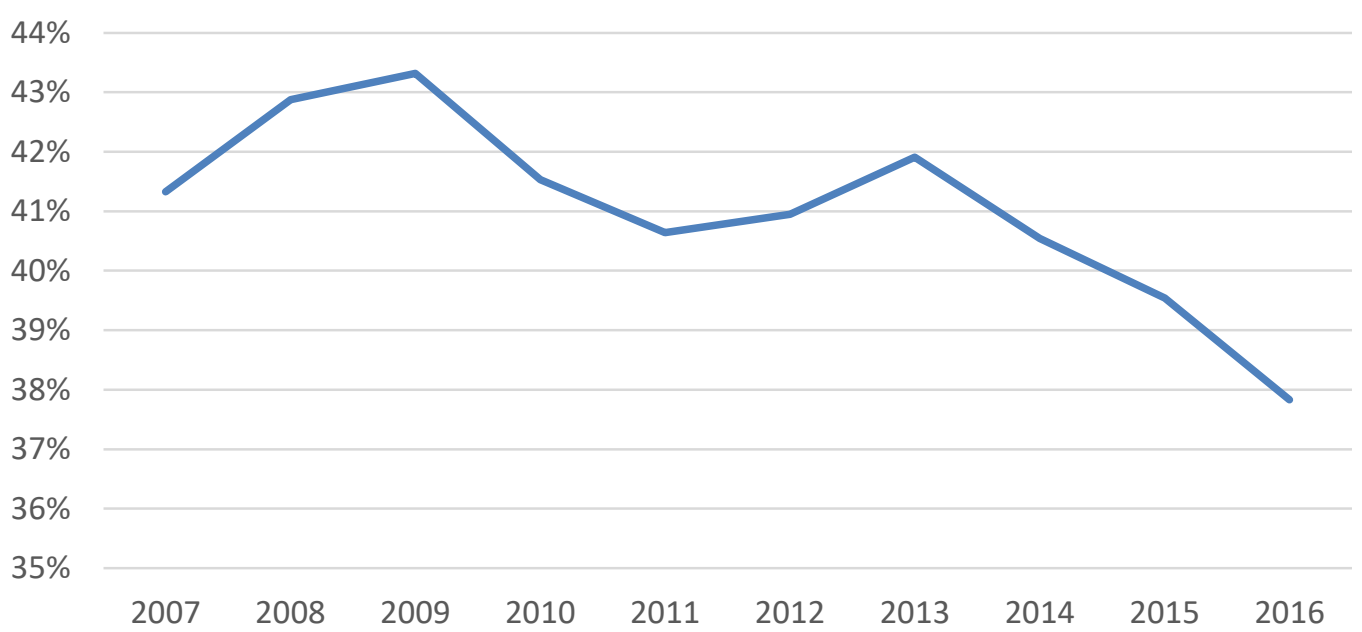

Source: Schiphol Airport Statistics

Schiphol operates as a hub for Europe (Figure 39): 95\% of Schiphol's hub connections link other European airports and to other destinations. 30\% of Schiphol's connections are between Europe and North America, $19 \%$ between Europe and Asia Pacific, while intra-European connections account for $22 \%$ of Schiphol's hub connectivity.

Figure 39. Hub connectivity from Schiphol by region (2017)

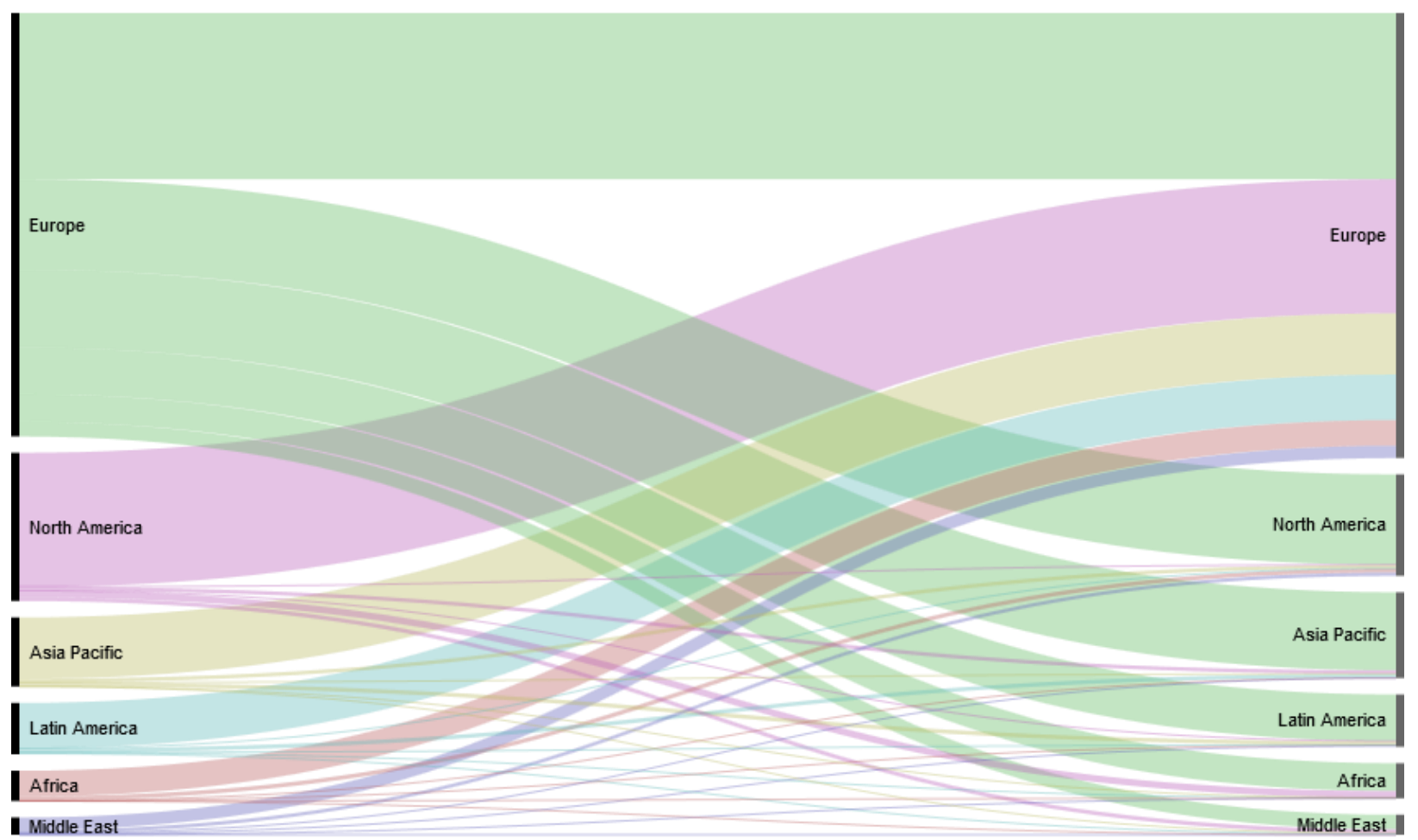

Source: SEO NetScan 


\section{Network connectivity provided from Schiphol against five benchmark airports}

Network connectivity metrics can serve as useful means of comparing route networks of different airports. The analysis below compares Schiphol against five benchmark airports: Frankfurt, Paris Charles de Gaulle, London Heathrow, Munich, and Istanbul. The selection of benchmark airports was based on (a) an analysis of the extent to which the hub network of the analysed airport is contested by other hubs and (b) internal discussions held with the airport operator.

The analysis of the extent to which Schiphol's hub network is contested by other large hub airports included the following steps. The first step was to identify all connecting markets served by network carriers at Schiphol. The second step was to estimate the level of hub connectivity offered in each of these markets. The third step was to determine which connecting markets served via Schiphol are contested by other large hub airports in the region. The final step included estimating Schiphol's hub connectivity share contested by other hub airports. This share demonstrates the extent to which other hub networks overlap with Schiphol's hub network (Figure 40).

Figure 40. Degree of Schiphol's hub network overlap with hub networks of other airports in the region

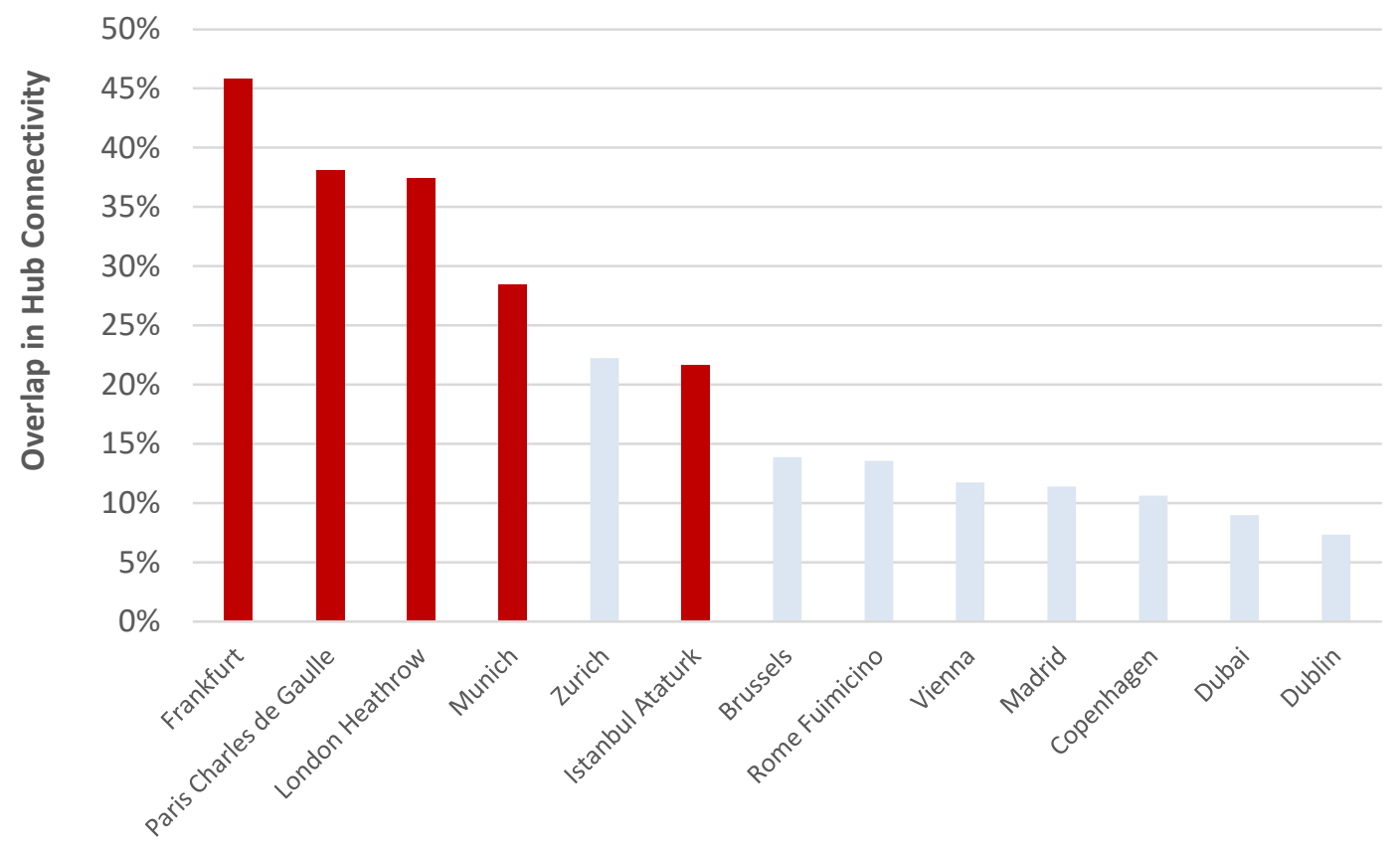

Source: SEO NetScan

Note: The five benchmark airports included in the comparative network connectivity analysis are depicted in red.

The five airports which show the largest overlap in their hub networks with Schiphol are:

1. Frankfurt International Airport (FRA), Frankfurt, Germany: 46\%

2. Paris Charles de Gaulle Airport (CDG), Paris, France: $38 \%$

3. Heathrow Airport (LHR), London, United Kingdom: 37\%

4. Munich International Airport (MUC), Munich, Germany: $28 \%$

5. Zurich International Airport (ZRH), Zurich, Switzerland: $22 \%$. 
Frankfurt International, Paris Charles de Gaulle and London Heathrow are, together with Schiphol, the largest European hub airports. Due to their size and proximity to Schiphol their hub networks significantly overlap with Schiphol's hub network.

While hubs in Munich, Zurich also show similar levels of hub network overlap with Schiphol, the Istanbul Atatürk Airport, unlike Zurich, has grown considerably over the past decade. ${ }^{11}$ Over time Istanbul is expected to be a more important competitor in the connecting markets served via Schiphol than Zurich. Istanbul is also a better fit for benchmarking than Dubai, another Middle Eastern mega-hub. This is because the hub in Dubai shows considerably less overlap with Schiphol's hub network than the hub in Istanbul; it only contests $9 \%$ of Schiphol's hub connectivity. Just like the North American hubs are less able to compete with Incheon due to their geographical distance from Incheon, Dubai is less conveniently positioned to compete in the connecting markets offered via Schiphol. Competition from Dubai is limited to the connecting markets between Europe and Asia, Europe and the Middle East, and between Europe and Africa.

Schiphol Airport therefore chose the following five benchmark airports to be included in the analysis:

1. Frankfurt International Airport (FRA), Frankfurt, Germany

2. Paris Charles de Gaulle Airport (CDG), Paris, France

3. Heathrow Airport (LHR), London, United Kingdom

4. Munich International Airport (MUC), Munich, Germany

5. Istanbul Atatürk Airport (IST), Istanbul, Turkey.

The choice reflects the extent of hub network overlap of these airports with Schiphol, with Istanbul being the only exception. The main characteristics of Schiphol against the five benchmark airports are presented in Figure 41.

Figure 41. Schiphol and its main competitors at a glance

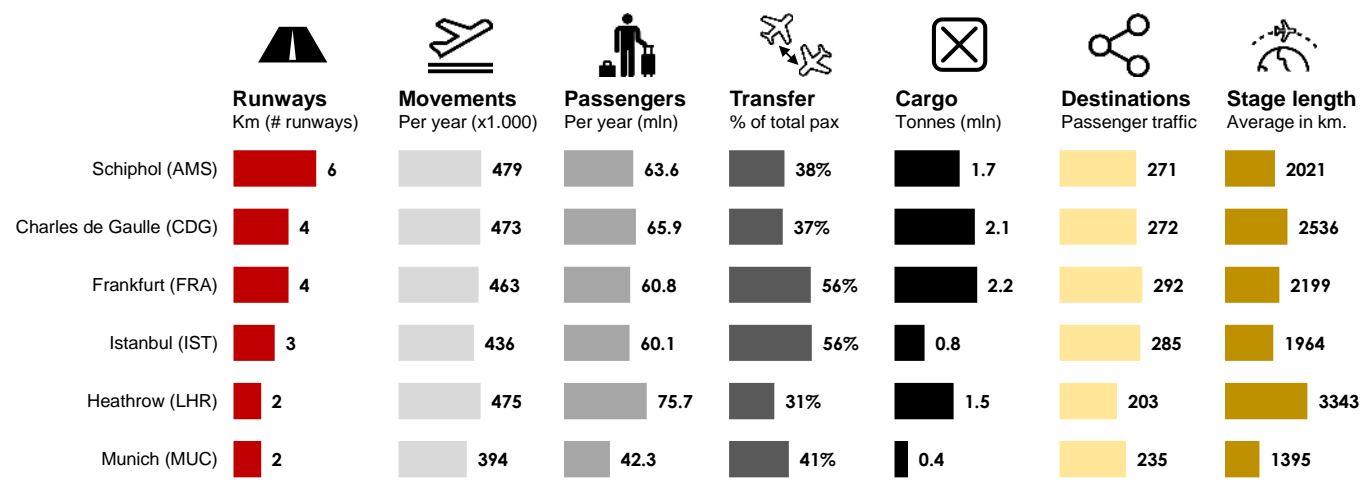

Source: SEO analysis based on ACI, OAG airport statistics

Note: Movements, passengers, cargo and transfer statistics (2016). Average stage length and number of destinations (third week of September 2017).

\section{Direct connectivity}

Schiphol offers the largest number of direct weekly flights of all European airports, followed by Frankfurt and London Heathrow (Figure 42). From 2016 to 2017, Schiphol experienced the strongest growth in direct connectivity $(4.5 \%)$, followed by Frankfurt (4.1\%). Istanbul, on the other hand, failed to keep up with its impressive average long-term growth rate of $8.6 \%$ over the past decade, mainly due to recent political and economic instability in Turkey. Direct connectivity levels between 2016 and 2017 increased only by $2.2 \%$. Direct connectivity levels between 2016 and 2017 increased only by $2.2 \%$. 
London Heathrow's direct connectivity has been relatively stable over the past decade, mainly due to capacity constraints that limit the number of new flights that can be added to the network. Frankfurt International and Paris Charles de Gaulle also have not increased their connectivity levels since 2007, which is related to both capacity issues and limited growth of their respective hubs operated by Lufthansa and Air France.

Figure 42. Level of direct connectivity from Schiphol and benchmark airports $(2007,2012,2016,2017)$

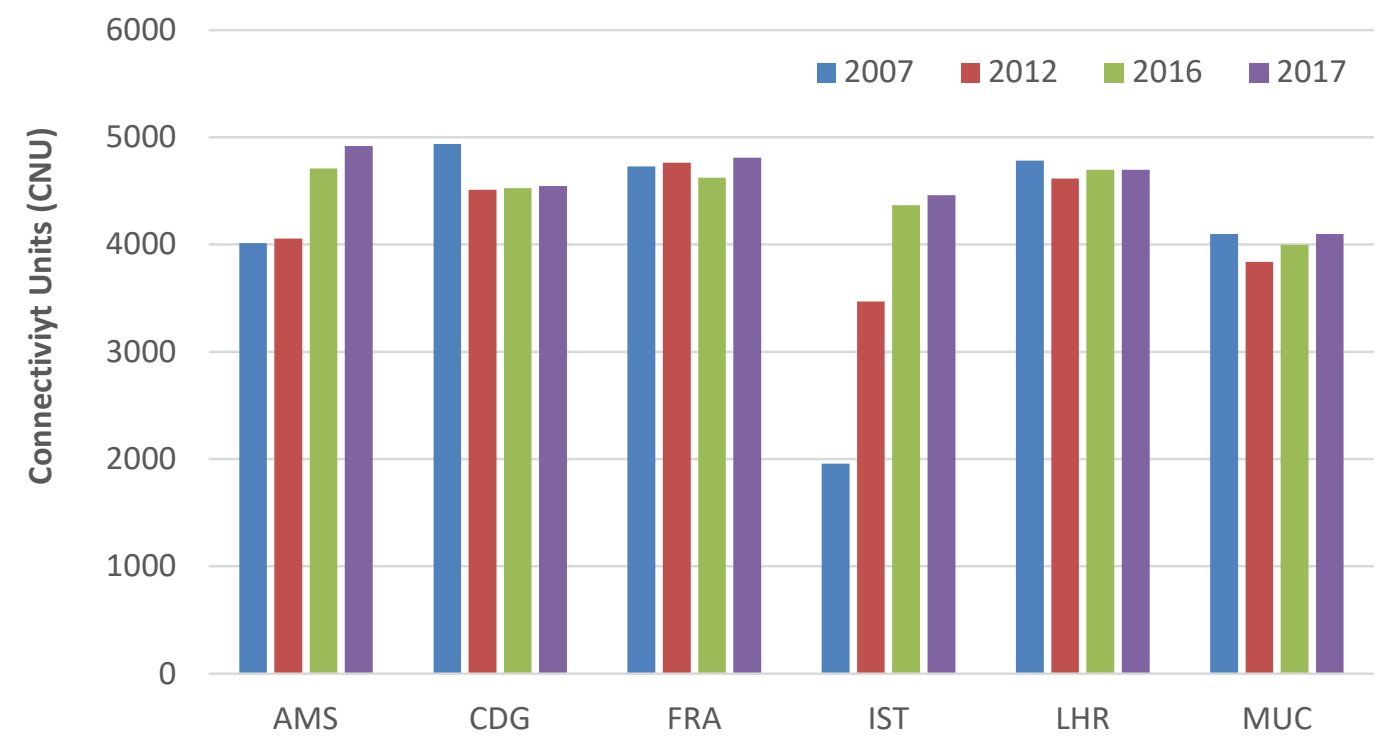

Source: SEO NetScan

Compared to its peers, Schiphol has a much higher share of LCC operations (Figure 43), with EasyJet being the airport's second largest carrier. While Paris Charles de Gaulle has a relatively high LCC penetration rate, it is much lower than that of Schiphol. London Heathrow and Istanbul both have very low shares of LCC activity. Due to capacity constraints as well as cost and operational considerations, LCCs operate mainly from secondary airports in these cities (Figure 44). Frankfurt International has seen its LCC share increase rapidly this year, as Ryanair opened its base at the airport. 
Figure 43. Share of flights operated by low-cost carriers from Schiphol and benchmark airports (2007, 2012, 2016, 2017)

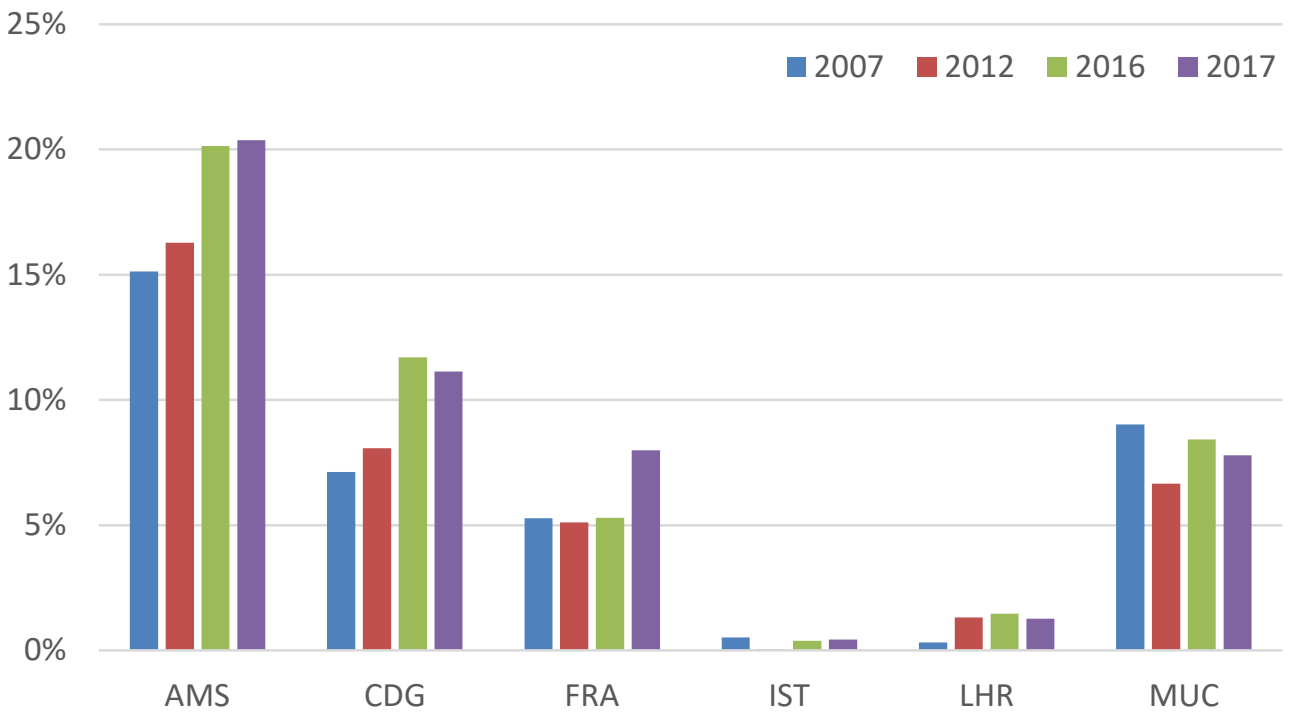

Source: SEO NetScan

Note: The list of carriers that were assigned to the low-cost category can be found in the glossary of terms.

Figure 44. Share of flights operated by low-cost carriers in selected multi-airport systems (2007, 2012, 2016, 2017)

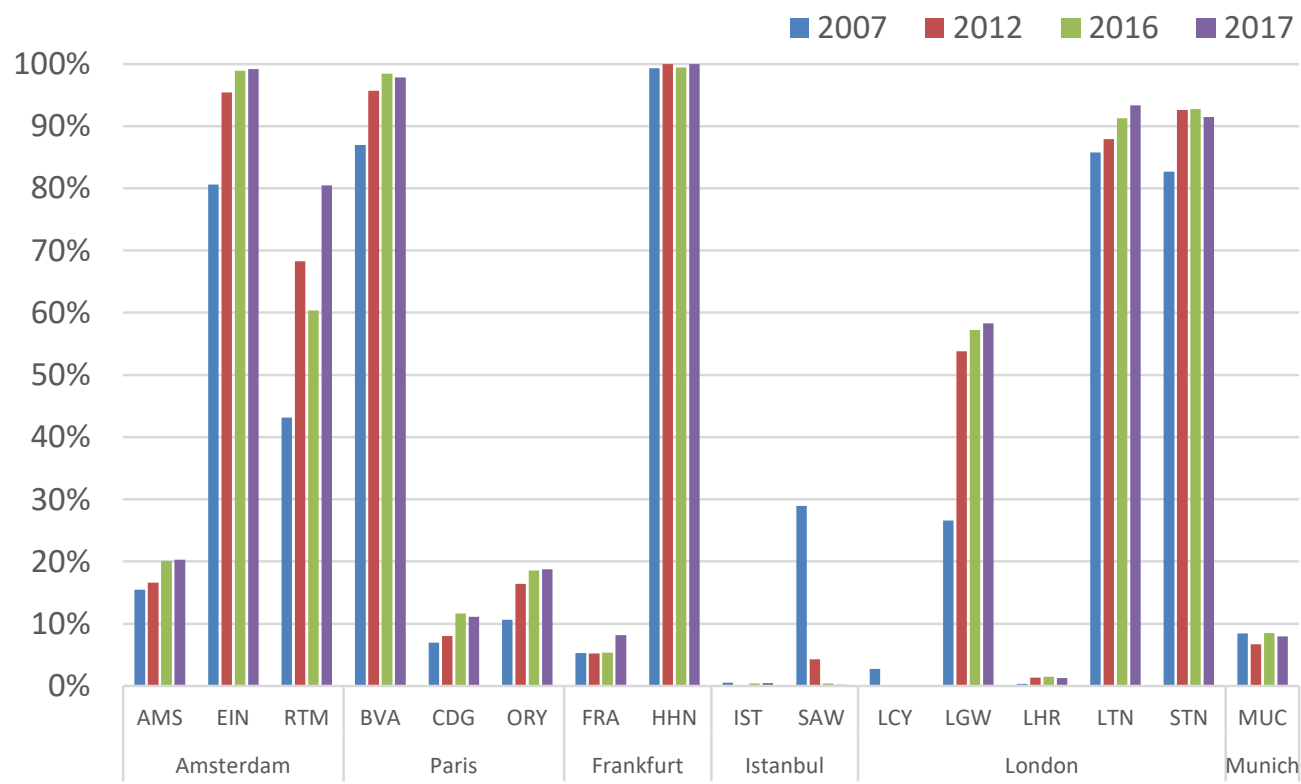

Source: SEO NetScan

Note: The list of carriers that were assigned to the low-cost category can be found in the glossary of terms.

Indirect connectivity

Schiphol's indirect connectivity is lower compared to the three other large European hubs (Figure 45). London Heathrow offers the highest level of indirect connectivity among the surveyed airports. Indirect connectivity from Heathrow has increased over the past decade, in part due to the crowding out of more 
marginal, often point-to-point, flights as a result of capacity constraints at the airport. Over the past year, Schiphol's indirect connectivity has increased more than at the other analysed airports, by almost $4 \%$.

Figure 45. Level of indirect connectivity from Schiphol and benchmark airports $(2007,2012,2016$, 2017)

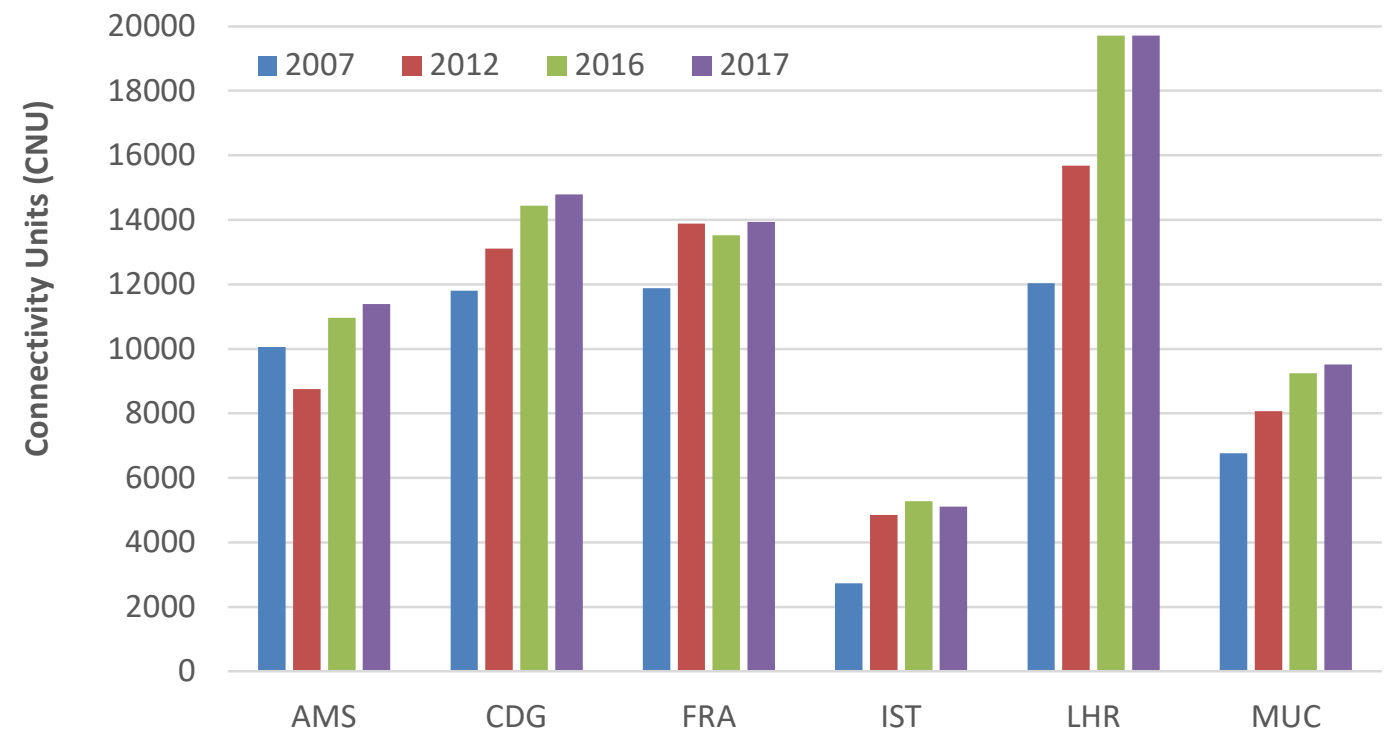

Source: SEO NetScan

Compared to its peers, Schiphol's direct network is strongly focused on Europe: $83 \%$ of its flights are to Europe, compared to $78 \%$ at Frankfurt, $69 \%$ at Paris Charles de Gaulle, and $62 \%$ at Heathrow (Figure 46 ). Only Munich - Lufthansa's second hub specialised in serving short-haul connections - has a higher share of European flights (90\%).

Indirect connectivity available from all surveyed airports is mostly to destinations in North America and Asia Pacific (Figure 46). In absolute terms, London Heathrow is characterised by the highest indirect connectivity levels to destinations in North America and Asia Pacific, while Paris Charles de Gaulle has the highest indirect connectivity to destinations in Europe. 
Figure 46. Share of direct and indirect connectivity from Schiphol and benchmark airports by region

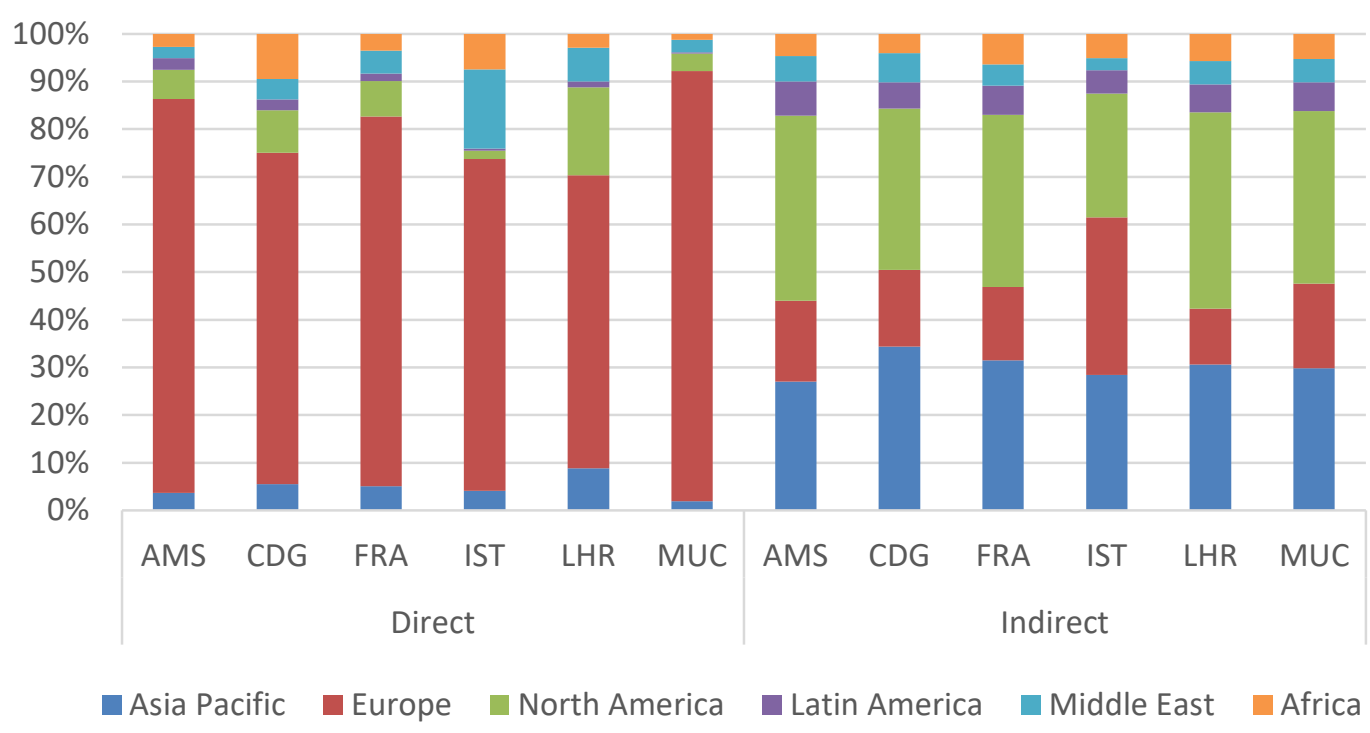

Source: SEO NetScan

\section{Hub connectivity}

Over the past decade, Schiphol's position in terms of hub connectivity has been strengthened (Figure 47). Its average annual growth rate over the past 10 years has been higher than for other European hub airports. Only Istanbul experienced higher rates of growth, on average $22 \%$ per year since 2007. Istanbul's hub connectivity, however, is still well behind that of Frankfurt or Schiphol.

Frankfurt's long-term growth in hub connectivity (1.8\% per year since 2007$)$ falls behind that of Schiphol. However, in 2017 hub connectivity at Frankfurt grew at a faster rate than Schiphol (6.3\% versus 5.6\% respectively). Paris Charles de Gaulle and London Heathrow lag behind in terms of hub connectivity, due to longer minimum connecting times and less efficient wave systems. Moreover, particularly in the case of London Heathrow, capacity constraints have severely limited the potential of the hub carrier to enhance hub connectivity. 
Figure 47. Level of hub connectivity from Schiphol and benchmark airports $(2007,2012,2016,2017)$

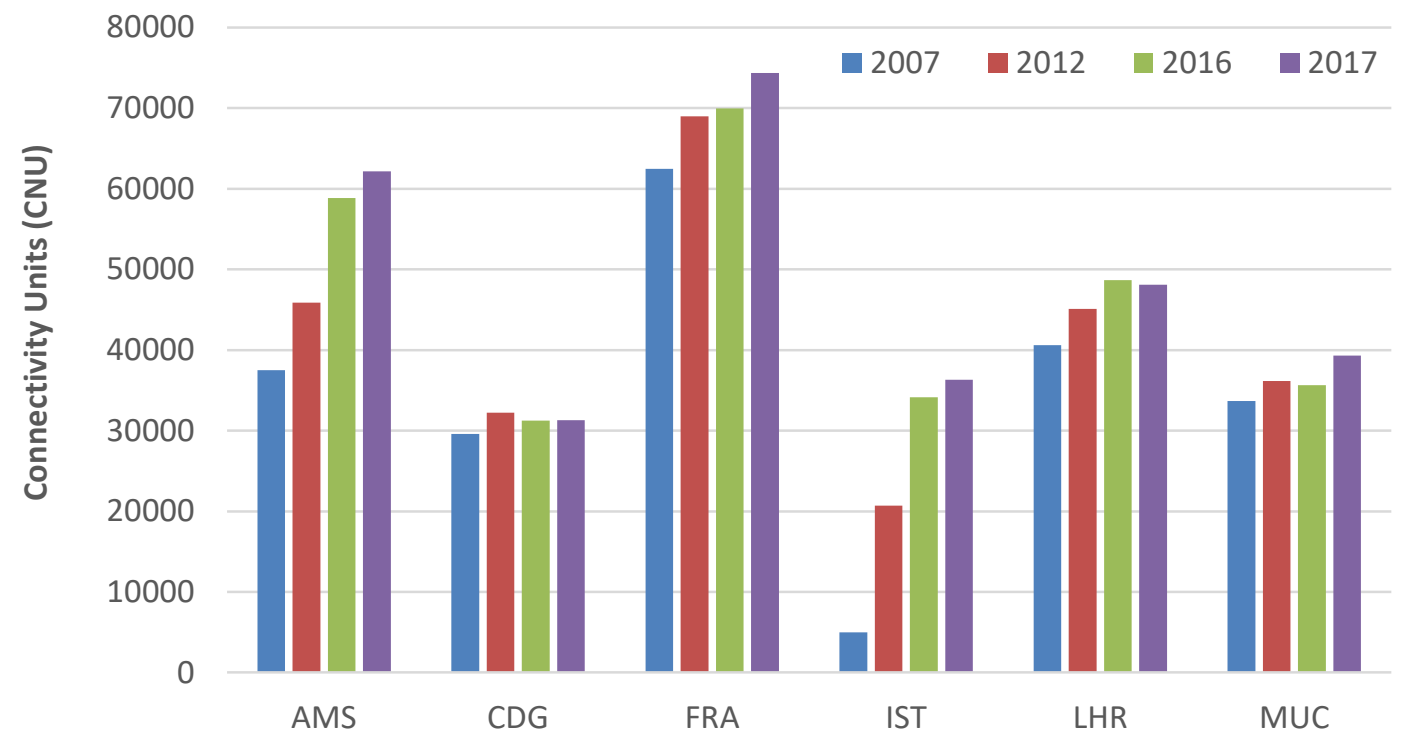

Source: SEO NetScan

Paris Charles de Gaulle and London Heathrow provide a very limited number of intra-European connections. This is partly due to significant shares of short-haul connectivity provided from other London and Paris airports (Figure 48). Their relatively long minimum connecting times (and less favourable geographic locations in the case of London Heathrow) also play a role in diminishing their short-haul connectivity levels.

On the other hand, Munich and Istanbul provide a relatively large share ( $50 \%$ and $45 \%$ respectively) of short-haul to short-haul connections. Their extensive domestic networks and Munich's central location in Europe makes these hubs more suitable for serving such type of traffic.

Figure 48. Share of hub connections by stage length combination from Schiphol and benchmark airports (2017)

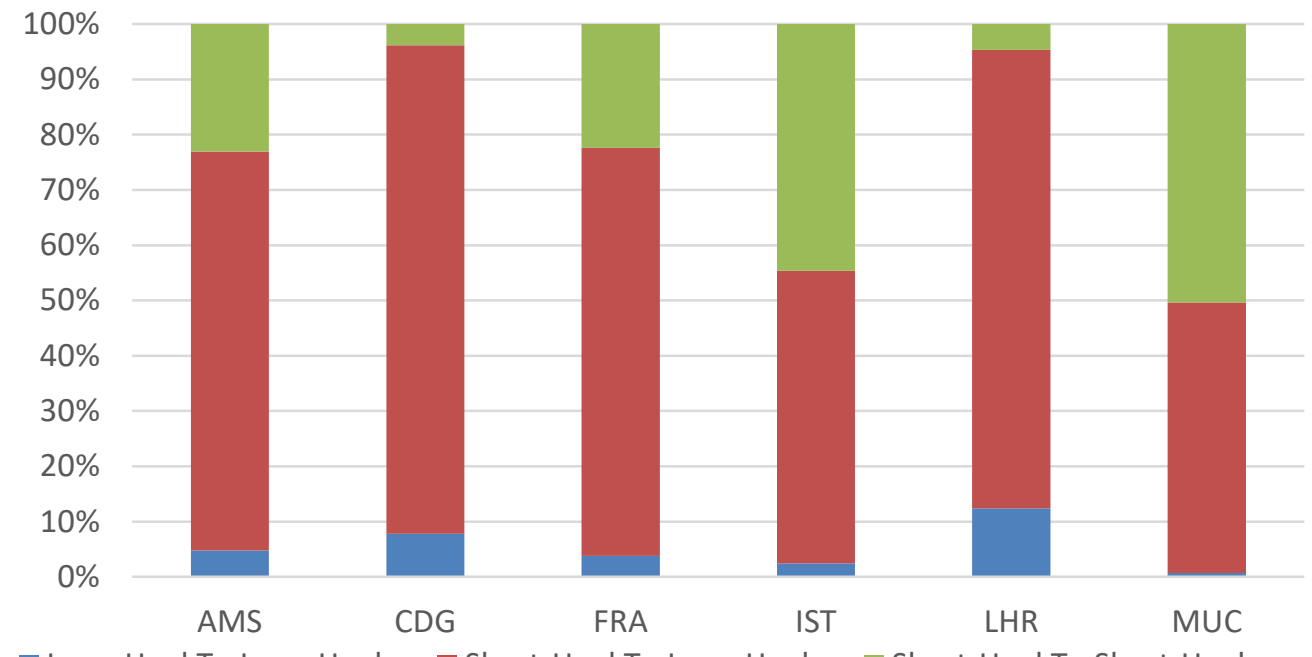

Source: SEO NetScan

Note: A long-haul (short-haul) flight is a flight with a stage length over (below or equal to) $3450 \mathrm{~km}$. 
To a large extent the relatively high share of long-haul to long-haul connections provided at London Heathrow and Paris Charles de Gaulle is a result of these airports being part of a multi-airport system. British Airways operates around 30\% of its short-haul services from London Gatwick and London City airports, while the long-haul network is mainly concentrated at Heathrow. In the case of Paris, Air France operates around $30 \%$ of its short-haul flights from Orly (Figure 49). Again, the lion's share of long-haul flights is served from Charles de Gaulle.

Figure 49. Level of direct connectivity at airports in London and Paris by stage length

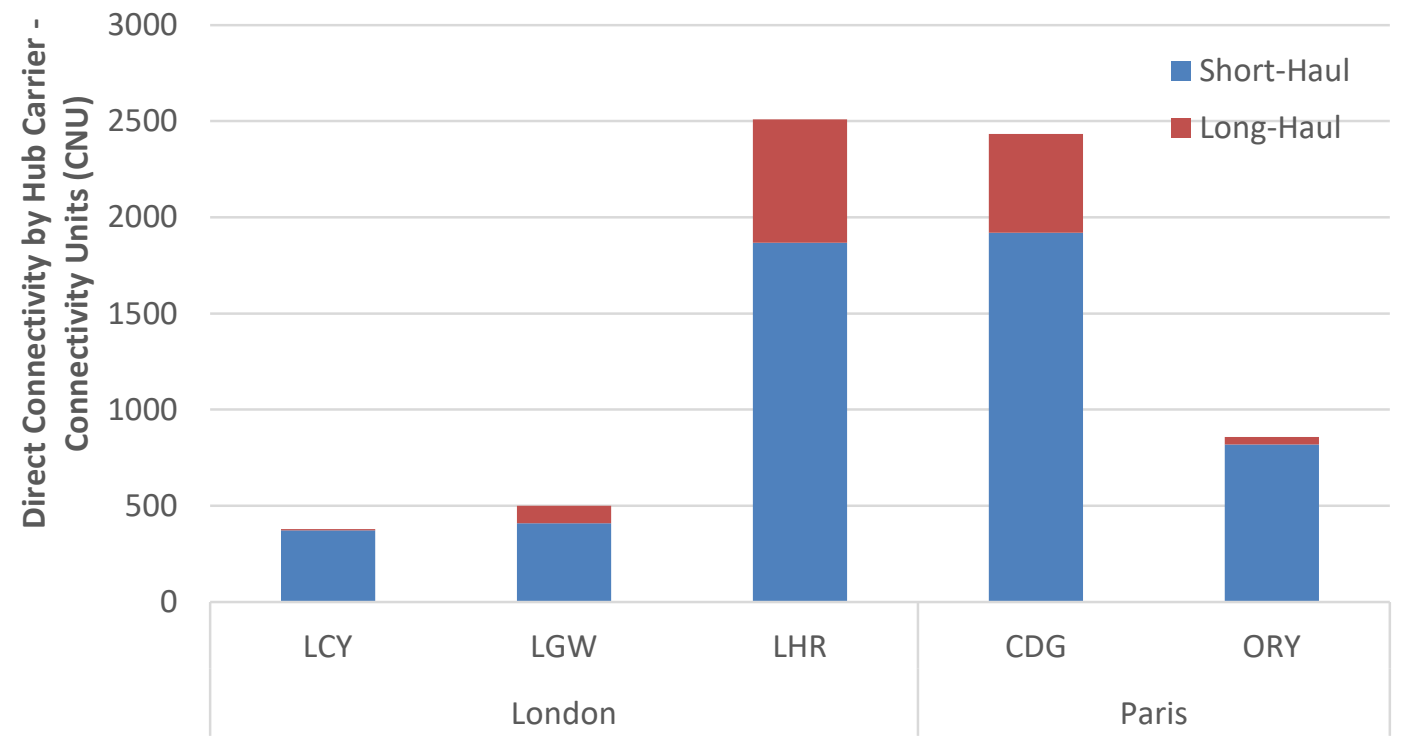

Source: SEO NetScan

Note: The main hub carriers are British Airways for London airports, and Air France for Paris airports. A long-haul (short-haul) flight is a flight with a stage length over (below or equal to) $3450 \mathrm{~km}$.

As shown in the hub network overlap analysis (Figure 50), Frankfurt is Schiphol's largest competitor for connecting markets: $46 \%$ of Schiphol's hub connections are also offered via Frankfurt. This share used to be closer to 50\%, but Schiphol established new routes between 2007 and 2012 that are not replicated at Frankfurt; these include Aalborg, Denpasar, Inverness, Nantes, Panama, Southampton and Xiamen.

Istanbul has gained importance as a competing hub for Schiphol over the past decade. Its share in terms of network overlap has increased from $8 \%$ in 2007 to $22 \%$ in 2017 . The extent to which Istanbul can compete with Schiphol in connecting markets is restricted by its geographical location. In particular, unlike other European hubs, Istanbul may not be positioned to fully compete with Schiphol in the Europe - North America markets. 
Figure 50. Degree of network overlap of benchmark airports with Schiphol's hub connectivity (2007, 2012, 2016, 2017)

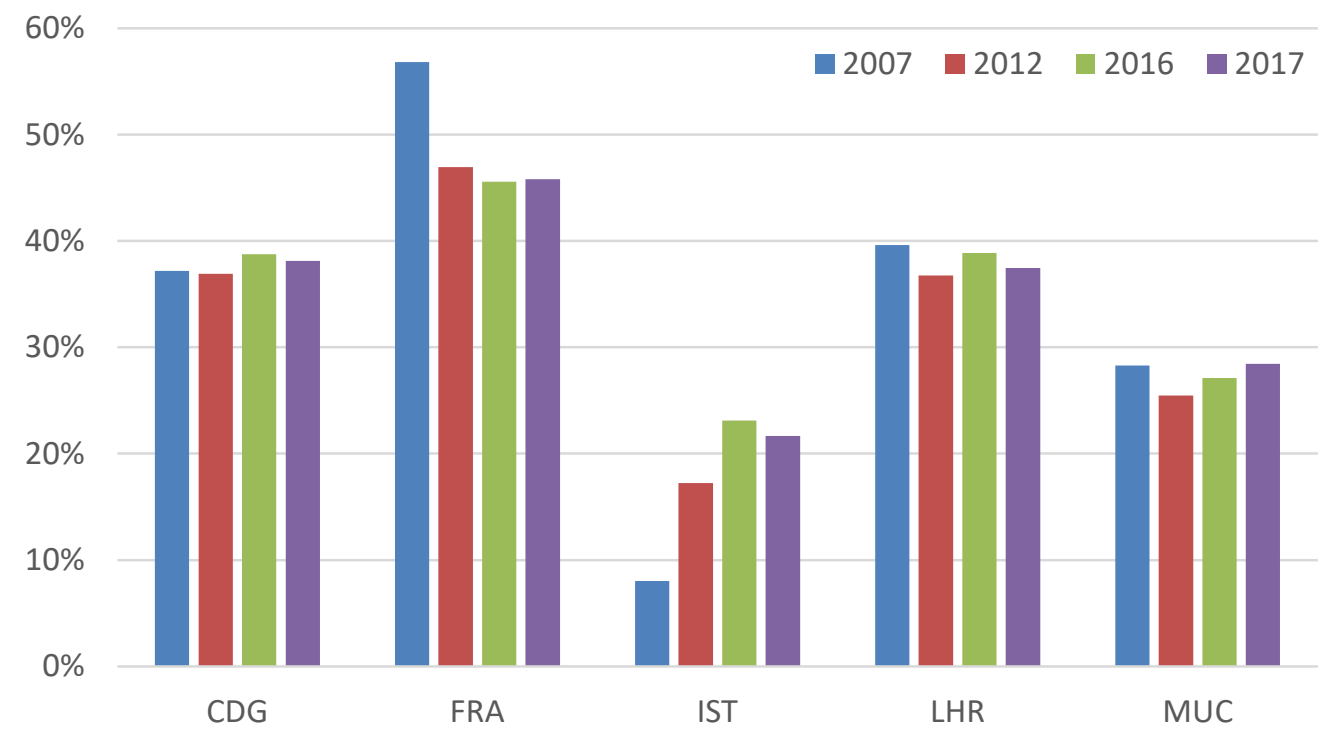

Source: SEO NetScan 


\section{Bibliography}

ACI EUROPE (2017), Airport Industry Connectivity Report 2017, Airports Council International Europe, Brussels.

Airports Commission (2013), "Aviation Connectivity and the Economy", Discussion Paper, No. 2, Airports Commission, London.

Allroggen, F., M. Wittman and R. Malina (2015), "How Air Transport Connects The World: A New Metric of Air Connectivity and Its Evolution Between 1990 And 2012", Transportation Research Part E: Logistics and Transportation Review, Vol. 80, pp. 184-201.

ATAG (2016), Aviation: Benefits Beyond Borders, Air Transport Action Group, Geneva.

Boonekamp, T. and G. Burghouwt (2017), "Measuring connectivity in the air freight industry", Journal of Air Transport Management, Vol. 61, pp. 81-94.

Bootsma, P.D. (1997), Airline flight schedule development: analysis and design tools for European hinterland hubs, PhD thesis, University of Twente, Utrecht.

Burghouwt, G. (2017), "Influencing Air Connectivity Outcomes", ITF Discussion Paper, No. 2017/24, OECD Publishing, Paris.

Burghouwt, G. (2007), Airline network development in Europe and its implications for airport planning. Aldershot, Ashgate.

Burghouwt, G. and R. Redondi (2013), "Connectivity in Air Transport Networks: An Assessment of Models and Applications", Journal of Transport Economics and Policy, Vol. 47/1, pp. 35-53.

Burghouwt, G. and J. Veldhuis (2006), "The competitive position of hub airports in the Transatlantic market", Journal of Air Transportation, Vol. 11/1, pp. 106-130.

Burghouwt, G. and J. de Wit (2005), "The temporal configuration of airline networks in Europe", Journal of Air Transport Management, Vol. 11/3, pp.185-198.

Burghouwt, G., J. de Wit, J. Veldhuis and H. Matsumoto (2009), "Air network performance and hub competitive position: evaluation of primary airports in East and Southeast Asia", Journal of Airport Management, Vol. 3/4, pp. 384-400.

Cattaneo, M. et al. (2017), "Evolution of the European network and implications for self-connection", Journal of Air Transport Management, Vol. 65, pp. 18-28.

Danesi, A. (2006), "Measuring airline hub timetable co-ordination and connectivity: definition of a new index and application to a sample of European hubs", European Transport, Vol. 34, pp. 54-74.

Dennis, N.P. (1994), "Scheduling strategies for airline hub operations", Journal of Air Transport Management, Vol. 1/2, pp. 131-144.

Doganis, R. and N.P. Dennis (1989), "Lessons in hubbing", Airline Business, March 1989, pp. 42-47.

Egeland, J. and P. Smale (2017), "Capacity Building through Efficient Use of Existing Airport Infrastructure", ITF Discussion Paper, No. 2017/27, OECD Publishing, Paris.

Heemskerk, L. and J. Veldhuis (2006), "Measuring airline network quality: analytical framework", The $10^{\text {th }}$ Air Transport Research Society (ATRS) - World Conference, Nagoya, Japan, 26-28 May 2006.

ITF (2014), "Expanding Airport Capacity in Large Urban Areas", ITF Roundtable Report, No. 153, OECD Publishing, Paris.

Lee, S.Y., K.E. Yoo and Y. Park (2010), "Continuous Connectivity Model for the evaluation of hub-and-spoke operations", Transportmetrica A: Transport Science, Vol. 10/10, pp. 894-916.

Lieshout, R. (2012), "Measuring the size of an airport's catchment area", Transport Geography, Vol. 25, pp. 27-34.

Lieshout, R. and G. Burghouwt (2013), "Airline Competition in Connecting Markets", in Forsyth, P., D. Gillen, K. Hüschelrath, H.-M. Niemeier and H. Wolf (eds) Liberalization in Aviation: Competition, Cooperation and Public Policy. Ashgate, Farnham. 
Lieshout, R. and H. Matsumoto (2012), "New international services and the competitiveness of Tokyo International Airport", Journal of Transport Geography, Vol. 22, pp. 53-64.

Lieshout, R., P. Malighetti, R. Redondi and G. Burghouwt (2016), "The competitive landscape of air transport in Europe", Journal of Transport Geography, Vol. 50, pp. 68-82.

Malighetti, P., S. Paleari and R. Redondi (2008), "Connectivity in the European airport network: 'Self-help hubbing' and business implications", Journal of Air Transport Management, Vol. 14/2, pp. 53-65.

Mandel, B., M. Gaudry and D. Ungemach (2017), "Europe-wide aviation connectivity measures and the PATH theorem", Université de Montréal, Agora Jules Dupuit, Publication AJD-161, 21 February 2017.

Matsumoto, H. and R. Lieshout (2014), "Effects of South Korean air carriers' network developments on route choice behaviour of travellers departing from Japan", in Duval, D.T. (ed.), Air Transport in the Asia Pacific. Ashgate, Farnham.

Matsumoto, H., J. Veldhuis, J. de Wit and G. Burghouwt (2008), "Network performance, hub connectivity potential and competitive position of primary airports in Asia/Pacific region", Proceedings of the Air Transport Research Society Conference, Athens, 6-10 July 2008.

Nieße, H. and W. Grimme (2015), "How to measure airport connectivity? Average shortest travel time and average highest path velocity as indicators", International Journal of Aviation Management, Vol. 2/3, pp. 226-240.

Paleari, S., R. Redondi and P. Malighetti (2010), "A comparative study of airport connectivity in China, Europe and US: which network provides best service to passengers?", Transportation Research E: Logistics and Transportation Review, Vol. 46/2, pp. 198-210.

Royal Schiphol Group (2018), 2017 Annual Report, Royal Schiphol Group, Schiphol.

SEO Amsterdam Economics (2016a), "Monitor Netwerkkwaliteit en Staatsgaranties 2009-2016" (in Dutch), SEO Report, No. 2016/105, Amsterdam.

SEO Amsterdam Economics (2016b), "Economic benefits of European airspace modernization", Report prepared for IATA, SEO Report, No. 2015/83, Amsterdam.

Veldhuis, J. (1997), "The competitive position of airline networks", Journal of Air Transport Management, Vol. 3/4, pp. 181-188.

de Wit, J., J. Veldhuis, G. Burghouwt and H. Matsumoto (2009), "Competitive position of primary airports in the Asia-Pacific rim", Pacific Economic Review, Vol. 14/5, pp. 639-650.

Zhu, Z., A. Zhang and Y. Zhang (2017), "Connectivity of intercity passenger transportation in China: A multi-modal and network approach", Journal of Transport Geography, in press. 


\section{Notes}

${ }^{1}$ See https://www.annualreportschiphol.com/ (accessed on 7 April 2018).

${ }^{2}$ For example, a routing factor of 1.4 means that all indirect connections of a total flight distance (or flight time) greater than 1.4 times the distance (or flight time) of a direct connection will be excluded from the assessment. Also see glossary of terms.

${ }^{3}$ See Allroggen et al., 2015; Boonekamp and Burghouwt, 2017; Burghouwt, 2007; Burghouwt and Veldhuis, 2006; Burghouwt and de Wit, 2005; Burghouwt et al., 2009; Danesi, 2006; Lee et al., 2014; Lieshout and Burghouwt, 2013; Matsumoto et al., 2008; Veldhuis, 1997; de Wit et al., 2009; Zhu et al., 2017.

${ }^{4}$ The quickest path is the path involving the lower shortest travel time from origin (O) to destination (D).

${ }^{5}$ See Heemskerk and Veldhuis, 2006; Lieshout, 2012; Lieshout and Matsumoto, 2012; Lieshout et al., 2016; Mandel et al., 2017; Matsumoto and Lieshout, 2014; SEO, 2016b.

${ }^{6}$ See https://www.ch-aviation.com/portal/news/57187-korean-air-delta-unveil-transpacific-joint-ventureplans (accessed on 19 February 2018).

${ }^{7}$ See the glossary of terms for an explanation of these terms.

${ }^{8}$ See www.thaiairways.com/en GB/news/news announcement/news detail/codeshare agreement THAI and Ba ngkok Airways.page (accessed on 19 February 2018).

${ }^{9}$ There is some indication that in fact Schiphol is among the top airports from self-hubbing in Europe, see: https://www.dublinairport.com/latest-news/detail/dublin-airport-tops-european-passenger-self-connectingleague (accessed on 21 March 2018).

${ }^{10}$ Such insurance products have not been available more widely, but there are travel agents who provide insurance for some airline combinations through online platforms like Skyscanner. Moreover, some airports decided to provide insurance for passengers self-connecting through their airports, e.g. ViaMilano programme at Malpensa Airport or GatwickConnects available at Gatwick Airport.

${ }^{11}$ Due to the political unrest in 2016 passenger demand has declined. It is expected, however, that growth will rebound in the near future, particularly when the new hub airport opens in 2018. 


\section{E International Transport Forum}

\section{Defining, Measuring and Improving Air Connectivity}

This report examines different approaches to defining and measuring air connectivity, focussing on the perspectives that can help governments, airports and airlines to improve their long-term aviation strategies. The findings are then applied to assess air connectivity at two major hub airports - Incheon International Airport and Amsterdam Airport Schiphol - to demonstrate how air connectivity assessments can help improve outcomes for the users of aviation.

The work for this report was carried out in the context of a project initiated and funded by the International Transport Forum's Corporate Partnership Board (CPB). CPB projects are designed to enrich policy discussion with a business perspective. Led by the ITF, work is carried out in a collaborative fashion in working groups consisting of CPB member companies, external experts and ITF researchers. 